\title{
Design and Evaluation of a Learning Assistant System with Optical Head-Mounted Display (OHMD)
}

\author{
by \\ Xiao Du, B.Sc. \\ A thesis submitted to \\ the Faculty of Graduate and Post-Doctoral Affairs \\ in partial fulfillment of the requirements for the degree of \\ Master of Applied Science \\ in \\ Human-Computer Interaction \\ School of Information Technology \\ Carleton University \\ Ottawa, Ontario \\ (C) 2014 Xiao Du
}


The undersigned hereby recommend to

The Faculty of Graduate Studies and Research acceptance of the thesis

\section{Design and Evaluation of a Learning Assistant System with Optical Head-Mounted Display (OHMD)}

Submitted by

Xiao Du

In partial fulfillment of the requirements for the degree of

Master of Applied Science in Human-Computer Interaction

Chair, Anthony Whitehead, School of Information Technology

Thesis Supervisor, Ali Arya

Faculty of Engineering and Design

School of Information Technology

Carleton University

August 2014 


\begin{abstract}
The rapid increase in the use of wearable technologies, especially Optical Head-Mounted Display (OHMD) devices, suggests potentials for education and requires more scientific studies investigating such potentials. In particular, the issue of information access and delivery in classrooms can be of interest where multiple screens and objects of attention exist and can cause distraction, lack of focus and reduced efficiency. This study explores the usability of a single OHMD device, as an alternative to individual and big projected screens in a classroom situation. We developed OHMD-based prototypes that allowed presentation and practice of lesson material through three display and two control options. We conducted user studies to compare various feasible combinations using a series of evaluation criteria, including enjoyment, ability to focus, motivation, perceived efficiency, physical comfort, understandability, and relaxation. Our results did not strongly support a significant effect caused by the use of alternative displays. However, participants' feedback showed that they favoured OHMD as a single screen in classroom learning situations, while their main complaints about it were related to physical comfort and ease of control. Our studies also showed that participants were more pleased and motivated to learn when using OHMD. This suggests that improved OHMD technology will have the potential ability to be effective in classroom learning.
\end{abstract}




\section{Acknowledgements}

I would like to express my sincere gratitude to my supervisor Dr. Ali Arya, for his understanding, wisdom, patience, and encouragement and for pushing me further than I thought I could go. This thesis would not have been possible without his guidance and persistent help.

I would like to thank my friends who helped me along the way. To Travis Swan, I appreciate your efforts and help to face the technical challenges with me. To Dr. Seyed Ali Etemad, I am extremely grateful for your enthusiasm and suggestions throughout my data analysis process. To Kathleen Dowdall, thank you for the valuable suggestions on designing the surveys. To Gerry Chan, thank you for sharing statistical knowledge and editing my language throughout writing work.

I would like to thank the members of my committee, Dr. Sonia Chiasson, Dr. Anthony Whitehead, and Dr. Richard Yu for their time and valuable feedback.

Finally, I would like to thank my parents for their endless love, encouragement and support. 


\section{Table of Contents}

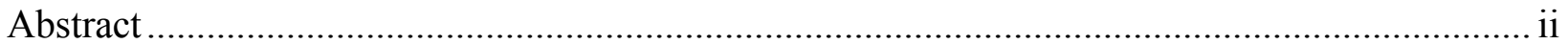

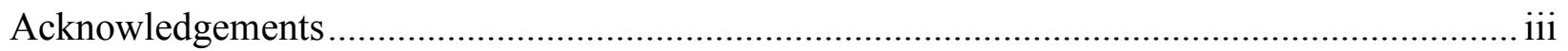

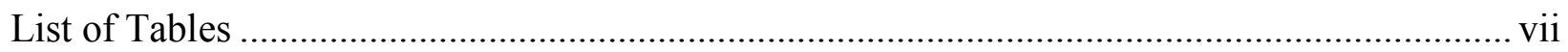

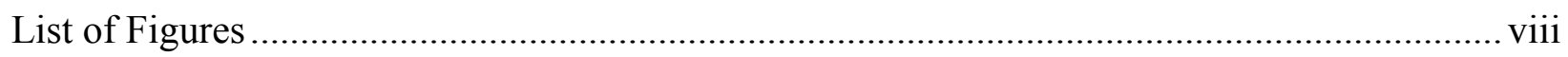

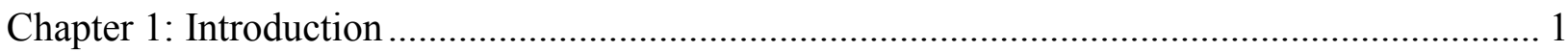

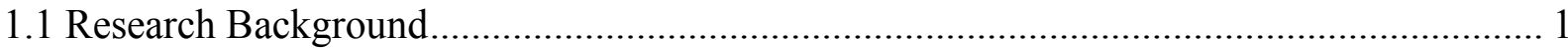

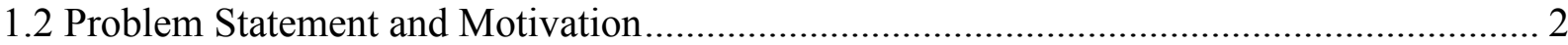

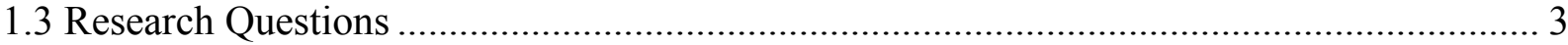

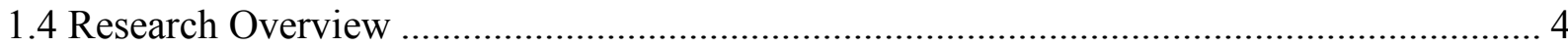

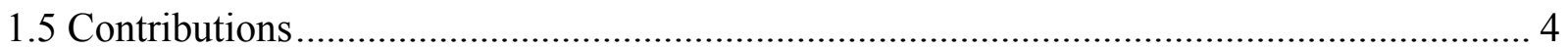

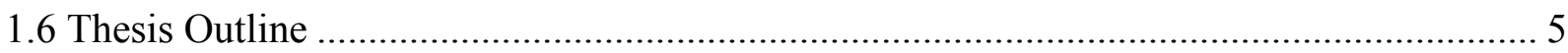

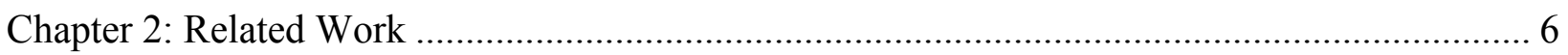

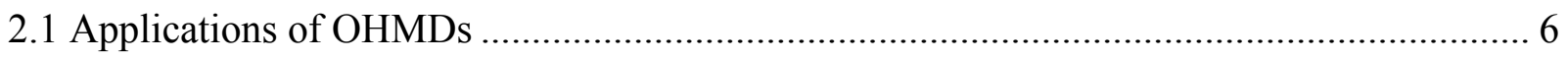

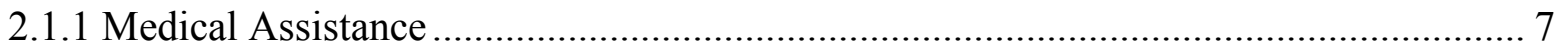

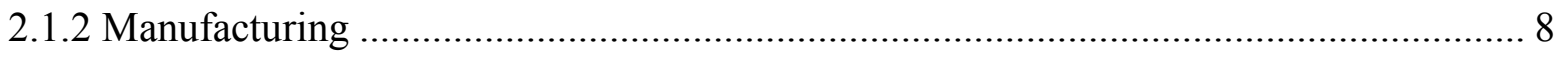

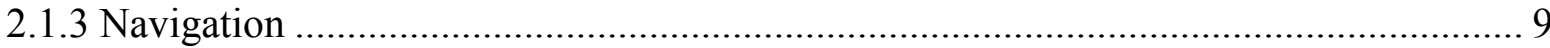

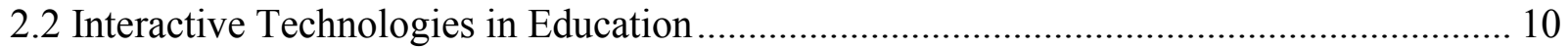

2.2.1 Mobile Learning ......................................................................................... 11

2.2.2 Augmented Reality Learning........................................................................ 11

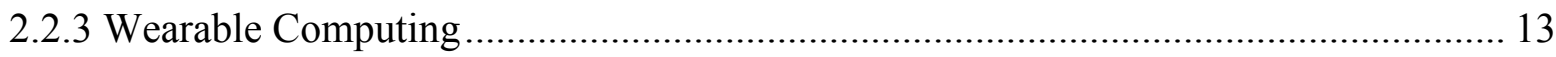

2.3 Related User Studies ........................................................................................ 14

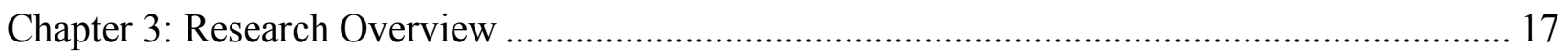

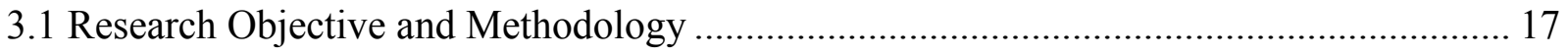

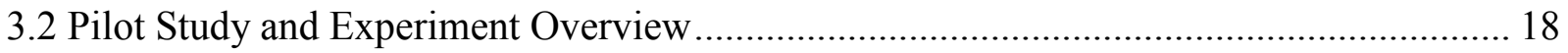




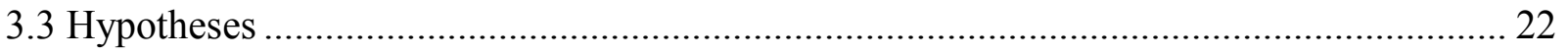

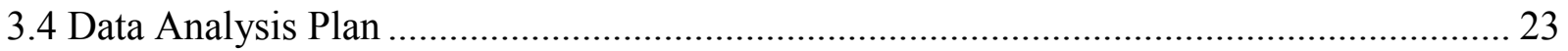

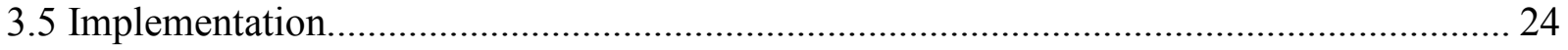

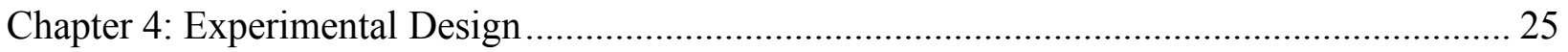

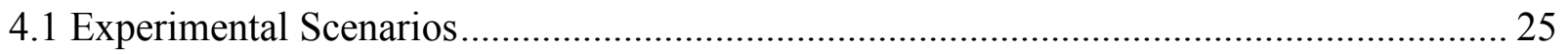

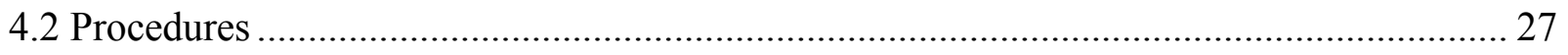

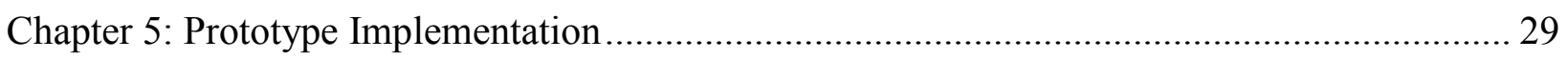

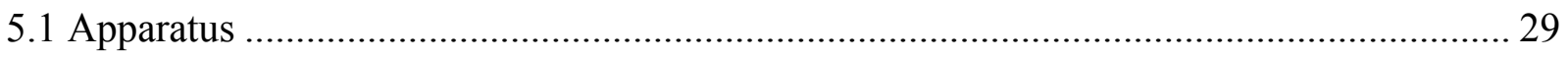

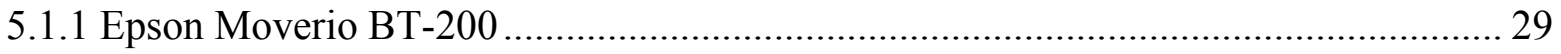

5.1.2 Equipment used for Experiment …………………….............................................. 30

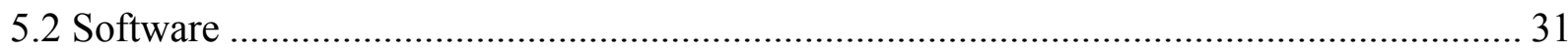

5.2.1 Epson Moverio \& Mobile Phone App …………………............................................... 31

5.2.2 Socket Communication Program................................................................................... 37

5.2.3 IntuiFace Desk Demo \& PC Simulated App ........................................................... 38

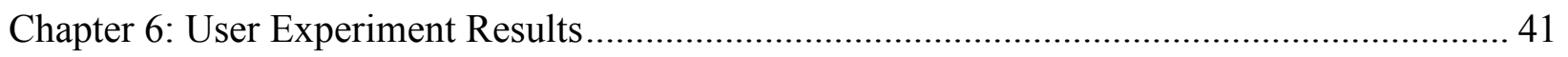

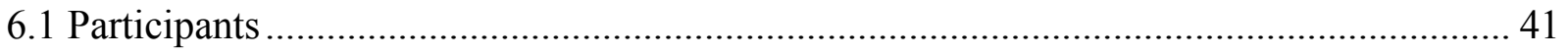

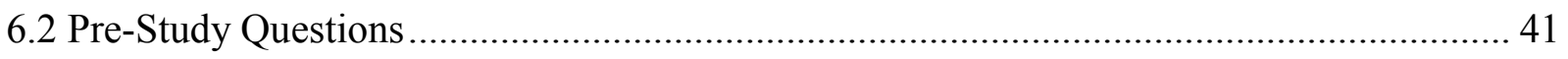

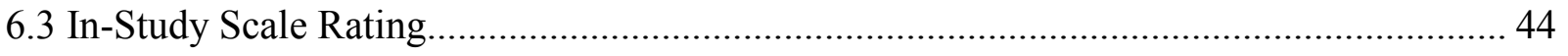

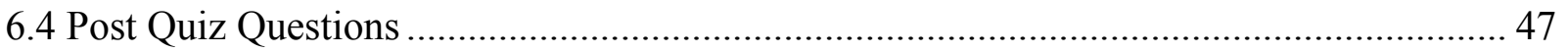

6.5 User Feedback in Post-Study Survey ................................................................................ 49

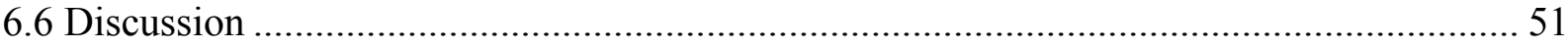

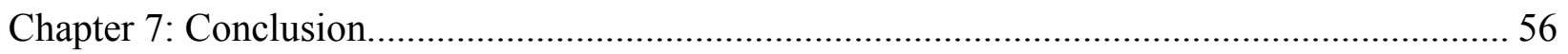

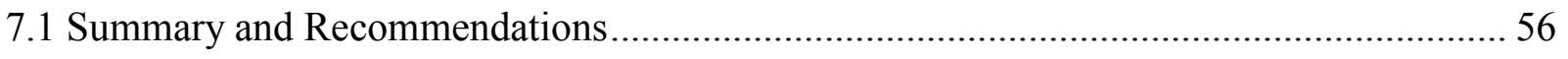

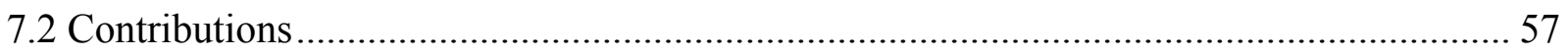

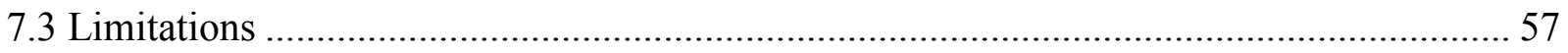




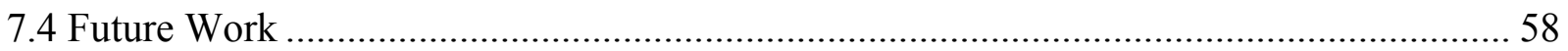

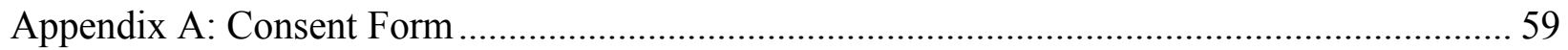

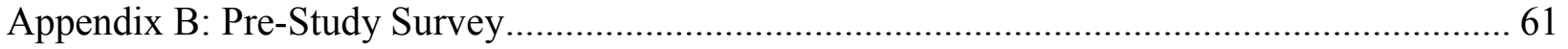

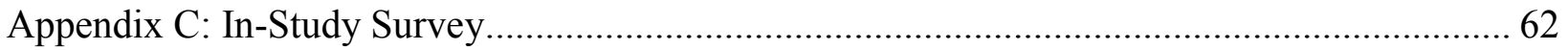

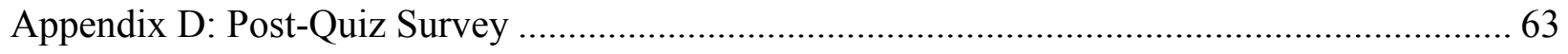

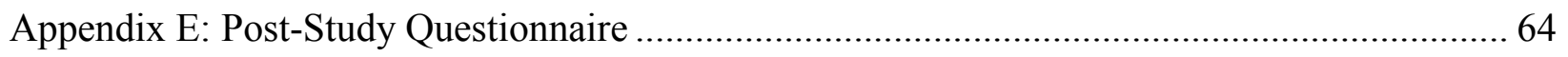

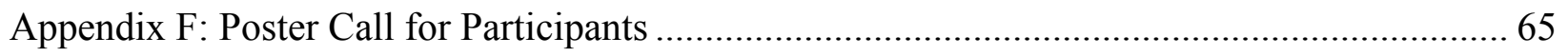

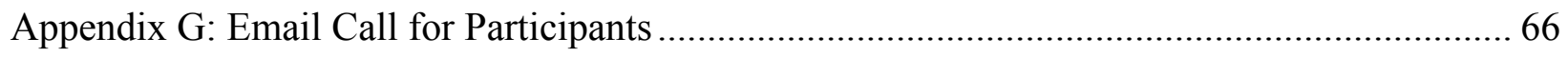

Appendix H: Results of Two-way Repeated Measures ANOVA of Scenarios and Evaluation

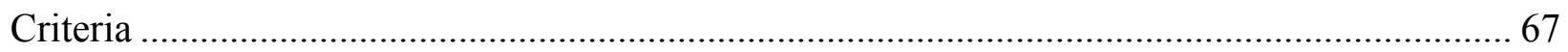

Appendix I: Participants’ Responses Results of Evaluation Criteria....................................... 72

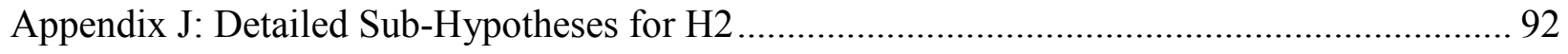

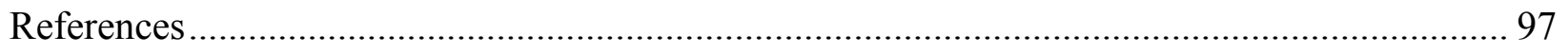




\section{List of Tables}

Table 1: The Diverse Wearable Technology Applications...................................................... 7

Table 2: View-Screens and Controllers' Combinations in Theory ....................................... 19

Table 3: Sub-Hypotheses (H2.1) Related to Enjoyment Effect among Scenarios ..................... 22

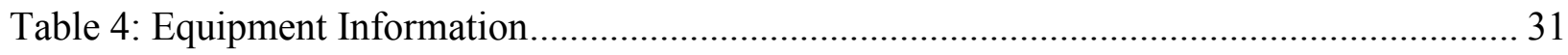

Table 5: Pre-Study Questionnaire Feedback......................................................................... 42

Table 6: The Results of Repeated Measures ANOVA with a Greenhouse-Geisser Correction

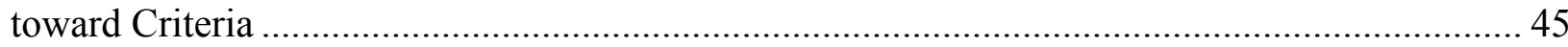

Table 7: The Results of Friedman's ANOVA and Wilcoxon signed-rank test with Bonferroni

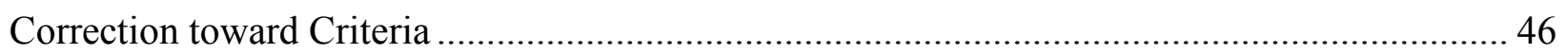

Table 8: The Results of Exercises' Difficulty in Each Experimental Scenario .......................... 48

Table 9: The Results of Helpfulness of Experimental Scenario for Each Exercise-Task. Values are percentage responses participants chose that task as the one scenario was most helpful for . 48

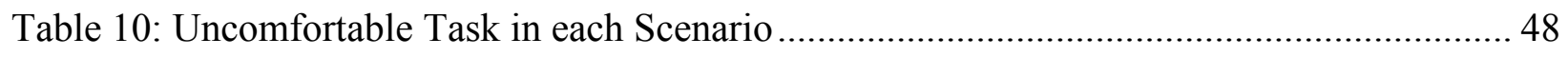

Table 11: Things Learned the Most in Each Experimental Scenario ...................................... 48

Table 12: Participants Response to overall, was there anything that made you feel uncomfortable

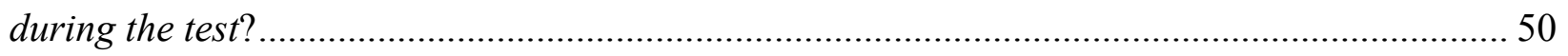

Table 13: Reasons for Participants’ Favourite Learning Scenario ........................................ 51 


\section{List of Figures}

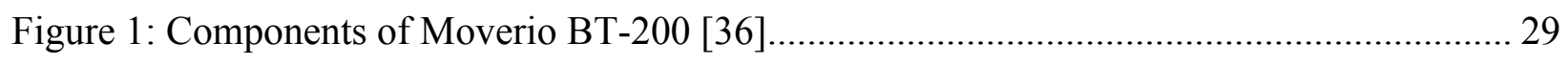

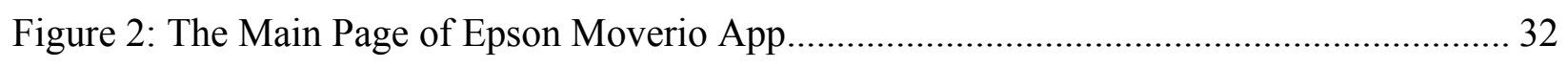

Figure 3: The Page of "Text" Module .................................................................................. 32

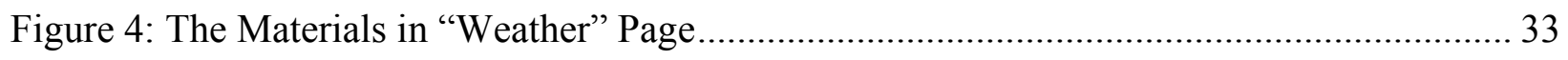

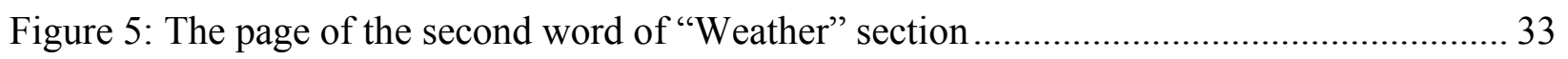

Figure 6: The creenshots when user is playing with the animation ...................................... 34

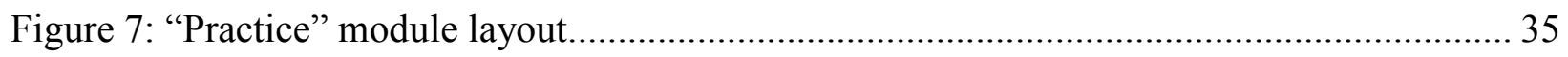

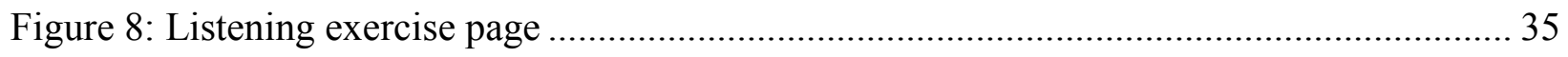

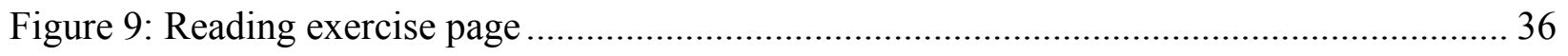

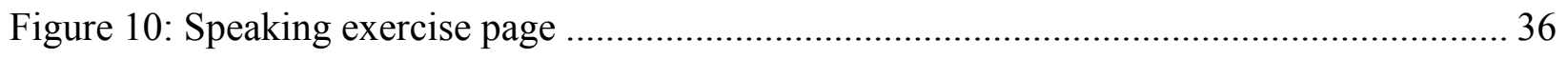

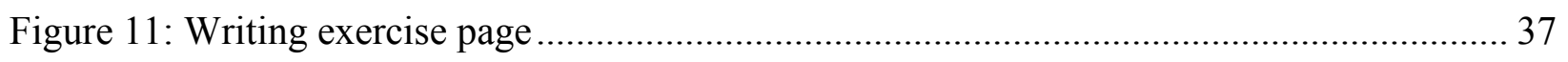

Figure 12: Framework of socket communication design in the user experiment ...................... 38

Figure 13: Screenshot of Working Space of IntuiFace .................................................... 39

Figure 14: Participants' Age Distribution...................................................................... 41

Figure 15: Participants' Interests in Studying the Subject................................................ 43

Figure 16: Frequency of Participants' using Mobile App in Daily life ................................... 43

Figure 17: Participants' Concentration Ability in a Typical Language Class .......................... 43

Figure 18: Participants' Response to overall, which was your favourite learning scenario? ....... 51 


\section{Chapter 1: Introduction}

\subsection{Research Background}

Traditional face-to-face education has played a primary role in human cultural heritage and development for thousands of years. Modern computer-, Web-, Mobile-, Virtual Reality-, Augmented Reality-based information technologies have opened up a new era for education by facilitating learning activities among various learners in different situations [2, 11, 15, 83, 89]. Yet the challenges and limitations in terms of learning caused by both conventional approaches and digital technologies are still being broadly discussed. For example, McPherson [53] has stated that children could learn better if the learning activities are designed to trigger their motivation and ownership in controlling the learning process. Park [65] reported students losing engagement in reading due to a lack of self-determination towards the reading materials. Other studies have investigated various topics, such as enhancing interactivity when learning[41], increasing learners' achievement [44], providing ubiquitous learning environment [15], making the subject easily understood [74], and satisfying learners' enjoyment [35]. In case of face-toface activities, classroom experience, student attention, causes of distraction, and effective presentation of material are also among topics of research in the field of education, particularly in the presence of technology [8, 18, 25, 27, 49, 51, 60, 97].

On the other hand, the emergence of wearable technologies, particularly Optical HeadMounted Display (OHMD) devices such as Google Glass, has changed the landscape of computing for the everyday person [66]. Prior and after the release of Google Glass, which has created a wave of popular interests in OHMD devices, other products have emerged in the ubiquitous wearable computer market. They come in a variety of shapes and sizes, from as light as the Google Glass to the more bulky Oculus Rift. The terms used for describing these technology and devices varies within the academic literature, such as wearable eye display [66, $67,86]$, project glass [17, 67, 69, 81], wearable see-through head-up display [30, 32, 81], optical head-mounted display [62].

According to Axholt et al. [5, 64], Heads-Up Display (HUD) is any transparent display that presents data without requiring users to look away from their usual viewpoints. For example, a pilot would view information with the head positioned "up" and looking forward, instead of angled down looking at lower instruments, in a HUD. Optical Head-Mounted Display (OHMD) 
is a wearable display that has the capability of reflecting projected images as well as allowing the user to see through it. According to their different features, we clarify the equipment used for this thesis study as OHMD. A detailed review of OHMD devices will be discussed in chapter 3.

The applications of wearable technology have been creating innovations in almost every aspect of people's ordinary life [14]. The projects like "Mono-glass" [87], Google Glass for assisting in Parkinson's disease [52], surgeons' operation assistance [55], "Fitnamo" [59] and "Museum Guide" [73] reflect the practical value of integrating wearable technology into those relevant fields. As an example in the field of education, students wear jewellery that alerts them to hazardous conditions [38] when working in chemical laboratories.

Wearable see-through displays provide advantages such as hands-free operation, and transparent view, while potentially helping to maintain attention, decrease an access time, and increased effectiveness of information access and communication. As suggested by Horizon Report [34], when wearing an optical head-mounted display (OHMD), students' hands are free so they can interact with the software they are learning without having to disengage from one screen in order to access another. Yet undeniably, most of these applications and systems are still in developing stages [30], and the application fields are generally concentrated on health care, medical, and navigation. Plus the use of these products has not been widespread in the market yet. Therefore, there are not many related studies that investigate the potentials of wearable seethrough displays, especially in the field of education.

\subsection{Problem Statement and Motivation}

The rapid increase in the use of wearable technologies and especially OHMD device, suggests potential for education and requires more scientific studies investigating such potentials. The work reported in this thesis is originally motivated by existing research on classroom performance $[8,18,25,27,49,51,60,97]$, observation of classroom learning, and a series of informal interviews with undergraduate students about the factors that could affect their concentration during class. In a typical classroom scenario, students are provided with various visual sources of information. Among them are big screens (projection screen), personal computing devices, and face-to-face interaction with the instructor/presenter. The distraction caused by multi-orientation moving activity (switching attention to various sources) can be one of the sources of reduced effectiveness of the classroom experience. The situation, for instance, 
when the teacher is speaking while the student is busy reading and taking notes from the materials displayed on the projection screen might make it hard for the student to follow the pace in any of the three interactions. Another problematic phenomenon reported by students in the informal interview was the inefficiency caused by switching focus between the portable computer (pc) display and the teacher's projection display. For example, some students felt it slowed them down by repeatedly looking up to check teacher's demonstration and looking back down to do his/her own practice.

The above observation prompted us to investigate the feasibility of utilizing OHMD in education, as well as to evaluate the usability of correlative learning experience. So far, OHMDs have not been considered in mainstream computer platforms, and the related applications have not yet been vastly developed. Despite that, the research groups and many consumers are optimistic towards its potential for future development [13, 81, 84]. OHMD devices could be a new accompanying device for individuals, just like smart phones, in the next few years. Therefore, it is the researcher's belief that there is significant value to investigate the usability and effectiveness of using OHMD for classroom learning as a less-explored application.

\subsection{Research Questions}

Smartphones, tablets, and laptops are increasingly common sights in today's classrooms. And predictably, the next wave of educational innovation is likely to come from wearable technologies like Google Glass, Samsung Galaxy Gear, and smart watches [36]. Effective utilization of OHMD devices in the classroom environment will depend on answering some fundamental questions such as what is the appropriate educational level for student to use OHMD, what are the mental and physical benefits and risks for students when using OHMD, or what is the usability of learning with OHMD.

The research presented in this thesis is focused on the usability of OHMD in classroom situations. More specifically, we aimed to investigate if the use of a single OHMD device, as an alternative to individual and big screens, can improve the learning process. Considering the need for controlling the content on this single screen, we also investigated the effect of user vs. presenter/instructor control in that process. In both cases, the effects were studied using a series of evaluation criteria such as pleasantness, ability to focus and effectiveness of learning. 
Considering the research limitations and the familiarity with the learning content, the researcher chose a Chinese language class (which was easier to design the lecture material for) as the subject for the study. To make the study more pertinent, we focused on higher education students, who are studying at a college stage level and above. So this thesis will investigate the questions:

- Can the optical head-mounted display (OHMD) assist students with learning in a typical classroom, based on a series of evaluation criteria?

- How do the control mechanisms for OHMD (student vs. instructor) compare based on the same criteria?

\subsection{Research Overview}

In order to answer the research questions, the following steps were taken in this research:

- Identifying the evaluation criteria: enjoyment, ability to focus, motivation, perceived efficiency, physical comfort, understandability and relaxation.

- Choosing proper learning experience: Chinese language lessons.

- Designing the user experiments: a series of hypotheses related to the research questions and designed five scenarios.

- Developing a proper computational framework for the experiments: an Epson Moverio BT-200 OHMD device and other required software and hardware.

- Preparing survey questions: a Pre-Study, two In-Study, and a Post-Study Survey.

- Conducting the experiments and analyzing the data.

\subsection{Contributions}

This research adds to the body of knowledge on the use of OHMD devices particularly in education. The main contribution of this research is to investigate the research questions on the usability of OHMD devices. This can be broken down into the following specific contributions:

- Design, development and integration of an educational system prototype (hardware, software and content) using the novel OHMD technology

- Initial exploration of using OHMD technology in classroom through identifying control approaches, evaluation criteria and usability studies 
- Recommendations for future work in the area of OHMD use in classroom

\subsection{Thesis Outline}

This thesis is organized as follows:

In Chapter 2, a literature review of the recent OHMD applications and their benefits, the interactive technologies that have been used in education and the related user studies will be examined.

In Chapter 3, the basic concept and methods used in our research will be introduced.

In Chapters 4 and 5, the user experimental design and our prototype system will be described in detail.

Chapter 6 will review and discuss the experimental results, and reveal what we can learn from them.

Finally in chapter 7 , some concluding remarks will be presented summarizing the main findings of this research, and discussing its limitations and direction for future work.

Additional documents which are used in this research will be provided in the appendices. 


\section{Chapter 2: Related Work}

In order to understand the research background on integrating OHMDs into classroom learning scenarios, three categories of relevant literature will be reviewed in this chapter.

- OHMD Applications. The reviewed literature in this category are mainly focused on the various applications of OHMD, examining the advantages and disadvantages of recent optical head-mounted display devices.

- Interactive Technologies in Education. This section will concentrate on studies of previous, existing and on-going digital technologies that have been applied into the educational domain to improve the effectiveness of learning.

- Related User Studies. This section will investigate research on the usability of wearable (particularly OHMD) devices and educational technologies. We review how those user studies were designed, conducted and analyzed in the situations when new technologies are applied to the educational domain, especially studies that were designed for the classroom learning environment.

\subsection{Applications of OHMDs}

Since the first IEEE International Symposium on Wearable Computers (ISWC) in October 1997, the subject of "wearable computer" has been actively investigated by the research community [86]. The forms of wearable computers vary from belt-mounted applications [29, 82], e-textiles devices [68], framed backpack systems [3, 28], wrist watches [50, 57], handheld applications [43], and Head-Mounted Displays (HMD) [79]. Most recently, wearable technology applications have started to have a more active presence in our everyday lives [91]. Table 1 shows the diversity of wearable technology applications in 6 different domains.

While recent products like Google Glass and Oculus Rift are responsible for popularizing the OHMD devices, the idea is not new. The Land Warrior system [12, 19, 48], developed by the U.S. army over the past decade, includes a heads-up eye display with an augmented reality visual overlay for soldier communication. Xybernaut Mobile Assistant [13] was a light-weight wearable computer system with a see-through head-mounted display with bright and clear picture. MicroOptical MV-1 [62] was released in 2002, and years later the patents were acquired by Google. Sony unveiled an eyeglass-shaped see-through display that at SID 2008, which was designed for MP4 [77]. In 2010, TRAVIS Callisto [88] was made for troubleshooting and 
training; and in 2013, the Motorola HC1 [31] was released which was a fully speech controlled system but only offering basic applications like document viewer. M100 by Vuzix [47] was a smart glass which functionally very similar to Google Glass but without projected virtual display. The other companies like Baidu, GlassUp, Innovega, Telepathy, Oculon Optoelectronics and Fujitsu have also explored OHMD devices.

Table 1: Diverse Wearable Technology Applications

\begin{tabular}{|c|c|c|c|}
\hline Domain & \multicolumn{3}{|c|}{ Applications } \\
\hline Medical & Brain/Eye Movement & $\begin{array}{c}\text { Chronic Disease } \\
\text { Management }\end{array}$ & $\begin{array}{c}\text { Vital Signs } \\
\text { Monitoring }\end{array}$ \\
\hline Wellness & $\begin{array}{c}\text { Weight/ Energy } \\
\text { Monitoring }\end{array}$ & Posture Correction & $\begin{array}{c}\text { Physiological } \\
\text { Monitoring }\end{array}$ \\
\hline Sport/Fitness & Sport Performance & Fitness Monitoring & Outdoor Navigation \\
\hline Communication & $\begin{array}{c}\text { Personal-Access } \\
\text { Voice, Text, E-mail }\end{array}$ & Interactive Group & Physical Expression \\
\hline Security Safety & Rescue/Tracking & $\begin{array}{c}\text { Environment } \\
\text { Surveillance }\end{array}$ & $\begin{array}{c}\text { Identity } \\
\text { Recognition }\end{array}$ \\
\hline $\begin{array}{c}\text { Lifestyle } \\
\text { Computing }\end{array}$ & Interactive Gaming & Data/Media Access & $\begin{array}{c}\text { Responsive } \\
\text { Learning }\end{array}$ \\
\hline
\end{tabular}

In the following section, several newer projects and applications based on OHMD technology will be reviewed. These examples belong mainly to the categories of medical assistance, manufacturing and navigation where wearable see-through displays have been used more often.

\subsubsection{Medical Assistance}

Researchers have utilized wearable computers to resolve medical problems for years. For example, to help people who have difficulty with short-range activities due to losing one eye, Toyoura et al. [87] implemented a pilot system called "mono-glass". The system is a wearable device, which has two cameras to capture images and then reconstruct them for the healthy eye.

McNaney et al. [52] presented a study on investigating the feasibility of utilizing Google Glass to help people who have Parkinson's Disease (PD). They examined the perception of features such as confidence and safety; security and vulnerability; and privacy of a small group of patients by letting them wear the device daily for 5 days. The authors found that the selfmanagement attribute resulted in the most promising feedback from patients. 
Similarly, Muensterer et al. [55] explored the possibility of using Google Glass to help surgeons in the operating room by conducting a study over 4 consecutive weeks. Despite the drawbacks such as low battery endurance, data protection, poor audio quality and long transmission latency, the authors indicated that there are benefits when integrating the device into surgery. Other online articles [1, 22, 39] also discussed the feasibility of using Google Glass in medical operating rooms. Generally, they concluded that the technology was indeed useful in the operating room as an adjunct device in delivering necessary information, but still had significant challenges to overcome before becoming a viable product.

To summarize, maintaining attention, intuitive, constantly accessing related information when making decision and real-time interaction with outside the room are the positive aspects that doctors reported during existing studies.

\subsubsection{Manufacturing}

Liverani et al. [45] presented a study on utilizing an augmented reality wearable system called a Personal Active Assistant (PAA) (early prototype of OHMD) to improve the overall integration between engineering design and real prototype manufacturing, by providing features such as object recognition and operation instructions. In particular, the operator would wear the device over his/her face to interact with physical objects. The work was monitored continuously by the system, since the bonded-camera provided real-time imaging from the external world while performing object recognition. When a wrong operation was noticed, the system would sound a warning, and give instructions to the operator. The benefits of PAA are relaxing the operator during working, improving the training capability and avoiding unwanted mistakes.

Shen et al. [75] developed an augmented reality (AR) system to support collaborative product design among members of a multi-disciplinary team. In that system, each user would wear a HMD with an IEEE 1394 camera mounted on his/her head. The users could freely walk around in order to observe the augmented environment from different perspectives. The users could be in the same room or distributed at different locations. A designer might have a real product in hand, together with his tools, such as machining cutters and inspection gages, and this formed part of the real scene. Other members of the design team also formed part of the scene.

Ong and Wang [61] presented a 3D bare-hand interaction in an augmented assembly environment to manipulate and assemble virtual components. The authors found that the Bare- 
Hand Augmented Assembly (BHAA) system could be used for manual assembly sequence evaluation and analysis of assembly operations, assembly directions and tool changes by integrating the developed bare-hand interface with an Augmented Assembly (AA) system. However, the main limitation of the BHAA system was the lack of force feedback.

\subsubsection{Navigation}

Compared with the two categories discussed above, navigation is more often used in casual activities. Wearable see-through displays have been used for navigation tasks mainly for museum guiding, car driving, and aircraft piloting.

The "museum guide", demonstrated by Schiele et al. [73], used a see-through display. Utilizing the ability of a wearable device to perceive, recognize, and analyze objects and environments from a first-person perspective, they made a prototype of a wearable heads-up display with three buttons to control the system. Detected by the Elmo camera embedded in the wearable display, the observed painting would automatically trigger an animation explaining the work on the display's window.

Another interesting project called Smart Sight was presented by Yang et al. [98]. It used an intelligent tourist system that would take advantage of multimodal interaction and wireless communication by providing voice command during touring. Research projects that focus on heads-up displays for driving/piloting navigations are more frequent $[4,23,40,96]$, while only a few of the applications are wearable [78]. Nevertheless, minimizing distractions and effectively communicating information to the driver are potential benefits of wearable technology.

While the above technologies have drawbacks and limitations, such as cumbersome design, system latency in reaction, and lack of force feedback, the positive aspects include:

- Reducing access time

- Minimizing distractions and maintaining the attention

- Constantly accessing related information

- Real-time interaction and effective communication

- Improving working performance

- Relaxing the user 
Considering these positive features, it is reasonable to investigate the feasibility of applying OHMD technology to fields (e.g. education) which can benefit most from these advantages.

\subsection{Interactive Technologies in Education}

With regards to interactive or digital technology for education, the more traditional and established examples are e-learning [20, 70, 71, 76, 99] applications or web-based learning systems $[16,41,46]$ that provide educational assistance in the classroom or remotely. These systems are broadly used all over the world and there have been many studies conducted on their usability and learning effects.

For example, a variety of content management and collaboration tools, like Blackboard (http://www.blackboard.com), WebCT (http://www.webct.com), and Moodle (http://moodle.org), have been developed and are available to educational institutions. These tools provide content and user management, discussion boards, chat, and different levels of interactivity. Some social networking and media sharing sites such as Facebook (http://www.facebook.com), MySpace (http://www.myspace.com), Twitter (http://www.twitter.com), Flickr (http://www.flickr.com) and YouTube (http://www.youtube.com) are also utilized community-building for selfeducation tools [54].

Furthermore, some online 3D virtual environments have also been widely used for educational purposes. Twinity (http://www.twinity.com) and IMVU (http://www.imvu.com), for example, were two virtual environments that targeted reconstruction of real cities and creating social meeting places, respectively. The Town of Mirror Lake [21], presented by Curran et al., was a virtual community for educating nurses and medical staff. Boulos et al. [10] provided a good review of potential uses of Second Life and other 3D virtual environments for health and medical education.

More recently, developing technologies such as wireless network technology, Augmented Reality (AR), and wearable computing have been integrated into education, which derive other educational approaches. The following sections will focus on discussing the use of these three groups of technologies in education. 


\subsubsection{Mobile Learning}

Compared with more traditional e-learning and web-based learning systems, mobile learning provides more flexibility with regards to learning time and space. For example, Chen et al. [15] proposed a study on using Personal Digital Assistants (PDA) handheld readers to provide a personalized situated learning experience in a museum. Particularly, a wireless network enabled communication between the handheld device and the mobile server which operated the learning system. When a user walked near the artifacts, his/her handheld device would detect the Radio-Frequency Identification (RFID) tag attached onto the artifacts in advance. Then the relevant audio introduction for the specific "trigger point" was played.

Additionally, Ahmed and Parsons [2] presented a mobile learning application "ThinknLearn" which aimed at assisting high school students in classroom learning. The "Savannah" project illustrated by Facer et al. [26], explored the feasibility of engaging young learners with mobile technologies (m-technology) by taking part in simulations and learning about life on a savannah while they were outside on the school playground. The "soundscapes" project, demonstrated by Williams et al. [92], encouraged students to explore their inner city community using m-technology to map their community with sounds from different locations.

To summarize, there are five technological affordances in the mobile learning scenario, namely portability, social interactivity, context sensitivity, connectivity and individuality, that enable a deeply personal relationship with the context or media being learned [42]. Therefore, customized portable media devices with personalized access to the content could provide access to library and particular social networks. On the other hand, the limitations of mobile devices, such as small screens, short battery lives, intermittent connectivity, and associated human factors, would affect usability and learners' ability to learn.

\subsubsection{Augmented Reality Learning}

Augmented Reality (AR) refers to a combination of live imagery and computer-generated

images. As a bridge linking virtual and real world, augmented reality technology creates a reality that is enhanced and augmented [11]. Considering its potential, many researchers have studied utilizing augmented reality technology into education. The AR-Jam books [35], for instance, were made by the British Broadcasting Corporation (BBC). These are two AR storybooks that combine physical pages and desktop interaction for children. In the experiment, children played 
with interactive sequences in an augmented book using physical paddles to control the main characters. The author found that children expected the digital augmentations to behave and react, and they were encouraged by the ability to act in 3D space and by the visual feedback.

The Augmented Reality Student Card, presented by EI Sayed et al. [72], was designed to help students visualize different learning objects, interact with theories and deal with information in a 3D format. The In-Place Augmented Reality 3D Sketching of Mechanical System [7] utilized hand sketching as a natural way for creating AR mechanical experiments. Users could sketch experiments and watch them simulated as 3D shapes.

Moreover, Shelton and Hedley [74] presented a paper on using augmented reality for teaching Earth-Sun relationships to undergraduate students. They utilized an AR Toolkit application to teach students the concepts of rotation/revolution, solstice/equinox, and seasonal variation of light and temperature. The authors reported promising results from the user study.

And lastly, the work Save the Wild [9] was an augmented reality based system with which children could interact by creating origami paper characters printed with fiducial markers recognized via the webcam attached to the computer. As children made visible their origami creations to the camera, the system displayed animated virtual characters that were attached to simple storylines that related to sustainability and environmental consciousness. The authors found that by using $\mathrm{AR}$, it was possible to enhance play-based learning without it became focused on the technology.

Based on the studies above, we summarize five affordances of AR systems in terms of education: (1) learning content using 3D perspective, (2) ubiquitous learning, (3) encouraging the learner's sense of presence, immediacy, and immersion, (4) visualizing the invisible, and (5) bridging formal and informal learning [94]. In other words, 3D content and the learner's sense of presence could increase students' motivation and interest; visualizing difficult topics, such as ecosystems of wetland, could enhance students' understanding of abstract concepts; and combining formal and informal learning could lead to ubiquitous student learning activities. However, there are also challenges related to learners and the learning process with AR technology. For example, students could be cognitively overloaded by the large amount of information they face. Moreover, students might feel overwhelmed and confused when they deal with complex tasks [24]. And lastly, losing track of the real environment could result in a threat to students' physical safety [24]. 


\subsubsection{Wearable Computing}

Besides the technologies that were mentioned in the previous paragraphs, integrating wearable computing with learning has begun to provoke researchers' interests.

For example, the Past View [56] system demonstrated by Nakasugi and Yamauchi was designed for helping users acquire historical viewpoints using a wearable computer. Specifically, by wearing the see-through head-mounted display, history learners could watch films and news related to the present scene in front of them, so that they felt like they were experiencing a real historical incident. The authors reported that they got positive feedback from the interviews with users. However, they did not provide technical details, such as how to trigger the film when looking at a particular monument, or who is controlling the content.

Another similar example presented by Osawa and Asai [63] was a wearable learning support system that was mainly developed for outdoor education. The system was comprised of a wearable computer, a head-mounted see-through display, and a foot-mounted radio frequency identification tag reader. When the user, who was equipped with the system, approached a plant or stone, a description of the plant or relevant hints were displayed in the head-mounted display.

Vallurupalli [89] discussed the feasibility of using Google Glass for medical education. The authors designed four scenarios that would be encountered during routine clinical care, and let a mock trainee wear Google Glass in each scenario. Live video stream from the glasses was transmitted via Wi-Fi or Bluetooth which could have been received by a smartphone, tablet or personal computer; thus, the senior fellow who reviewed the images could help the trainee to perform the appropriate treatment. The study concluded that helped improve education and patient outcomes in the cardiology fellowship program. Similarly, Wu et al. [95] found that Google Glass can be successfully integrated into simulation-based training exercises without disrupting the learners' experience. It can increase learners' experiences and their attention on a current task and on the people with whom they are interacting.

There are fewer wearable computing projects and systems for education than other interactive educational technologies up to now. In particular, they have not yet been used in a classroom environment. Yet, as indicated by Thad Starner [81], the potential benefit of wearable technology is that it can conveniently integrate tools, devices, power needs, and connectivity with a user's everyday life and movements. Initially, it could integrate our bodies more seamlessly with devices and more thoroughly into network infrastructures, which provides the 
learners with so-called "ubiquitous learning". Then, it reduces the access time for finding answers. Lastly, it provides inconspicuous and non-distracting [85] learning patterns. When technologies are used to supplement students' learning activities and when the additional information being provided is of direct relevance, then learners' attention could become more highly focused and their understanding and retention enhanced.

Over the past few years, with the development of technology in optical, material science, ergonomics, and micro-processor chip technology, OHMD technology has been enormously improved. Yet, OHMDs have not been embraced in the mainstream as a legitimate computer platform in the league of the smartphone or the laptop [67]. As indicated by Pedersen and Trueman [67], the OHMDs' multi-field applications, particularly in the educational domain, could lead to the adoption of a new paradigm in human-computer interaction.

\subsection{Related User Studies}

In this section, we provide a discussion on the design, implementation and analysis of the related user studies on the use of digital interactive technologies in education.

To begin, a study on evaluating mobile learning [90] will be examined. The authors proposed a three-level evaluation framework named M3, which comprised a micro level concerned with usability, a meso level concerned with the learning experience, and a macro level concerned with integration within existing educational and organisational contexts. Particularly, the micro level examined the individual activities of the technology users and assessed the usability and utility of the educational technology system; the meso level examined the learning experience as a whole, to identify learning breakthroughs and breakdowns; and the macro level examined the impact of the new technology on established educational and learning practices and institutions. Their study suggested a lifecycle approach of continuous strategy evaluation: usability stage, educational effectiveness stage, and institutional adoption stage. Although this study was based on mobile learning context, this evaluation frame work is still transferable to our research design.

In the "ThinknLearn" project [2], the authors used this M3 evaluation framework to investigate the effectiveness of using a mobile app to facilitate student learning. They applied the micro level evaluation in the pilot study, collecting a data concerning usability and mobile quality. Then in the final experiment, they applied meso level evaluation with a larger sample to 
assess the impact of the application on learners' assessment between experimental and control groups in pre-post and retention tests.

Similarly, Ngai et al. [58] discussed a framework with the objective of facilitating the integration of wearable computing into computer science and engineering education. The evaluation of their platform was divided into three stages: the usability of the platform, the achievement of learning outcomes, and the comparison with traditional methods.

A study on using mobile media device for youth learning [80] sought to explore technological affordance in regards to how adolescents construct mobile technology for learning by using a Social Construction of Technology (SCOT) approach. The authors conducted a design intervention study with three user groups by tracking usage of their assigned mobile devices over three weeks'. In the project "Past Viewer" [56], the authors interviewed ten people about whether they changed their own historical viewpoints after using the system by overlaying past and present information.

Interestingly, Sayed et al. [72] designed five scenarios to simulate how users would use the ARSC application. The scenarios were (1) offline maximum solution, (2) offline medium solution, (3) offline minimum solution, (4) online solution, and (5) joystick game controller. In the user experiment, participants answered the questionnaires according to their overall experience with the system. The survey questions included subjects such as "overall reaction to the described product", "need for the ARSC system", "the efficiency of using ARSC in all subjects", "comfort level when using ARSC", and "the usability level". The authors found that $89 \%$ of the students were satisfied by the efficiency of the ARSC, and found that Science and Biology were rated as the most suitable to be used with the ARSC system..

A study on the effects of mobile learning on inquiry-based instruction [6] explored the practices of engaging students in inquiry-based learning experiences using a suite of technological tools, including a mobile app, that were developed to support citizen science and research data collection. Within the study, participants were randomly divided into four different groups. Group one represented users who had full participation plus using mobile device, group two represented the users who had full participation but no mobile device, group three represented the users who had limited participation plus mobile device, and group four represented the users who had limited participation but no mobile device. The authors expected 
that in the full participation plus using mobile device group would have the most favorable outlook towards perceived learning and engagement.

The studies reviewed above reflect significant approaches that have been used to evaluate learning effectiveness and learners' perception when integrating digital technologies into the educational field. There are few studies on using wearable computing devices, especially OHMD, to facilitate learning and there is no mention of relevant user experiments. The methodologies that previous m-learning, AR-learning and wearable-learning projects that used to evaluate primarily consisted of three stages: the initial usability evaluation of the learning system/platform, the effectiveness/achievement of educational outcomes, and comparison with traditional methods/new adoptions. According to the literature, the two sets of evaluation criteria that existing projects used for analyzing technical applications in education: usability (comfort, ease of use, enjoyment) and learnability (motivation, attention, relevance, confidence, satisfaction, efficiency). The method for designing the user study in this thesis and our evaluation criteria have taken some of these approaches. Our methodology consists of usability studies in a classroom environment, comparing multiple scenarios (including traditional and OHMD-based) and using criteria similar to those commonly used. Variations and details are discussed in the next chapters. 


\section{Chapter 3: Research Overview}

\subsection{Research Objective and Methodology}

With the general goal of examining the feasibility of assisted learning experiences with OHMD devices, this research is a first step toward the use of wearable devices in the classroom. With the research background and problem statement described in Chapter 1, our main objective was to find answers to two research questions on (1) the helpfulness of OHMD in classroom, and (2) identifying a suitable control mechanism for it. This was done through:

- Investigating methods of providing visual information in the classroom and comparing those with and without OHMD, through relevant criteria.

- Designing and developing of a series of control approaches for OHMD, include manual control, timer control, voice control, remote mobile control. (Details see chapter 5)

- Designing and developing of a user study including three "screen" options (OHMD, PC screen, and projection display) and three controller factors (teacher, student, and machine), plus the required software programs.

- Verifying a series of hypotheses that would help us answer the research questions (usefulness of OHMD and effect of control methods) by associating usage scenarios to specific evaluation criteria.

Our methodology consisted of the following steps:

(1) Specify the subject of the class, and design the related content.

- We chose 30 Chinese words as the class content

- The annotations, images and animations that represent the content were designed

- Listening, reading, writing and speaking exercises were defined for participants' self-evaluation

(2) Design scenarios that simulate a classroom learning environment, and create a multicontrol \& multi-interface system to evaluate learners' experience.

- Based on a pilot study and possible combinations of display and control methods, we chose five scenarios that include the most likely situations that are helpful in our study

- We developed the control app for OHMD, projection display and PC 
(3) Design and conduct a user experiment with 15 participants at a pre-set lab using the interfaces and control approaches to simulate real class learning environment.

- Recruiting the Chinese learning class students as participants

- Using Likert scale questions to gather feedback from the participants

- Using questionnaires to gather further opinions from participants

The questions were designed generally around the two groups:

1. The students' perceptive responses towards OHMD's usability during learning experience. We used 7-point Likert scale questions, which include the criteria of enjoyment, ability to focus, motivation, perceived efficiency, physical comfort, understandability and relaxation, to evaluate students' perception.

2. Students' subjective evaluation of learning effects. We let students do the exercises of listening, reading, speaking and writing, respectively; and gathered their selfevaluation by survey questions.

An interactive learning system was developed, which covered all the interfaces and controlling approaches needed for the five scenarios. The students could navigate and review the content being learned, and do the reading, listening, speaking, and writing quizzes respectively to evaluate the learning effectiveness for each scenario. Paper-based survey questions were then asked to evaluate the experience.

\subsection{Pilot Study and Experiment Overview}

With options for various combinations of display or control mechanism, a series of possible scenarios existed in our study. In order to identify the potential issues and effective ways of doing the user study, a pilot study was first conducted.

We considered three possible options for screen: the OHMD device, projection (or large screen monitor) shared display, and personal computer (or any other common device with personal screen). To control the content on screen, three mechanisms can be considered: teacher, student, and a computer. The teacher-controlled method corresponds to a traditional classroom experience. The student-controlled classroom is similar to cases where students receive handouts to view while following a lecture or tutorial sessions where they perform actions on a computer following spoken instructions. The machine-controlled option was imagined as a possibility where a timer-based slideshow is used. Theoretically, the scenarios for user 
experiments should include all the combinations of screen variables (OHMD, PC screen, and projected display) and controller variables (teacher, student, and machine). Additionally, for some cases, it was possible to have more than one visual screen or controller involved in the scenario. The set of all possible experimental-scenarios are shown in Table 2.

Table 2: View-Screens and Controllers' Combinations in Theory

$\mathrm{T}=$ teacher control;

$\mathrm{S}=$ student control;

$\mathrm{M}=$ machine (timer) control;

Pro = projection display;

$\mathrm{PC}=$ personal computer;

OHMD = optical head-mounted display

\begin{tabular}{|c|c|c|c|c|c|c|c|}
\hline$\overline{-}$ & $\mathrm{T}$ & $\mathrm{S}$ & $\mathrm{T}+\mathrm{S}$ & $\mathrm{M}$ & $\mathrm{T}+\mathrm{M}$ & $M+S$ & $\mathrm{~T}+\mathrm{S}+\mathrm{M}$ \\
\hline OHMD & $\checkmark$ & $\checkmark$ & $x$ & $\checkmark$ & $x$ & $x$ & $x$ \\
\hline $\mathrm{PC}$ & $x$ & $\checkmark$ & $x$ & $x$ & $x$ & $x$ & $x$ \\
\hline Pro & $\checkmark$ & $x$ & $x$ & $\checkmark$ & $x$ & $x$ & $x$ \\
\hline $\mathrm{OHMD}+\mathrm{PC}$ & $x$ & $x$ & $x$ & $x$ & $x$ & $x$ & $x$ \\
\hline OHMD+Pro & $x$ & $x$ & $\checkmark$ & $\checkmark$ & $\checkmark$ & $\checkmark$ & $x$ \\
\hline Pro + PC & $x$ & $x$ & $\checkmark$ & $x$ & $x$ & $\checkmark$ & $x$ \\
\hline $\mathrm{OHMD}+\mathrm{PC}+$ Pro & $x$ & $x$ & $x$ & $x$ & $x$ & $x$ & $x$ \\
\hline
\end{tabular}

As illustrated above, " $\checkmark$ " indicates that the scenario is possible, while " $x$ " indicates that the scenario is not possible in the real classroom learning situation. For example, it was not realistic for a teacher to control a student's PC during the lecture as it does not provide any potential benefit over the use of a traditional projection screen. Similarly, it did not make sense if a student controlled a teacher's projection display in class. Next, one controller should not control two devices at the same time; and two controllers should not control one device simultaneously. Moreover, the combinations of the three controllers/three visuals were also not reasonable. So based on these considerations, the scenarios shaded in green were left, which was the original design for the study.

Two HCI students were invited for individual pilot study sessions. A brief introduction to this study was presented to participants. We let the participants fill the surveys and do the scenarios as designed. We gathered the participants' comments and suggestions right after completing the questionnaires and each scenario test in case they forgot. The total experimental 
time for one participant was measured excluding the time when gathering comments and having discussions. And finally, we gathered the participants' overall opinions toward the study design and the OHMD technology.

According to participants' comments, we found that the "machine control" scenario (app materials moving forward automatically as time goes) was not appropriate for student learning in a real classroom situation. It was possible that participants were interested in some content or did not fully understand some material, thus, they wanted to stay at that page longer or to let the teacher explain more. However, the system was unaware and kept moving forward, which made participants unsatisfied. Similarly, if the system stayed at certain page too long, student felt impatient. The participants and researcher both found it hard to follow the pace of the materials when controlled by timer. Therefore, this scenario was removed after the pilot tests, and was not presented in the final user experiment. A more intelligent mechanism for machine control may be studied in the future.

Another alternative approach was to let voice control the program, but it could cause new issues: (1) if OHMD was worn by students, the teacher's voice was not able to reach it, and (2) it was impractical and noisy to allow all students to control their devices by voice. Thus, we did not involve a voice control option in the experiment either. However, the voice control scenario could also be considered in further work, for example, in an outdoor education scenario. Therefore, we set the final scenarios for user experiment as follows:

A. single projection display with teacher controlling;

B. single OHMD with teacher controlling;

C. single OHMD with student controlling;

E. projection display with teacher controlling \& PC with student controlling;

F: projection display with teacher controlling \& OHMD with student controlling.

The label D was originally assigned to the machine control scenario which was removed after the pilot. For the sake of continuity of documentation, we kept the original naming.

Additionally, participants suggested limiting the overall test time to one hour to avoid boredom, since the class content and exercises were repeated across scenarios. We also decided to spend the same amount of time for each experimental scenario. Moreover, several minor modifications were made according to participants' comments and feedback, such as adding some opening questions to the survey. Some prototype aesthetic issues were fixed, such as 
making the layouts on different viewing-screens consistent to make sure student responses would only be affected by changing scenarios not class material. Details of the scenarios will be presented in chapter 4 .

To conclude, the pilot study helped us initially examine our research questions and establish the potential assumptions. Participants generally were excited to use the OHMD to learn things; even though they were not familiar with the subject. They believed that enjoyment, motivation and concentration could be the main advantages of OHMD for classroom learning; meanwhile, they considered the current ergonomic limitations of OHMD would affect the overall user experience. The first time wearing OHMD for learning, one participant commented she needed a rest when wearing it for more than one hour. Moreover, because of the elaborate classmaterial design, participants indicated that the content was easy to understand and remember. However, they were unaware whether OHMD could be useful for speaking skill's practice, since they felt it needed real communication.

Based on the pilot study, we decided to narrow down the $3 \times 3$ study plan and make it into a series of doable scenarios as presented below:

- A. single projection display with teacher controlling;

- B. single OHMD with teacher controlling;

- C. single OHMD with student controlling;

- E. projection display with teacher controlling \& PC with student controlling;

- F. projection display with teacher controlling \& OHMD with student controlling.

For each scenario we considered the following evaluation criteria:

- students' perceptive responses towards OHMD's usability, including enjoyment, ability to focus, motivation, perceived efficiency, physical comfort, understandability and relaxation;

- students' subjective evaluation of learning outcomes.

Most of the evaluation criteria were chosen based on similar studies as discussed in Chapter 2. The ability to focus was added as one of the major motivations of this research is to decrease visual distraction. 


\subsection{Hypotheses}

In order to answer the two main research questions about students' perception towards OHMD's usability among various learning experiences and students' subjective evaluation of learning effects, we made several hypotheses.

Our initial concern was regarding the validity of our study. It was important to make sure that participant did in fact consider scenarios and criteria, and responded to survey questions based on them, as it is possible that they simply answered the same or randomly. In order to investigate this, we established the following initial hypothesis:

\section{H1. The participants' responses will vary significantly over scenarios and criteria.}

Then, in order to answer our two main research questions about students' perception towards OHMD's usability among various learning experiences and students' subjective evaluation of learning effects, we made a main hypothesis as follow:

\section{H2. The evaluation criteria will be more positive in OHMD-based scenarios with} student control.

Since we tested seven evaluation criteria in five experimental scenarios, participants' responses in terms of the criteria and their learning outcomes might vary for scenarios and criteria. So we made a series of sub-hypotheses breaking down $\mathrm{H} 2$ for all seven evaluation criteria. For example, H2.1 was related to enjoyment and it included 4 sub-hypotheses comparing relevant displays and control mechanisms, as shown in Table 3. The full description of subhypotheses for $\mathrm{H} 2$ can be found in Appendix $\mathrm{J}$.

Table 3: Sub-Hypotheses (H2.1) Related to Enjoyment Effect among Scenarios

\begin{tabular}{|l|l|}
\hline H2.1(a) & $\begin{array}{l}\text { The enjoyment rating will be significantly higher with OHMD compared to projection } \\
\text { display, both controlled by the teacher. }\end{array}$ \\
\hline H2.1(b) & $\begin{array}{l}\text { The enjoyment rating will be significantly higher with student-control compared to } \\
\text { teacher-control both OHMD worn by student. }\end{array}$ \\
\hline H2.1(c) & $\begin{array}{l}\text { The enjoyment rating will be significantly higher with teaching without projection } \\
\text { display compared to teaching with projection display, both OHMD worn by student. }\end{array}$ \\
\hline H2.1(d) & $\begin{array}{l}\text { The enjoyment rating will be significantly higher with student using OHMD } \\
\text { compared to student using projection display and student using personal computer, all } \\
\text { taught with projection display. }\end{array}$ \\
\hline
\end{tabular}

Finally, in order to investigate the general preferences of participants with respect to exercise tasks (listening, speaking, reading and writing), we defined the following hypothesis: 


\section{H3. For specific tasks, participants will prefer the use of OMHD with their own}

control.

While $\mathrm{H} 1$ and $\mathrm{H} 2$ were verified using the rating of evaluation criteria for each scenario, H3 was verified using extra questions related to the tasks and preferred devices.

\subsection{Data Analysis Plan}

We had the same sample group throughout the experiment, and measured the same participants 5 times ( 5 experimental scenarios). In each scenario, we measured the same usability criteria (enjoyment, motivation, perceived efficiency, understandability, ability to focus, physical comfort, and relaxation).

Based on the hypotheses described in previous section, we conducted a two-way repeated measures ANOVA test to examine H1. Two-way repeated measures analysis of variance (rANOVA) is a commonly used statistical approach to evaluate a repeated measure designs. With such design, the repeated-measure factors (independent variable) are the within-subjects factors, while the participants' responses ratings are the dependent variable. The two-way repeated ANOVA was suitable because we had two categorical independent variables (scenarios and usability criteria), and we would like to examine their effects upon one dependent variable (participant's response ratings). Normality of the sample was planned to be assessed by examining histograms of the distributions, and examining the skewness and kurtosis of the distribution. Histograms were to be evaluated for evidence of central tendency and for skewness and kurtosis statistics.

To test sub-hypotheses of $\mathrm{H} 2$, we conducted one-way repeated measures ANOVA with Greenhouse-Geisser correction and Post-hoc tests using the Bonferroni correction to test participants' responses on each criterion among scenarios. Repeated measures ANOVA usually occurs in two situations: (1) when participants are measured multiple times to see changes to an intervention; or (2) when participants are subjected to more than one condition/trial and the response to each of these conditions wants to be compared. Moreover, since the data was collected by Likert scales questionnaires, non-parametric ordinal methods are more appropriate. So we conducted a Friedman's ANOVA and Wilcoxon signed-rank test with Bonferroni correction for the pairwise comparison to re-examine the results. These two test method were used because Friedman's ANOVA is the related non-parametric method for repeated ANOVA, 
and Wilcoxon signed-rank test is the related non-parametric method for paired t-test. Even though the ANOVA test was preferred in presence of multiple variables, we added the Friedman's ANOVA and Wilcoxon sign-rank test as a measure of extra reliability of results.

To test H3, we planned to collect participants' reactions and feedback towards the exercise tasks' in each experimental scenario results by self-evaluations using the survey which is available in Appendix D. The questions were related to perceived difficulty levels of tasks, helpfulness of and comfort level of scenario, and ability to learn those tasks.

Open-ended commentary questions were also provided in the survey as extra source of information. Due to reliance on the quantitative parts as the main research method, no interviews or formal qualitative data acquisition and analysis tools were considered.

\subsection{Implementation}

In order to examine the hypotheses and conduct the experiments, we designed and developed a series of simple prototypes centered on OHMD to demonstrate learning materials. The app included text and practice sections. We implemented the app onto pc, mobile phone, and OHMD platforms, and we developed relevant control approaches to control the content on the OHMD. The wearable device used in our study was Epson Moverio BT-200. A detailed discussion will be presented in chapter 5 . 


\section{Chapter 4: Experimental Design}

\subsection{Experimental Scenarios}

In each scenario, participants completed the In-Study survey after the Text module and the Post-Quiz survey after the Practice module. The In-Study survey took about 1 minute to complete and the Post-Quiz survey took about 2 minutes.

\section{Scenario A: single projector display with teacher controlling}

In this scenario, the participants learned the lecture materials and completed the exercisetasks only by teacher teaching with the projection display on the wall. To be specific, participants were instructed to sit beside the projector on one side of a long desk, facing the display on the wall. Once they were ready, the teacher ran intuiFace (see chapter 5) on the laptop, and used the projector to display the content. After learning the content in the "Text" module, participants were asked to take a break and completed the paper In-study Survey (Appendix C), which took approximately one minute. Then, participants continued to do the exercise-tasks in the practice module lead by the teacher (who is also the researcher), and gave their answers orally. When the exercise-tasks were completed, participants were asked to fill-in the paper PostQuiz survey (Appendix D) to end the experiment for this scenario.

This experimental scenario simulated the traditional teacher-based class mode. Primarily, students listen to the instructor's presentation and view class material on the projection display. The instructor teaches with the projection display.

\section{Scenario B: single OHMD with teacher controlling}

In this scenario, participants viewed the lecture material and completed exercise-tasks by wearing OHMD. Participants did not need to touch the control pad; all the activities in the two modules were controlled by the teacher. Participants completed the surveys as above.

This experimental scenario simulated a new class mode that included having OHMDs. Primarily, students wear OHMD, and view class material on the OHMD. The instructor has

his/her presentation and controls what content is shown on students' OHMD. There are no other visual screens, such as a projection display, in this new learning situation. 


\section{Scenario C: single OHMD with student controlling}

In this scenario, the participants viewed and interacted with the class material software and completed the four exercise-tasks manually with OHMD, but with the teacher's oral guidance. To be specific, in the Text module, the teacher would orally explain the class material, guide the participants to check the audio clips, play with the animations, and jump to a specific page to learn. Participants would follow teacher's pace to view, interact and learn the content. The teacher orally instructed the participants to do the practice module.

This experimental scenario simulated another new class mode including OHMDs. Students wear OHMD, view class material on the OHMD; the instructor has his/her presentation; but there are no other visual screens, such as a projection display, in this new learning situation. Differing from Scenario B, students view and interact with the content on OHMD; instructor only takes care of the oral presentation.

\section{Scenario E: projection display with teacher controlling \& PC with student controlling}

During this scenario, two displays (projection display and PC screen) were involved. The projection display was controlled by the teacher and PC program was controlled by the participant. In the Text module, the class contents showed on the two displays were the same. The difference was that the participants had the options either to follow the teacher's pace to view the class material on their own PC, or browse other relevant information according to what teacher was teaching. There was a slight change in the Practice module, extra instructions of how to do the exercise-tasks (e.g. tap the logo to hear audio and answer the listening question according to the audio) were displayed on the projection display; whereas the layouts in the PC did not have these instructions.

This experimental scenario simulated the traditional teacher-based class mode, while students use their digital device as an assistant. Primarily, students listen to the instructor's presentation, view class material from the projection display, and take notes/ explore other relevant information with their personal digital device. The instructor teaches the content on the projection display.

\section{$\underline{\text { Scenario F: projection display with teacher controlling \& OHMD with student controlling }}$}

In this scenario, two displays (projection display and OHMD screen) were involved. The projection display was controlled by the teacher and the OHMD was controlled by the participant. 
The content shown on the two displays were the same as in the Text module. The participants had the option of either following the teacher's pace to view and interact with the content on their own OHMD, or browsing other relevant information at will. In the Practice module, extra instructions on how to do the exercise-tasks were displayed on the projection display, but not on the OHMD.

This experimental scenario simulated a new class mode where the instructor teaches with the projection display, while students have OHMD as a replacement for their own digital device. When students listen to the instructor's presentation, they have the option of either following the teacher's pace to view the class material, or exploring related knowledge with OHMD. Since the OHMD screen is always "worn" in front of students' eyes, it will allow students to view the content of the projection display and OHMD screen simply by switching eye-focus. Also, the instructor teaches the class material with the projection display.

\subsection{Procedures}

Individual experimental scenario tests were done with each participant. Each test was conducted following these same steps.

\section{Preparation}

First, all instruments were pre-set in a lab to simulate the classroom environment. The projector was placed on a long desk, and projected the display on the wall. The Moverio OHMD, mobile phone, Acer laptop and MacBook were manually connected to the wireless network of the lab. Then, the android socket server program, the "student side" app on the Moverio OHMD, the "teacher side" app on the mobile phone, the application emulator on the MacBook, and the intuiFace program on the Acer laptop were launched. The participants were informed of the brief agenda of the test, as well as that they would not make any mistakes during the experiment, and that they should feel free to make comments. Next, the participants were asked to read and sign the consent form (Appendix A), and fill out the pre-study questionnaire (Appendix B). Lastly, a short instruction of how to manipulate the OHMD device was given to the participants, such as how to adjust the virtual screen size and how to use the control-pad. 


\section{During the Experiment}

Our user experiment involved of five scenario tests, and participants needed to view the class material and complete the exercise-tasks five times. So it was possible that some participants became tired or bored with the content after repeated tests. Moreover, we asked the same group of participants to experience five different learning scenarios. It was possible that some participants favoured the first scenario tested and rated the usability feedback biasedly, since the first experience was usually fresh and impressing. Furthermore, it was possible that participants' performance improved throughout the session simply due to their guessing/remembering the correct answer rather than being affected by the related experimental scenario.

Therefore, to minimize data errors caused by the biases and prejudices mentioned above, participants performed the experimental scenarios in a randomized order. The researcher prepared five paper cards with the scenarios' names printed on the back. Before starting each scenario, the participant selected one card and opened it; and then the corresponding scenario was performed.

\section{After the Experiment}

The participants were asked to fill out a final paper questionnaire (Appendix E) providing their overall experience, and then they were debriefed. A \$10.00 Tim Card was provided to the participant as compensation and appreciation for their time and assistance with the study. The entire study was approximately $50-65$ minutes. 


\section{Chapter 5: Prototype Implementation}

In this chapter we introduce and discuss hardware and software components of the prototype OHMD-based learning system used in this study.

\subsection{Apparatus}

\subsubsection{Epson Moverio BT-200}

Our prototype uses Moverio BT-200 manufactured by Epson [37] as shown in Figure 1. It is a pair of binocular digital glasses that put a micro-projection display in each transparent lens. Moverio BT-200 has a VGA camera, GPS, compass, gyroscope, and accelerometer embedded, and has a 960x540 resolution 16:9 ratio with 80-inch image from 5 meters away perceived display, which hovers with a 23-degree field of view. A handheld android 4.0.4 console with a touchpad controller powers and controls the floating display. The controller has Bluetooth 3.0, built-in Wi-Fi, 32 GB SDHC card. It supports H.264 video playback, works with Dolby Digital Plus to carry audio to connected headphones for surround sound, and there is a microphone in the headset too.

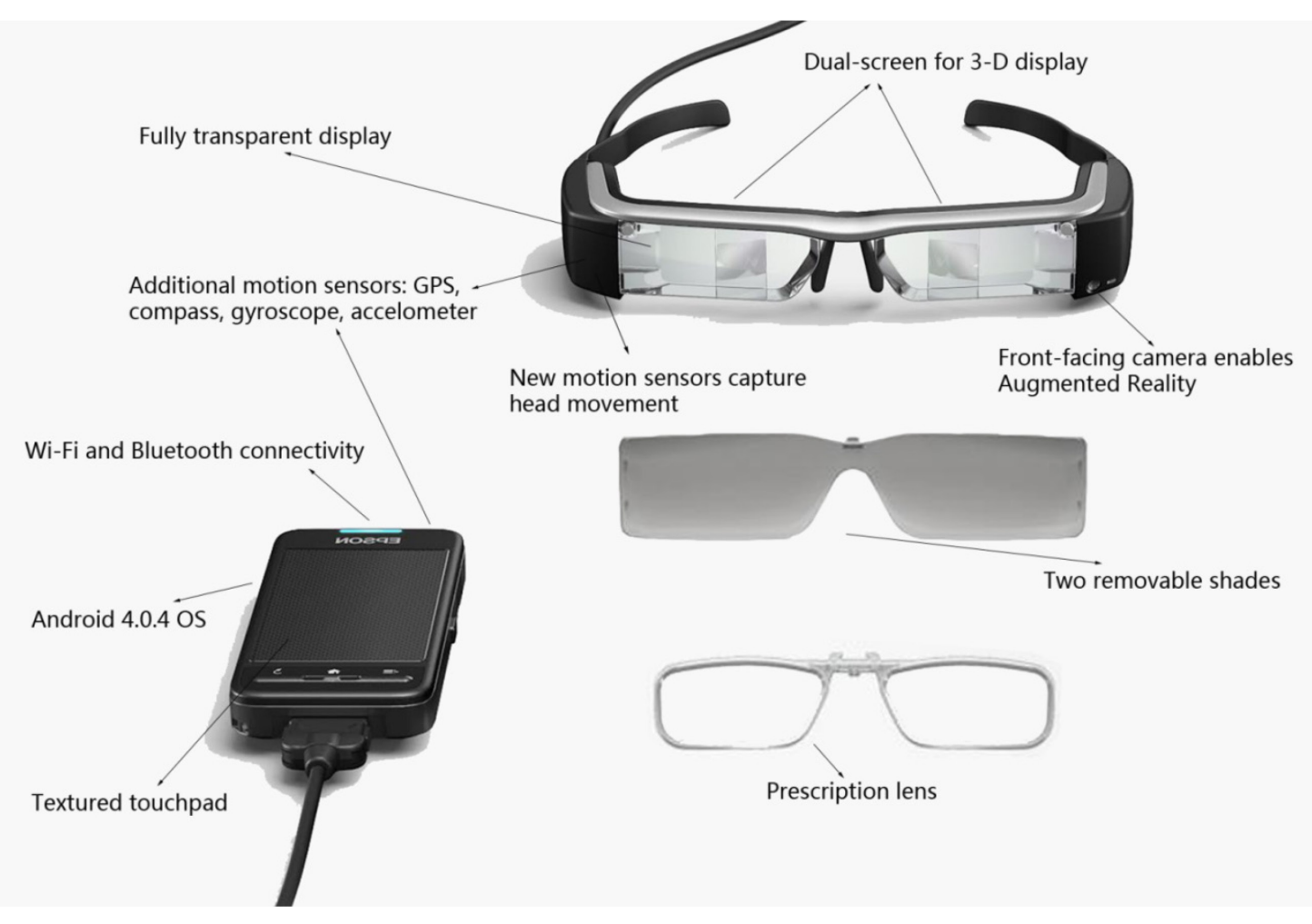

Figure 1: Components of Moverio BT-200 [36] 
The goal of this study is to test the applicability, particularly of a wearable device, within a language learning class. For practical purpose, the device should be easy to wear. Epson's OHMD is small and comparatively light. Unlike Google Glass, Epson's OHMD is heavier yet still acceptable. Other related products are Facebook-owned Oculus Rift or Sony's Project Morpheus for the PlayStation 4. They are virtual reality (VR), not augmented reality: they block out the real-world view in total preference of the digital version. That makes for immersive gaming, but isn't much use in a classroom environment, since it would probably block communication between students and teachers. From a view of controlling methods, touchpad, compatible device, speech recognition, gesture recognition and eye-tracking are the main approaches. Considering the practical concerns in a classroom such as reduced noise and need to look around, touchpad input is a good choice. Considering all these features and the cost, Epson Moverio was used for the research.

\subsubsection{Equipment used for Experiment}

As discussed above, an Epson Moverio BT-200 was worn by participants to control the content. Instructions on how to use the device were provided prior the experiment, and software was pre-installed on the device. Participants needed to use the wired touchpad to view the images, animations, and video streams shown on the display. Additionally, a pair of earphones was prepared for participants to hear the audio chips.

A BENQ W1100 projector was connected to an Acer laptop, and projected the app interfaces that launched on a PC platform. The content of the display was controlled by the teacher during the experiment.

A Samsung Galaxy S3 Android phone was used for the teacher to remotely control the content which projected on the Epson Moverio. The app was pre-installed as well, which had a UI layout consistent with the one displayed on OHMD.

Furthermore, an Apple MacBook laptop was prepared ahead of the experiment. Participants could view and manipulate the app which illustrated the class-related instructions on an Android emulator during the experiment. This laptop was used for the experiment scenario $\mathrm{E}$ when the student controlled the PC and the teacher talked of the content on the projection display. 
Finally, the Acer laptop (mentioned in BENQ W1100) was used to maintain the server program, and to run the intuiFace (details in 5.2.3) program to play the class app demo which projected on the wall.

All the equipment used in the experiment is listed in table 4.

Table 4: Equipment Information

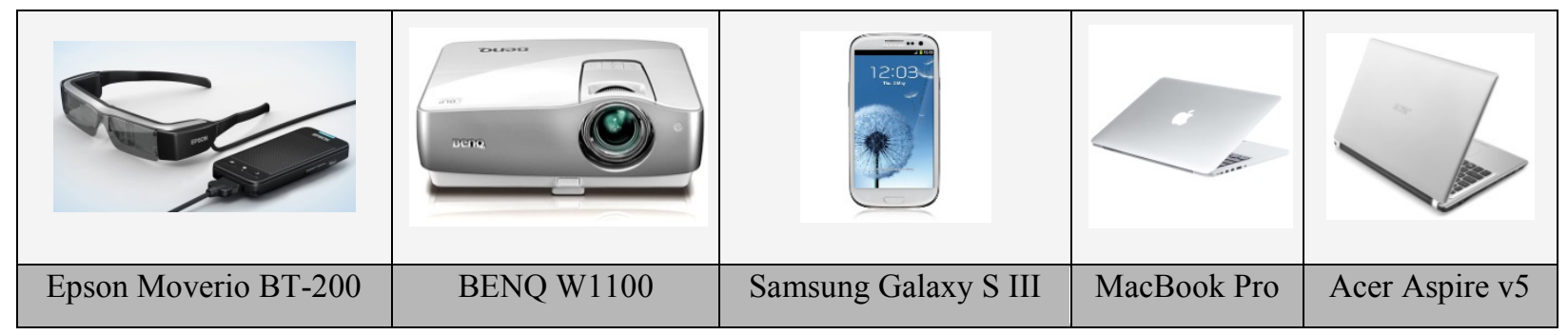

\subsection{Software}

In order to examine the two main research questions as illustrated in chapter 1, we designed and developed three sets of programs for different platforms and functions for the user experiment: the programs developed for OHMD and mobile phone, the socket communication program, and the programs that ran on the display and PC.

\subsubsection{Epson Moverio \& Mobile Phone App}

As described in chapter 3, the Epson Moverio was originally designed to come with two functions: one, allow the users to view the materials of the lecture either by manual-control or by teacher's control; and two, allow the users to do the exercise-tasks (listening, reading, writing, and speaking exercises) either by manual control or by teacher's control. Thus, three modules, which are "Text", "Practice" and "Communication", were designed and implemented for both Epson Moverio and Mobile control app.

Because the OS on Epson Moverio BT-200 is Android 4.0.4, the programs were developed using Android SDK with API level 15 (Ice Cream Sandwich). The input method for the Epson Moverio display is to use finger touch on the touchpad to control the "cursor" on the display. In other words, users did finger tapping and moving on the touchpad, which was similar to the way people use a regular phone touchscreen. The touchpad did not support left/right click; long pressing on the touchpad would bring up a pop-up menu which offers the relevant options. 
So based on these, the app layouts and interaction approaches were designed by combining WIMP (windows, icons, menus, and pointer) and android-patterns.

The user interfaces under the "Text" module are shown in Figures 2-6. Since the Epson Moverio does not support screenshot, the images are captured from the app on the mobile phone.

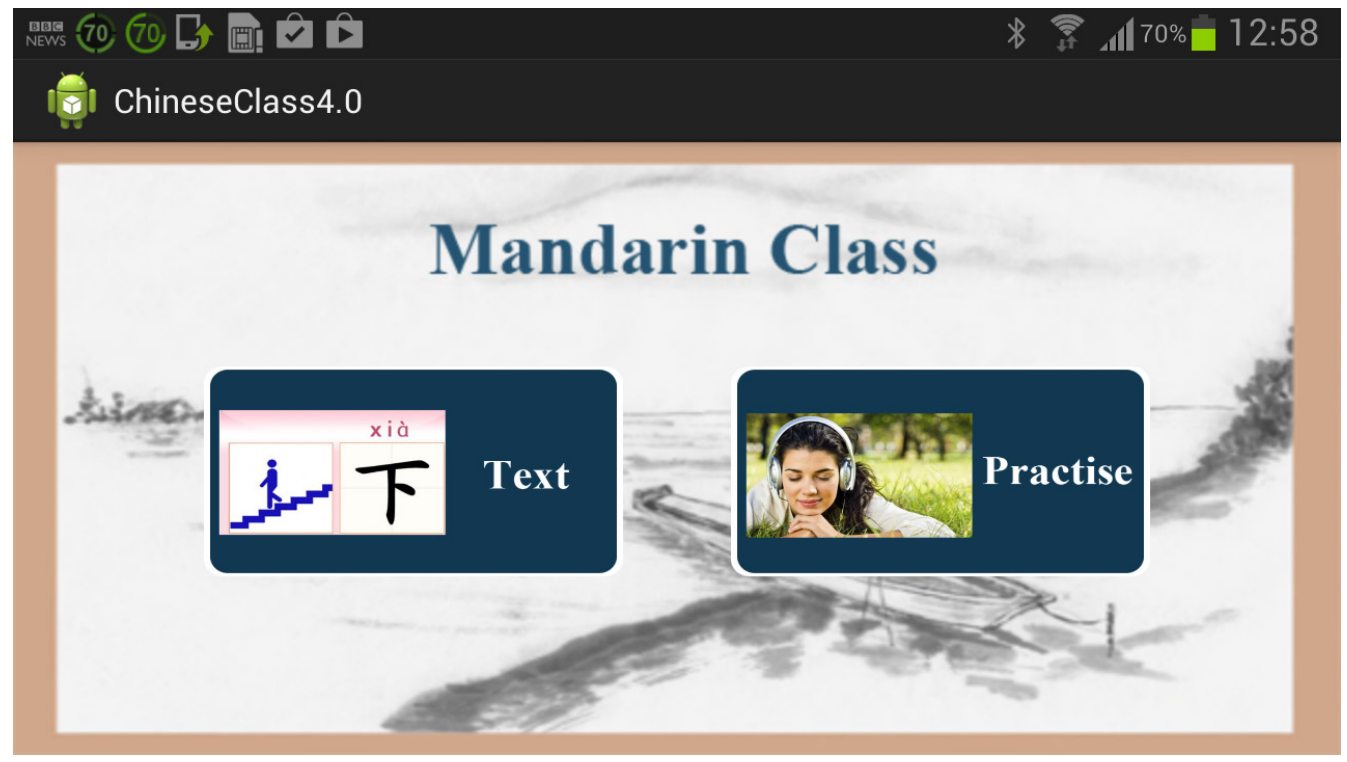

Figure 2: The Main Page of Epson Moverio App

Users could browse the lecture materials by tapping the "Text" image from Figure 2. The material included thirty primary Chinese words, which were categorized into six categories: weather, water \& mountain, tools \& weapons, numbers \& comparisons, creature \& animals, and human beings, as shown in Figure 3. Users could choose the cards to check further details.

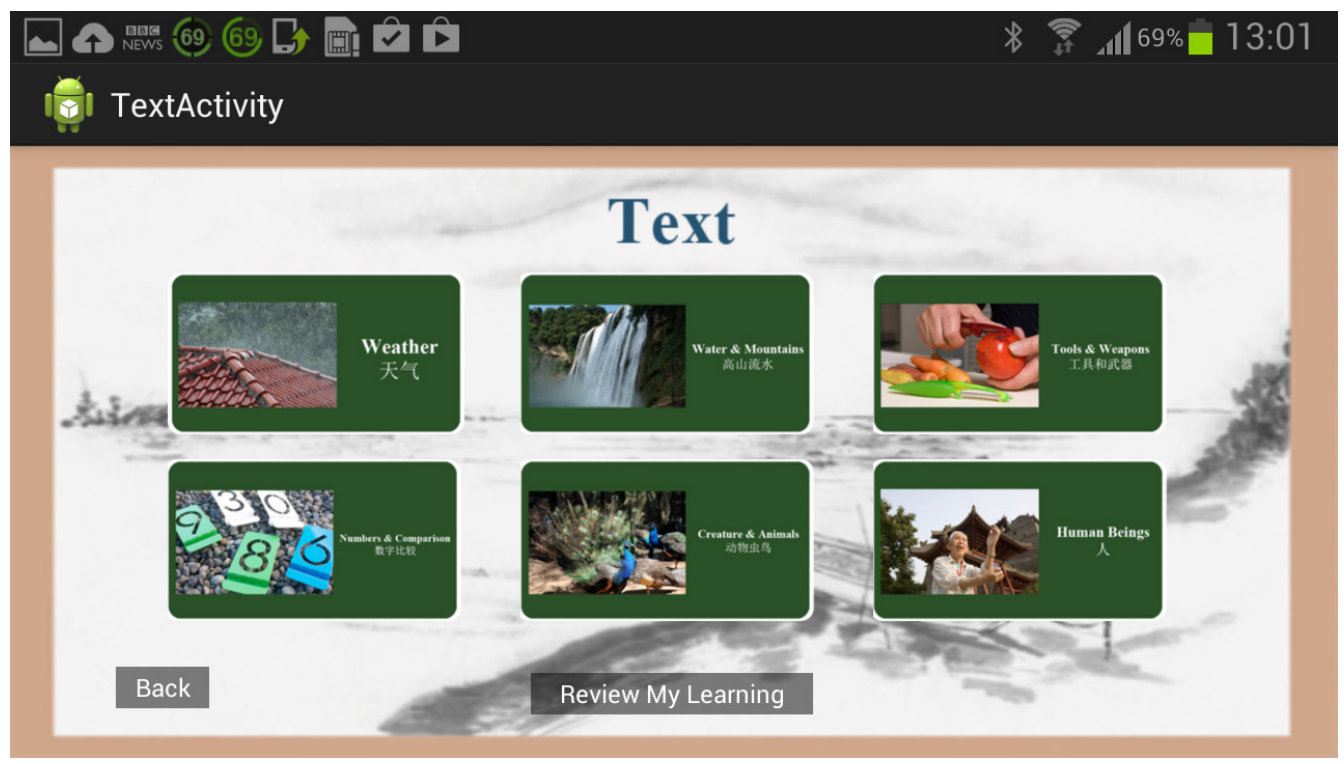

Figure 3: The Page of "Text" Module 
For example, if a user selected the "Weather" card, the page would jump to the weather page as shown in Figure 4. Learning materials for six words related to weather would be displayed. He/she could review the detailed information of each word by tapping it. The "back" button was designed because the touchpad did not support manipulation methods such as sliding. The other reason was that we did not want complicated manipulation approaches affect the participants' judgment towards our major goal of designing the experiment.
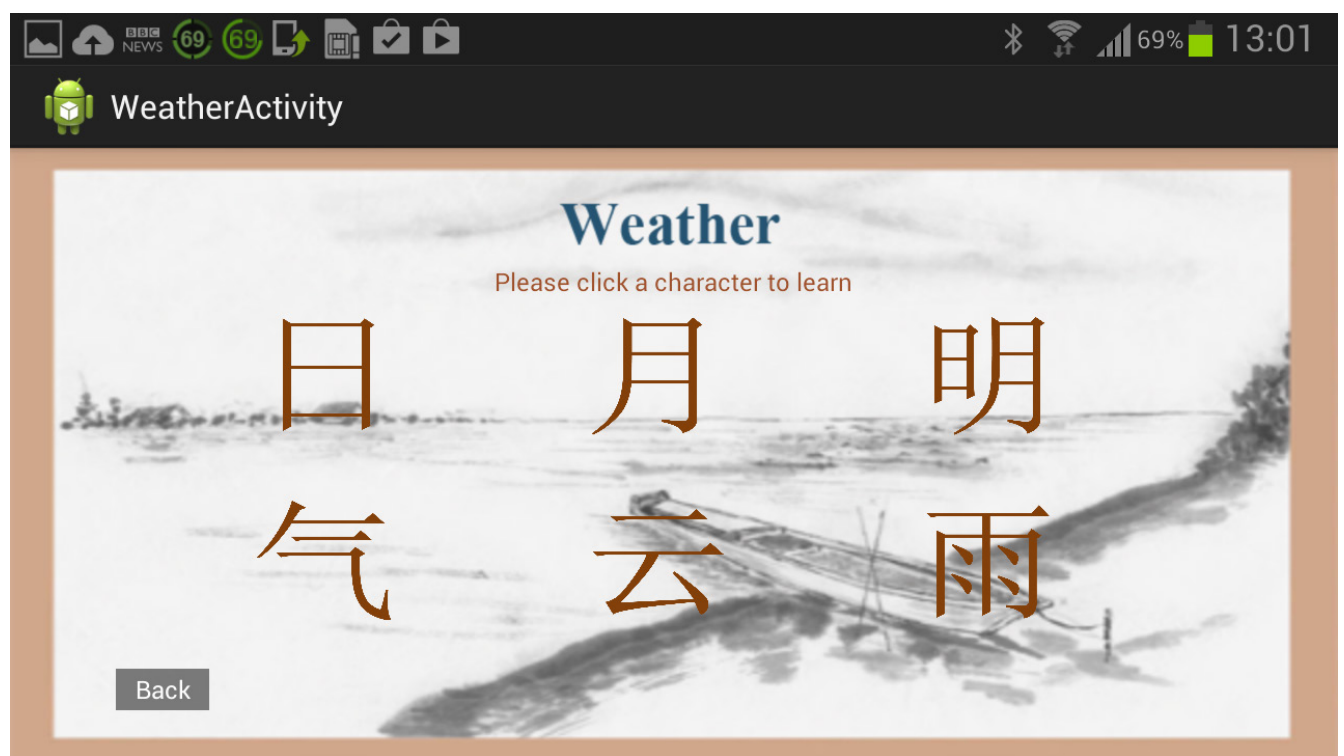

Figure 4: The Materials in "Weather" Page

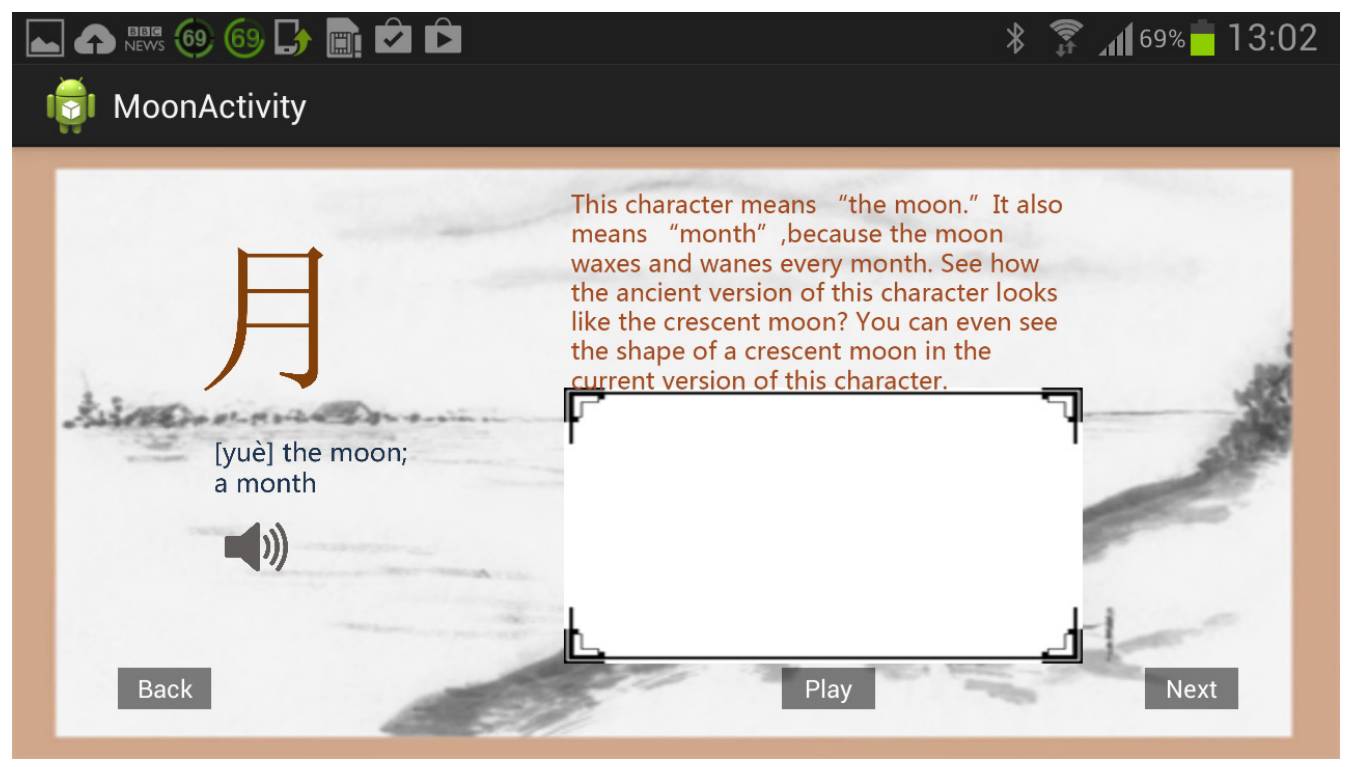

Figure 5: The page of the second word of "Weather" section 

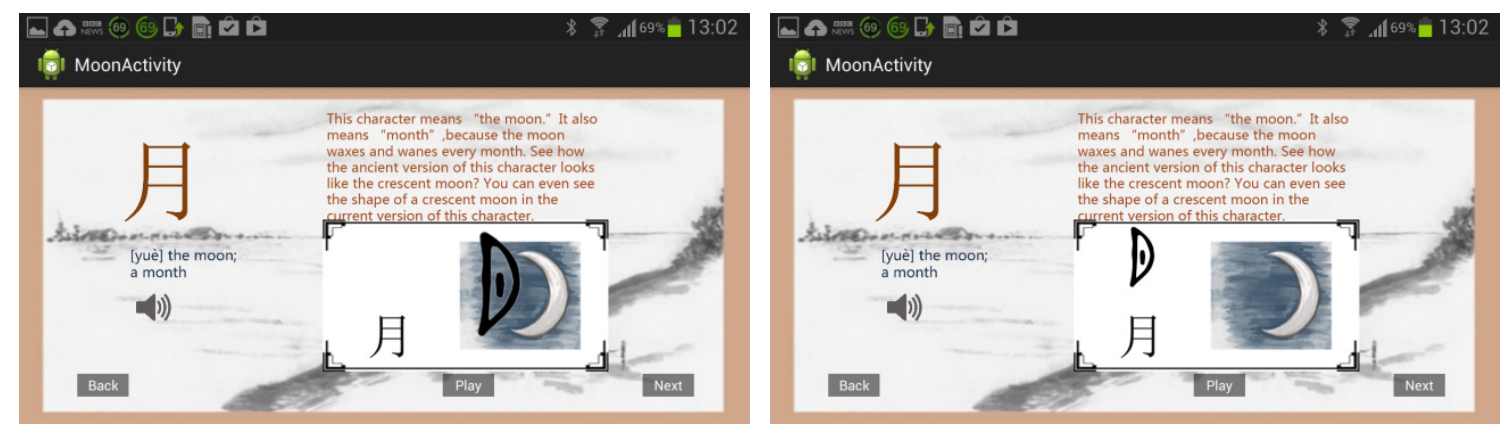

Figure 6: The screenshots when user is playing with the animation

The Text module material was designed to cover listening, reading, writing and speaking components as shown in Figure $5 \& 6$. To be specific, the "speaker" audio information, the brief description, the image, and the animation were designed to help the learner understand and remember the word, and a short writing demo was used to present how to write it.

In the "Practice" module, exercises in terms of listening, reading, writing and speaking were designed to allow users to do self-evaluation based on what they had learned in the "Text" module as shown in Figure 7. The user interfaces are shown in Figures 7-11. These layouts were also captured from the mobile version.

Consistent with the "Text" module, users tapped the portal images to review the quizzes for each exercise. For example, when entering the listening exercise as shown in Figure 8, the users would tap the "radio speaker" to listen to the audio which presented the pronunciation of a Chinese word, and then chose the written character that matched with the audio from the four options the provided. The learner would get feedback right after he/she made the choice; therefore he/she could examine his/her learning performance. 


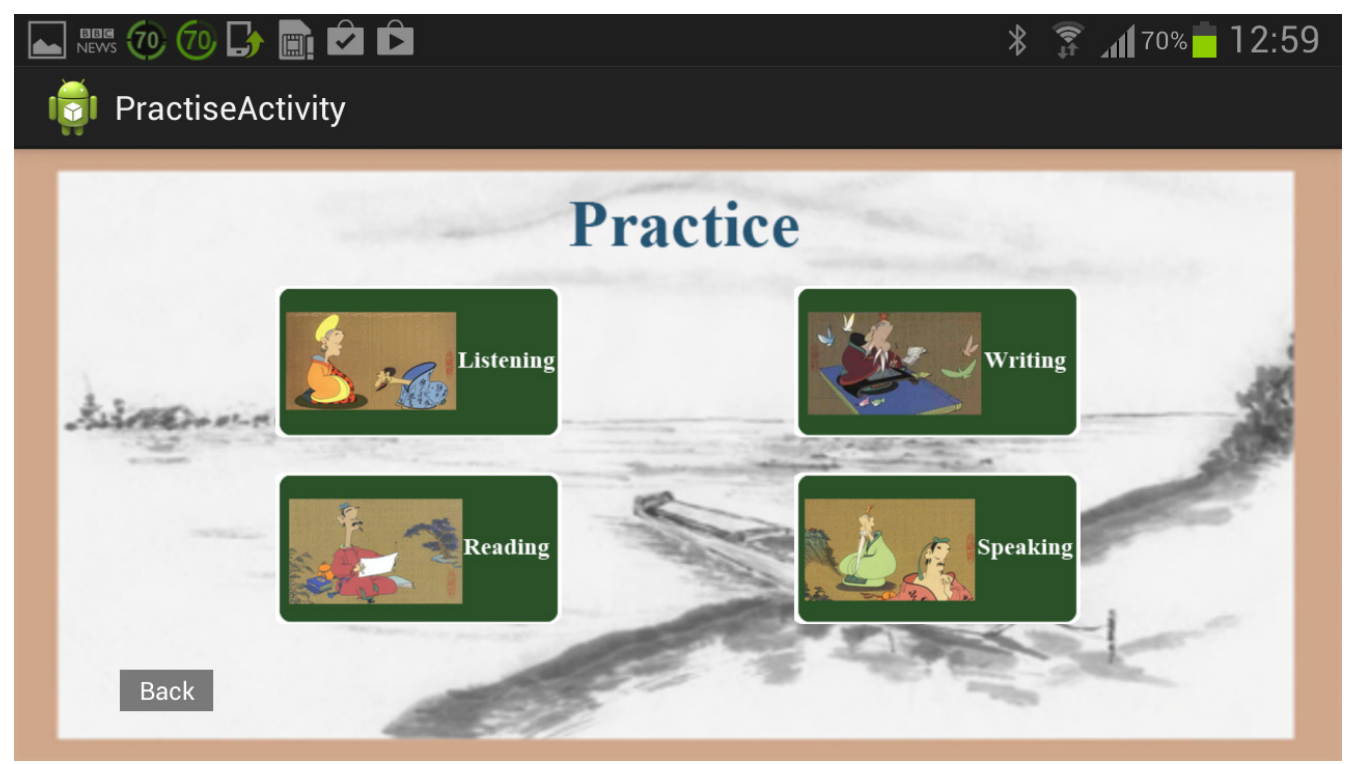

Figure 7: "Practice" module layout
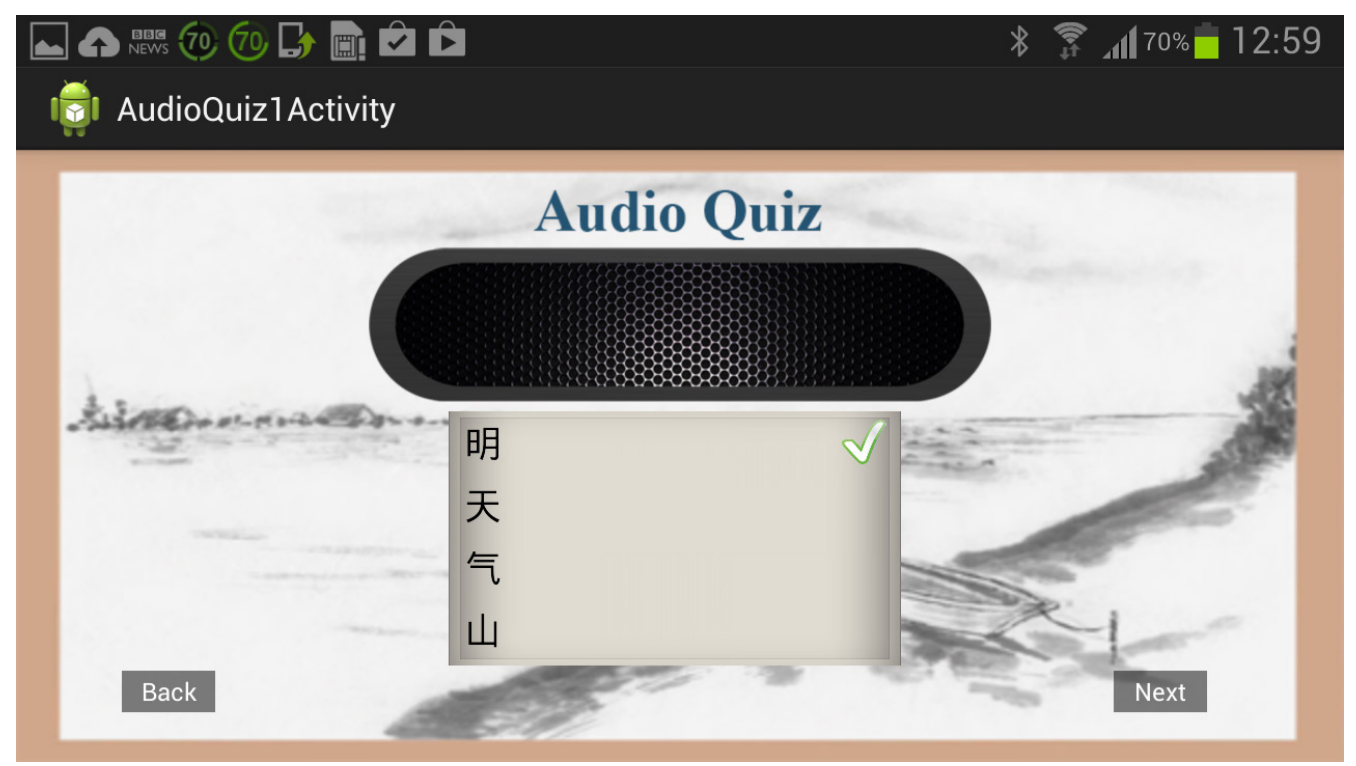

Figure 8: Listening exercise page

The way in which participants performed the reading and speaking exercises were quite similar to the listening exercise. Exercise for reading as shown in Figure 9, a Chinese word was shown on the green board, and user should determine the right English explanation among the four options. For the speaking exercise as shown in Figure 10, a word and an image hint were given on the green board; the participant could check the audio chips of each choice by tapping phonetic alphabet options that were provided, and then choose the right one by tapping the check box. 


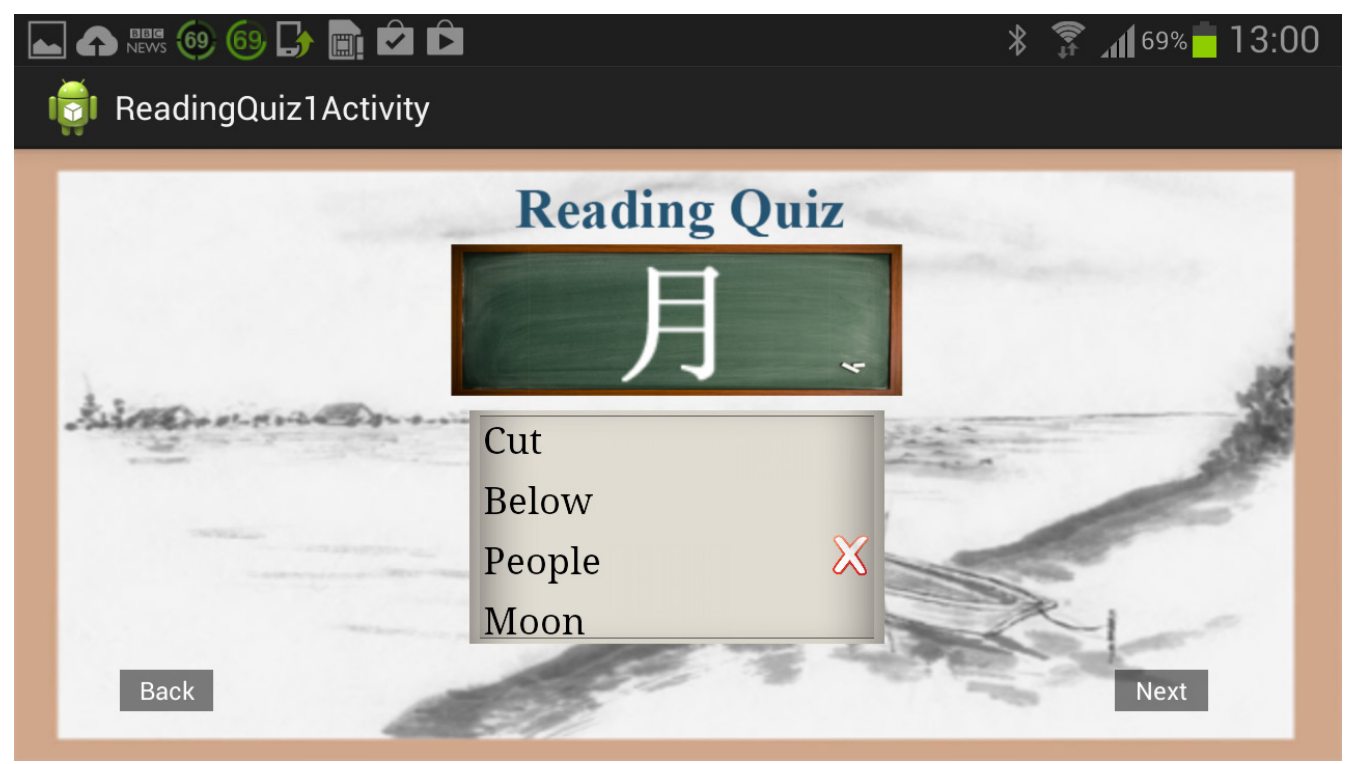

Figure 9: Reading exercise page
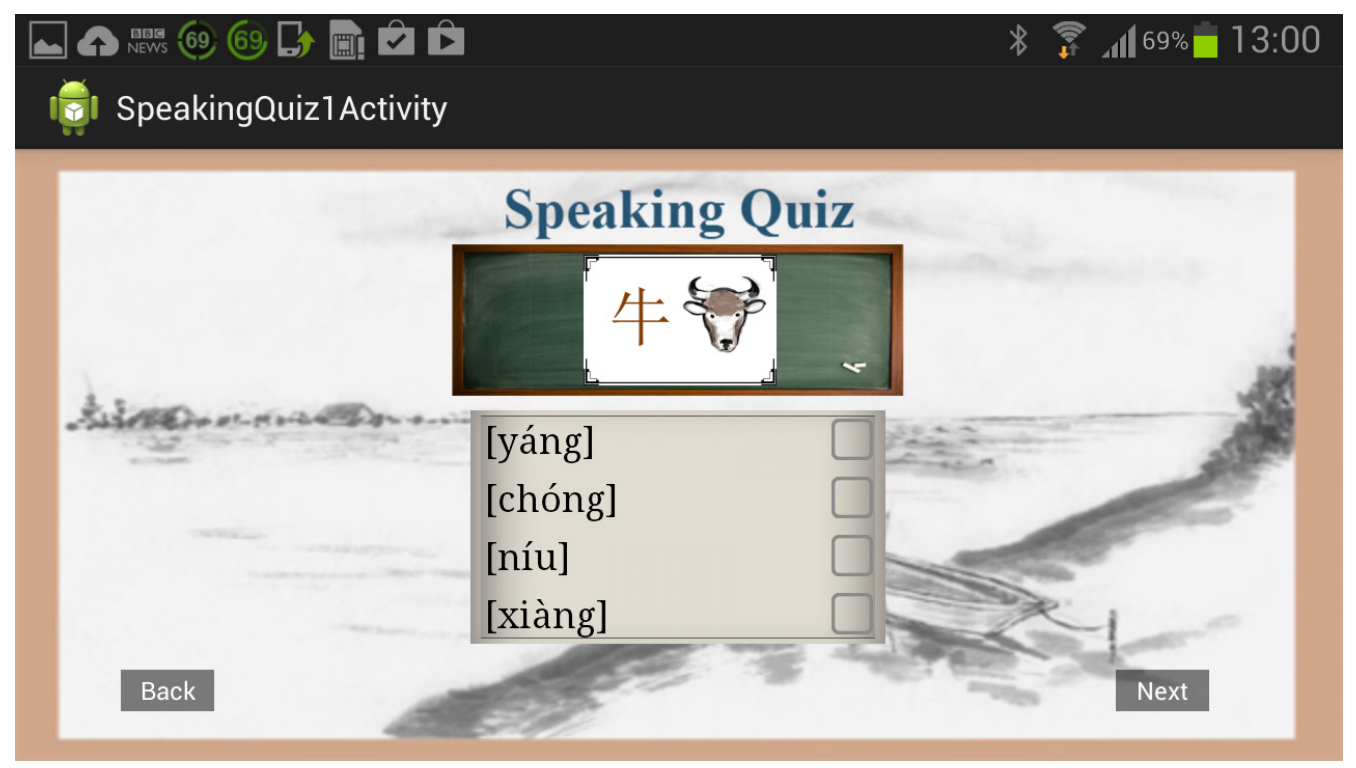

Figure 10: Speaking exercise page

We decided the evaluation rationale of these three exercises as follows: if the user could make the correct answer by what he/she had heard, then we knew that he/she could recognize the word by listening to it; if the user could give the corresponding English explanation of a Chinese word, then we knew that he/she could recognize that word when reading articles; and if the user could make the correct audio clip of a word, then we knew that he/she should be able to speak it. 


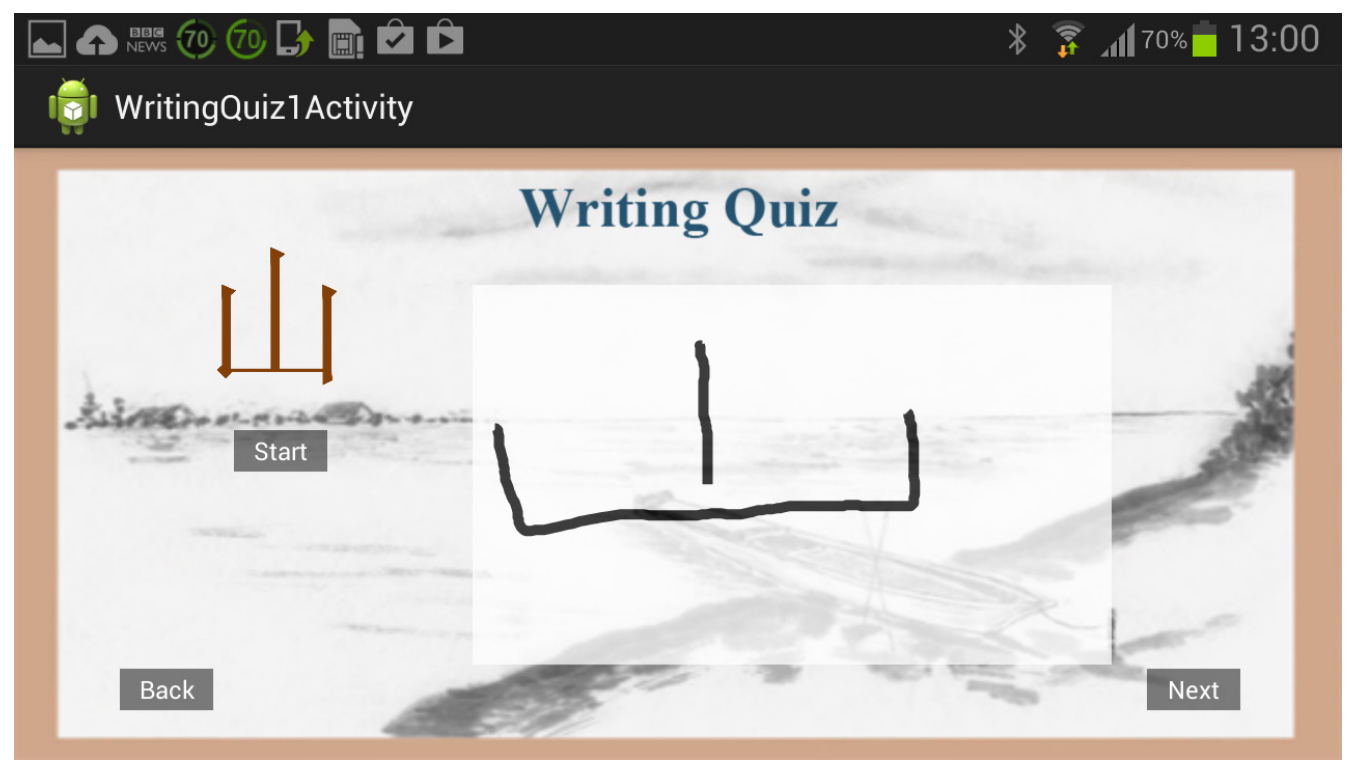

Figure 11: Writing exercise page

The writing exercise was a little different as shown in Figure 11. Usually people could understand and evaluate the writing from two directions: 1. the examinee is able to write an article with fluent sentences; 2 . the examinee is able to draw the letters/characters/words that could be identified and understood. This exercise was designed according to the latter criteria. Users could practice drawing the word on the canvas referring to the writing demo in the "Text" module. The drawing approach was just like finger drawing on a table's surface.

The app layouts on the Epson Moverio and the mobile platform were consistent. There were only two differences between these two prototypes. First, the interaction approach was different. Second, the app on the Epson Moverio, which was called "Student Side", could support controlling from both the participants manually and the teacher using the mobile phone. While the app on the Samsung, which was called "Teacher Side", did not allow reverse controlling by "Student Side". The teacher could monitor the students' performances in the practice module, so the orders only transferred from "Teacher Side" to "Student Side" unidirectionally. The section below will discuss the socket communication in detail.

\subsubsection{Socket Communication Program}

We used the android socket protocol to build the communication between Epson Moverio and mobile phone, as demonstrated in Figure 12. The server program was written in Java on a laptop with Windows 7 operation system, while the student and teacher computers were running clients. We decided to run the server on an independent computer, apart from Teacher and 
Student' devices. Once the "Student Side" and "Teacher Side" programs on the Moverio and mobile phone were launched, they created a socket connection to the server individually. Then, whenever a certain activity was initiated from the "Teacher Side" program, a corresponding socket stream message was sent to the "Student Side" program. The "Student Side" program would do the related activity according to the socket stream message that it read. For example, when the "Text" image button was tapped in the "Teacher Side" program, a string message like "HomeToText" was delivering through the server and read from the "Student Side" program; then, a pre-coded activity for the message "HomeToText" would be triggered in the "Student Side" program. This approach could be used to allow the teacher to monitor students' performances as well, and we may consider it in a future experiment.

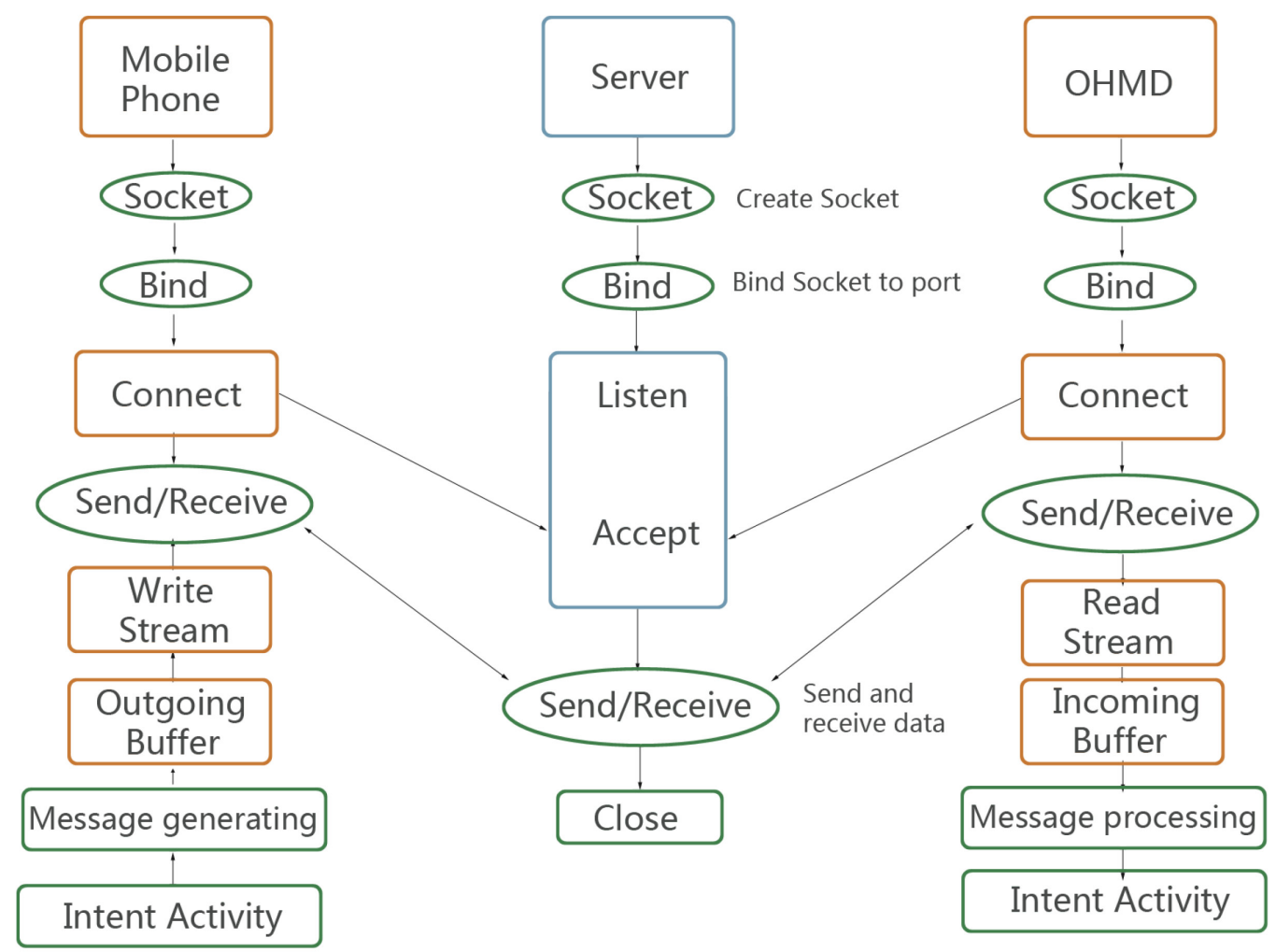

Figure 12: Framework of socket communication design in the user experiment

\subsubsection{IntuiFace Desk Demo \& PC Simulated App}

IntuiFace is a tool for creating interactive presentations, information kiosks and other demonstrations, which could support multi-touch, gesture and tag-driven environments' 
interactions (http://www.intuilab.com/). In this user experiment, intuiFace was used to create the app that projected on the wall. It simulated the OHMD app.

For example, when making comparison between experiment scenario A: "single projection display with teacher controlling" and scenario B: "single OHMD with teacher controlling", the same app layout and manipulation method are needed for both OHMD and projection display. The simulated app was created for the windows platform (the Acer laptop) and was projected on the wall. The controller (controlled by teacher for both scenarios), the content, layout and manipulation method (same layout and manipulation method for both cases) were constant; only the device (projection display vs. OHMD) changed.

The software intuiFace was used to create the simulated app on Windows. This program simulated all the functions and layouts that participants viewed and interacted with on the Epson Moverio. Figure 13 is a screenshot for it.

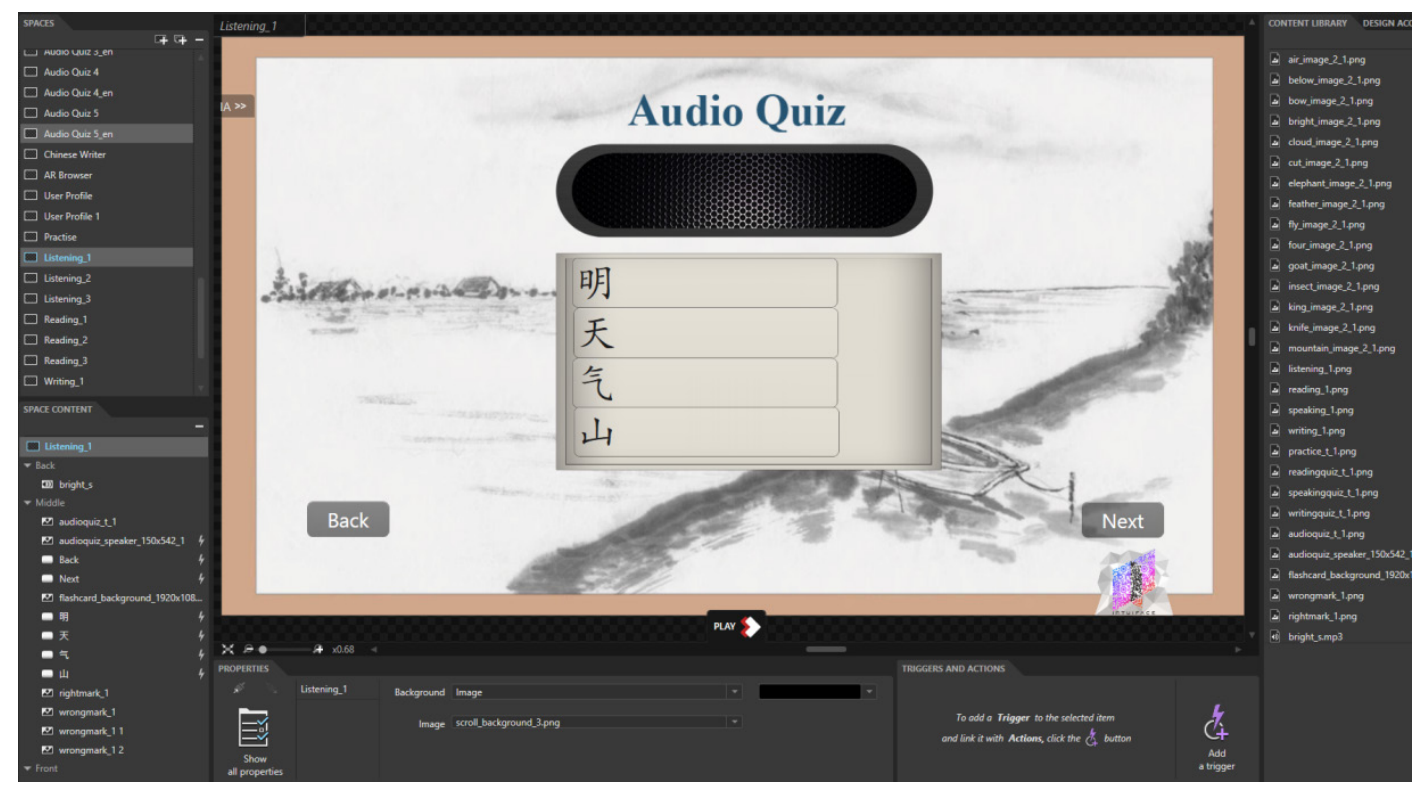

Figure 13: Screenshot of Working Space of IntuiFace

The program that participants used on the MacBook was an android emulator that was created based on the source project. It simulated the program from the OHMD.

To sum up, all the user interfaces on different platforms were kept as consistent with the Epson Moverio. A small change on the projection demo was that we added short instructions for the practice module, to inform the participants how to do the exercises (for example, tapping the speaker to hear the audio). The intention of the change was to test users' reaction in the scenario 
of learning with OHMD and projection display. Furthermore, we had two other software modules, the timer control and voice control for the Epson Moverio, which were removed for this user experiment, due to the decision that they were not suitable for the classroom learning environment. They will be taken into consideration in future experiments. 


\section{Chapter 6: User Experiment Results}

\subsection{Participants}

The user study was approved by the Carleton University Research Ethics Board. The participants were partially recruited from School of Linguistics and Language Studies of Carleton University by e-mail notices (Appendix G), and others recruited from students who were interested in this study by posters (Appendix F). Our participants were informed of a study on using OHMD in education, and they were required to be at least 18 years old.

All the participants completed the surveys and questionnaires regarding their experiences during the experiments.

15 participants ( 8 males, 7 females) ranging in age from 18-36 years old participated in the study. Figure 14 shows the age distribution of all participants.

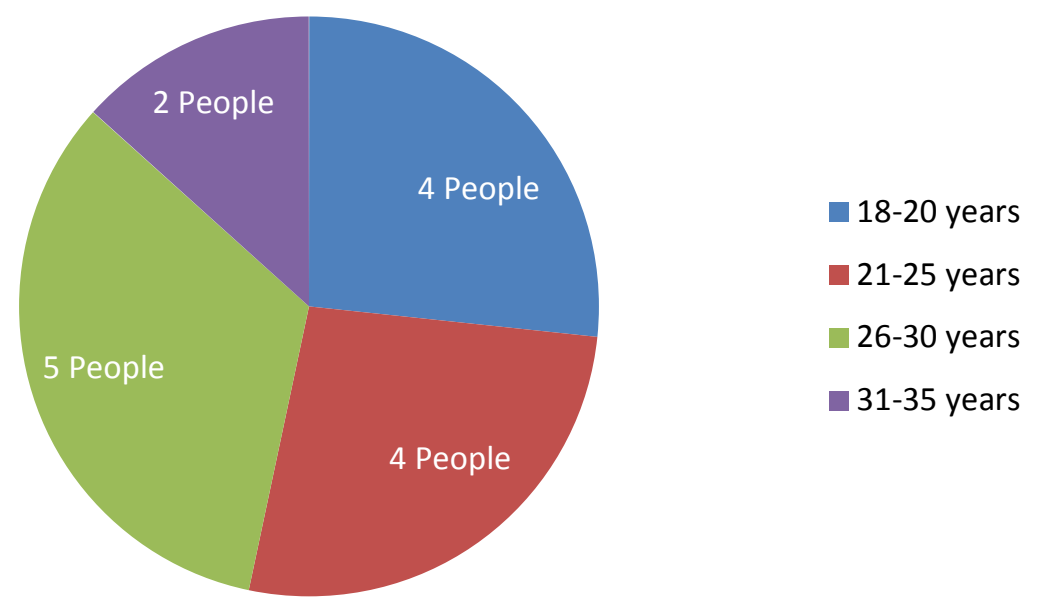

Figure 14: Participants' Age Distribution

\subsection{Pre-Study Questions}

The intention of the pre-study questions was to understand general demographic information, the participants' background knowledge and interests towards the subject, their experience using head-mounted and touch pad devices, their frequency of using mobile app in daily life, and their current capability of maintaining focus in a typical language classroom. 
Out of 15 participants, 11 indicated they were native English speakers, and 4 were not as shown in Table 5. Majority of participants came with zero relevant background knowledge: 9 did not have much Chinese learning experience, 2 had half a year learning experience, 2 had one year of learning experience, and 2 had almost 2 years of learning experience.

Moreover, only 3 subjects reported they had used a Head-Mounted Display before as shown in Table 5). The number of participants who had used touch pad devices (7 subjects) was almost tied with the number of those who did not ( 8 subjects). Since majority of the participant had used mobile apps, this can be an error due to not understanding the question, or they used non-touch devices.

On a 7-point Likert scale $(1=$ very low, $2=$ low, $3=$ somewhat low, $4=$ neutral, $5=$ somewhat high, 6 = high, 7 = very high), participants generally rated themselves having medium interests level in learning the main subject $(\mathrm{M}=4.6, \mathrm{SD}=1.9)$ as shown in Figure 15 , the majority of the participants used mobile apps often $(\mathrm{M}=5.3, \mathrm{SD}=2.1)$ as shown in Figure 16 , and most of them could make themselves concentrate in class $(\mathrm{M}=5.1, \mathrm{SD}=1.4)$ as shown in Figure 17.

Table 5: Pre-Study Questionnaire Feedback

Q1: Is English your mother tongue?

Q2: For how many days have you been studying Chinese (Mandarin)?

Q3: Have you ever used a head-mounted display, such as Google Glass or GlassUp? Q4: Have you ever used padding-touch controlled devices?

\begin{tabular}{|c|c|c|c|l|}
\hline Q1 & English (11/15) & Non-English (4/15) & & \\
\hline Q2 & Zero (9/15) & Half year (2/15) & One year (2/15) & Two years $(2 / 15)$ \\
\hline Q3 & Yes (3/15) & No (12/15) & & \\
\hline Q4 & Yes (7/15) & No (8/15) & & \\
\hline
\end{tabular}




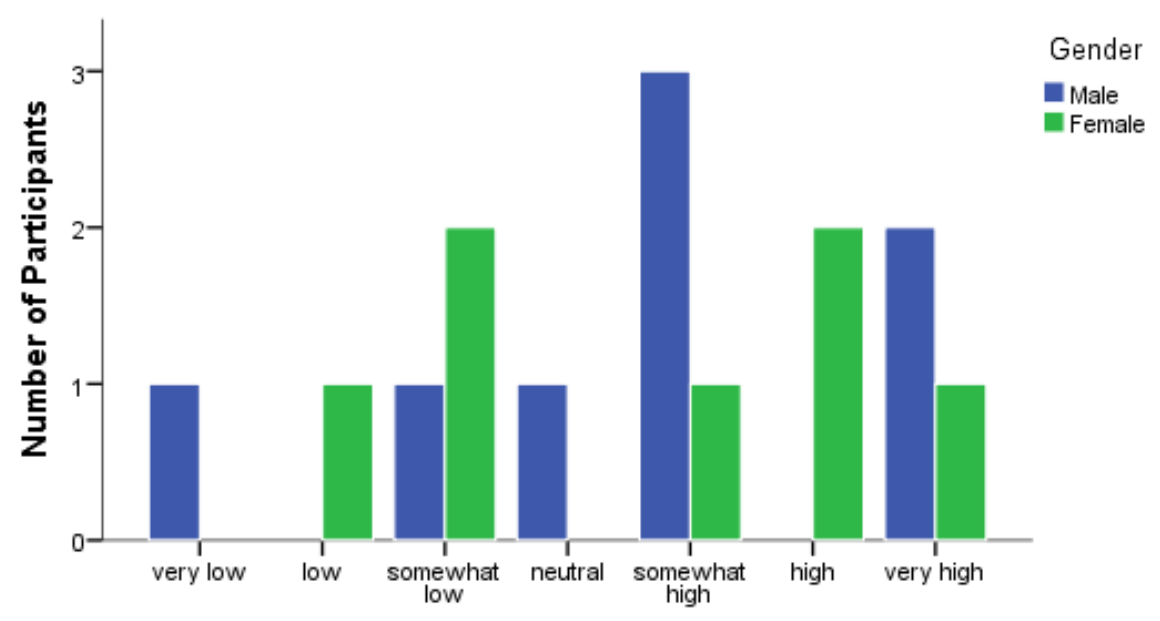

Figure 15: Participants' Interests in Studying the Subject

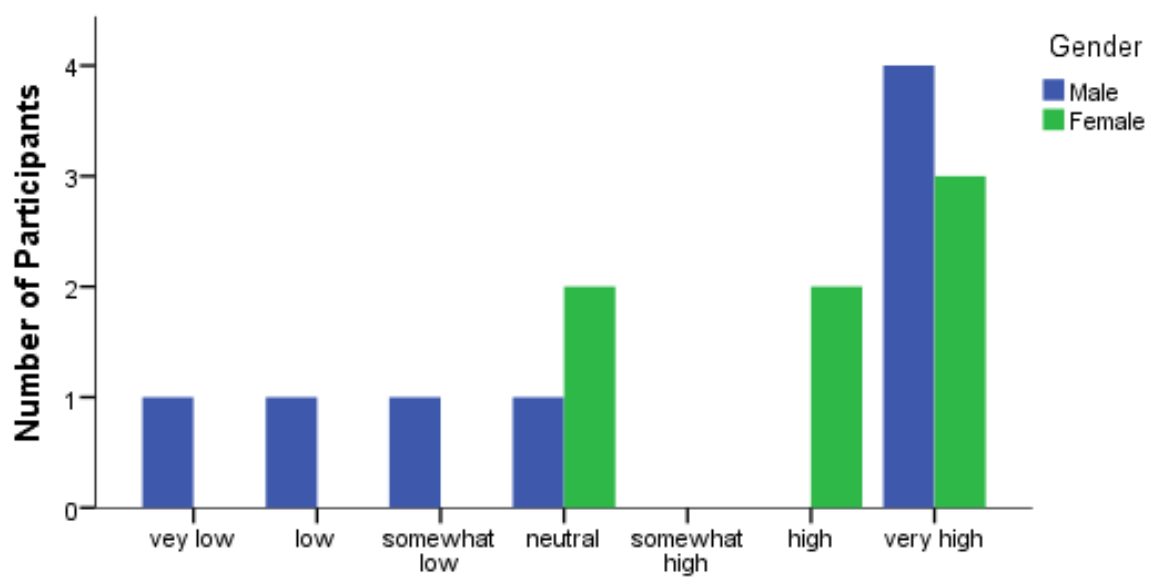

Figure 16: Frequency of Participants' using Mobile App in Daily life

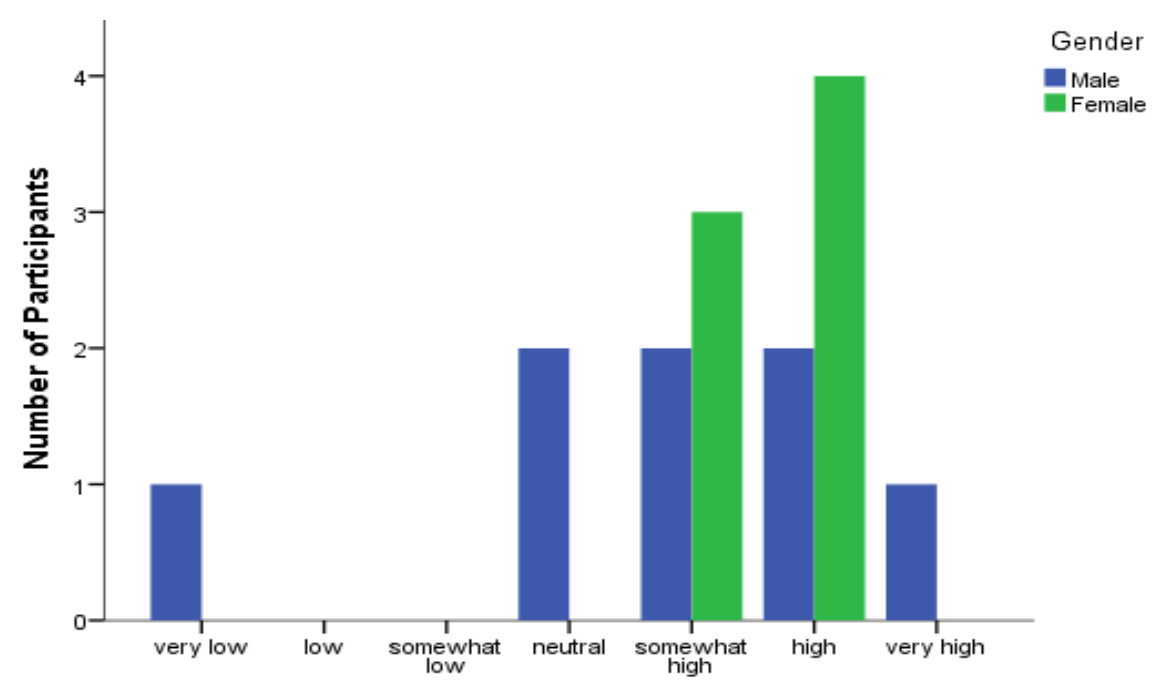

Figure 17: Participants' Concentration Ability in a Typical Language Class 
In the final question, "what makes you distracted when learning in a typical language class?", 5 participants reported that they would get confused and distracted when "materials are too hard"; 5 of them reported that they would be affected by classmates' activities (e.g. chatting, classmates suggesting wrong answers to their questions, phone notification); 3 of them reported that "boredom with repetitive learning"; and "lack of customized learning" was indicated by 2 out of the 15 participants. Although this may seem to suggest that multiple objects of attention were not a source of distraction, it could be due to the fact that such arrangements are assumed normal and the only possibility. The participants may in fact have been distracted by them without knowing that other options (such as OHMD) could be available.

\subsection{In-Study Scale Rating}

As described previously, we used a combination of parametric and non-parametric methods to analyze the data and verify our hypotheses. Our analysis showed that participants did in fact respond differently to changing the control mechanism or students' viewing-screen, but no significant change was observed in our evaluation criteria based on changing scenarios. In this section, we will present details of the data analysis.

To verify the Hypothesis 1 (dependence of responses to scenarios and criteria), a twoway repeated measures ANOVA of scenarios (A, B, C, E, F) and usability criteria (enjoyment, motivation, perceived efficiency, understandability, ability to focus, and physical comfort, and relaxation) on participants' rating responses was conducted. The participants' agreement ratings were analyzed in a two-way within factorial ANOVA, with scenarios and usability criteria manipulated as within-subjects variables [93]. A 5 x 7 within-subjects ANOVA was conducted on participants' agreement ratings, with scenarios and usability criteria as factors. An alpha level of 0.05 was used in our data analysis results.

Overall, it was observed that scenarios and evaluation criteria did in fact have significant effect on the ratings, which indicates that the participants did change their responses based on variables. This suggests that the responses had a reasonable level of reliability and at least were not the same when variables changed. Details are presented next.

A significant main effect of scenarios on participants' responses was found (Appendix I), $\mathrm{F}(4,56)=3.432, \mathrm{p}<.05$. Participants' ratings for scenario $A$ (single project display with teacher controlling, $\mathrm{M}=5.50$ ) were higher than that for scenario $C$ (single OHMD with student 
controlling, $\mathrm{M}=5.27$ ), scenario $E$ (projection display with teacher controlling \& PC with student controlling, $M=5.17$ ), scenario $B$ (single OHMD with teacher controlling, $M=4.96$ ), and scenario $F$ (project display with teacher controlling \& OHMD with student controlling, $\mathrm{M}=$ 4.55).

A significant main effect of evaluation criteria on participants' responses was found (Appendix H), F $(6,84)=7.694, \mathrm{p}<.001$. Participants' ratings for understandability $(\mathrm{M}=5.71)$ were higher than that for motivation $(\mathrm{M}=5.41)$, enjoyment $(\mathrm{M}=5.11)$, ability to focus $(\mathrm{M}=$ $5.03)$, efficiency $(\mathrm{M}=4.93)$, relaxation $(\mathrm{M}=4.79)$, and physical comfort $(\mathrm{M}=4.65)$.

To verify the Hypothesis 2 (higher rating of OHMD and student control), a combination of parametric statistic method (repeated measures ANOVA with a Greenhouse-Geisser correction and post hoc tests using the Bonferroni correction) and non-parametric statistic method (Friedman's ANOVA and Wilcoxon signed-rank test with Bonferroni correction) were conducted toward the seven evaluation criteria, respectively (Table $6 \& 7$ ). Table 6 also shows the mean and standard deviation of the ratings for all criteria in each scenario. We found that only physical comfort $(\mathrm{F}=17.555, \mathrm{p}<0.001)$ showed a statistical significant difference among five scenarios, and that was not in favour of OHMD. (Appendix I) The result of repeated measures ANOVA with Greenhouse-Geisser correction for relaxation showed $\mathrm{p}<0.05$. However, we still did not find statistically significant difference in the Post-hoc tests using Bonferroni correction $(\mathrm{p}<0.005)$.

\section{Table 6: The Results of Repeated Measures ANOVA with a Greenhouse-Geisser Correction toward Criteria}

Scenario A: single projection display with teacher controlling Scenario B: single OHMD with teacher controlling

Scenario C: single OHMD with student controlling

Scenario E: projection display with teacher controlling \& PC with student controlling

Scenario F: projection display with teacher controlling \& OHMD with student controlling

\begin{tabular}{|c|c|c|c|c|c|c|c|}
\hline Criteria & Scenarios & $\mathrm{N}$ & Mean & $\begin{array}{c}\text { Std. } \\
\text { Deviation }\end{array}$ & Source & $\mathrm{F}$ & Sig. \\
\hline \multirow{6}{*}{ Enjoyment } & Scenario A & 15 & 5.33 & 1.113 & \multirow{6}{*}{$\begin{array}{l}\text { Scenario } \\
\text { Greenhouse- } \\
\text { Geisser }\end{array}$} & \multirow{6}{*}{2.370} & \multirow{6}{*}{0.079} \\
\hline & Scenario B & 15 & 5.13 & 1.125 & & & \\
\hline & Scenario C & 15 & 5.67 & 0.976 & & & \\
\hline & Scenario E & 15 & 4.67 & 1.291 & & & \\
\hline & Scenario F & 15 & 4.73 & 1.033 & & & \\
\hline & Total & 15 & 5.11 & 1.146 & & & \\
\hline \multirow{3}{*}{$\begin{array}{l}\text { Ability to } \\
\text { Focus }\end{array}$} & Scenario A & 15 & 5.47 & 1.552 & \multirow{3}{*}{$\begin{array}{l}\text { Scenario } \\
\text { Greenhouse- } \\
\text { Geisser }\end{array}$} & \multirow{3}{*}{1.423} & \multirow{3}{*}{0.253} \\
\hline & Scenario B & 15 & 5.20 & 1.568 & & & \\
\hline & Scenario C & 15 & 5.20 & 1.474 & & & \\
\hline
\end{tabular}




\begin{tabular}{|c|c|c|c|c|c|c|c|}
\hline & Scenario E & 15 & 4.73 & 1.438 & & & \\
\hline & Scenario $\mathrm{F}$ & 15 & 4.53 & 1.302 & & & \\
\hline & Total & 15 & 5.03 & 1.470 & & & \\
\hline \multirow{6}{*}{ Motivation } & Scenario A & 15 & 5.20 & 1.207 & \multirow{6}{*}{$\begin{array}{l}\text { Scenario } \\
\text { Greenhouse- } \\
\text { Geisser }\end{array}$} & \multirow{6}{*}{1.424} & \multirow{6}{*}{0.254} \\
\hline & Scenario B & 15 & 5.53 & 1.125 & & & \\
\hline & Scenario C & 15 & 5.87 & 0.990 & & & \\
\hline & Scenario E & 15 & 5.20 & 1.082 & & & \\
\hline & Scenario $\mathrm{F}$ & 15 & 5.27 & 1.163 & & & \\
\hline & Total & 15 & 5.41 & 1.116 & & & \\
\hline \multirow{6}{*}{$\begin{array}{l}\text { Perceived } \\
\text { Efficiency }\end{array}$} & Scenario A & 15 & 4.93 & 1.100 & \multirow{6}{*}{$\begin{array}{l}\text { Scenario } \\
\text { Greenhouse- } \\
\text { Geisser }\end{array}$} & \multirow{6}{*}{2.123} & \multirow{6}{*}{0.117} \\
\hline & Scenario B & 15 & 4.93 & 1.163 & & & \\
\hline & Scenario C & 15 & 5.67 & 0.816 & & & \\
\hline & Scenario E & 15 & 4.87 & 1.642 & & & \\
\hline & Scenario $\mathrm{F}$ & 15 & 4.27 & 1.751 & & & \\
\hline & Total & 15 & 4.93 & 1.379 & & & \\
\hline \multirow{6}{*}{$\begin{array}{l}\text { Physical } \\
\text { Comfort }\end{array}$} & Scenario A & 15 & 6.27 & 0.704 & \multirow{6}{*}{$\begin{array}{l}\text { Scenario } \\
\text { Greenhouse- } \\
\text { Geisser }\end{array}$} & \multirow{6}{*}{17.555} & \multirow{6}{*}{0.000001} \\
\hline & Scenario B & 15 & 3.67 & 1.397 & & & \\
\hline & Scenario C & 15 & 3.80 & 1.612 & & & \\
\hline & Scenario E & 15 & 5.87 & 0.915 & & & \\
\hline & Scenario $\mathrm{F}$ & 15 & 3.67 & 1.496 & & & \\
\hline & Total & 15 & 4.65 & 1.704 & & & \\
\hline \multirow{6}{*}{$\begin{array}{l}\text { Understanda } \\
\text { bility }\end{array}$} & Scenario A & 15 & 5.53 & 1.125 & \multirow{6}{*}{$\begin{array}{l}\text { Scenario } \\
\text { Greenhouse- } \\
\text { Geisser }\end{array}$} & \multirow{6}{*}{0.607} & \multirow{6}{*}{0.595} \\
\hline & Scenario B & 15 & 5.73 & 0.884 & & & \\
\hline & Scenario C & 15 & 5.87 & 0.743 & & & \\
\hline & Scenario E & 15 & 5.87 & 0.990 & & & \\
\hline & Scenario $\mathrm{F}$ & 15 & 5.53 & 0.915 & & & \\
\hline & Total & 15 & 5.71 & 0.927 & & & \\
\hline \multirow{6}{*}{ Relaxation } & Scenario A & 15 & 5.73 & 1.163 & \multirow{6}{*}{$\begin{array}{l}\text { Scenario } \\
\text { Greenhouse- } \\
\text { Geisser }\end{array}$} & \multirow{6}{*}{4.512} & \multirow{6}{*}{0.011} \\
\hline & Scenario B & 15 & 4.53 & 1.187 & & & \\
\hline & Scenario C & 15 & 4.80 & 1.373 & & & \\
\hline & Scenario E & 15 & 5.00 & 1.254 & & & \\
\hline & Scenario $\mathrm{F}$ & 15 & 3.87 & 1.506 & & & \\
\hline & Total & 15 & 4.79 & 1.407 & & & \\
\hline
\end{tabular}

Table 7: The Results of Friedman's ANOVA and Wilcoxon signed-rank test with Bonferroni Correction toward Criteria

\begin{tabular}{|c|c|c|c|c|}
\hline Criteria & $\mathrm{N}$ & Chi-Square & df & Asymp.Sig. \\
\hline Enjoyment & 15 & 8.912 & 4 & 0.063 \\
\hline Ability to Focus & 15 & 5.145 & 4 & 0.273 \\
\hline Motivation & 15 & 6.070 & 4 & 0.194 \\
\hline Perceived Efficiency & 15 & 7.915 & 4 & 0.095 \\
\hline Physical Comfort & 15 & 37.790 & 4 & 0.00000012 \\
\hline Understandability & 15 & 1.219 & 4 & 0.875 \\
\hline Relaxation & 15 & 11.631 & 4 & 0.20 \\
\hline
\end{tabular}


The mean rating of physical comfort ranged from 3.67 in scenario B (single OHMD with teacher controlling) and F (projection display with teacher controlling \& OHMD with student controlling) to 6.27 in scenario A (single projection display with teacher controlling). (Appendix H) Histograms of the distributions of ratings in five scenarios suggested that the distributions are approximately abnormal. The skewness and kurtosis statistics showed that all the conditions (scenarios) were within the range of $+/-3$. Generally, the skewness shapes were positive shift, except the ones for scenario A (single projection display with teacher controlling) and E (projection display with teacher controlling \& PC with student controlling) which skewed left

and a little leptokurtic. Switching the control mechanism had no significant effect but changing the display from projection display to OHMD would decrease the physical comfort.

These suggested that scenarios in which students wore OHMD for learning $(\mathrm{B}, \mathrm{C}, \mathrm{F})$ elicited a statistically significant reduction on physical comfort perceptions compared with the scenarios which did not (A and E); but there were no significant difference of physical comfort among the scenarios with OHMD, or between the scenarios without OHMD.

\subsection{Post Quiz Questions}

To verify the Hypothesis 3 and let participants evaluate the learning outcomes among the five scenarios, we designed listening, speaking, writing, and reading exercises based on the lecture materials. Participants would automatically obtain the quiz result right after completing it, which helped them to estimate the relevant learning performance.

Tables 8 to 11 show the average perceived difficulty level, helpfulness, comfort and learnability of the tasks for each scenario. Overall, and similar to the rating of evaluation criteria, there was no significant difference in dealing with individual tasks over the 5 scenarios. Some general observations are:

- Educational material and tasks were more suitable for listening and reading as opposed to writing and speaking, regardless of scenarios.

- Student control would result in easier reading. 
Scenario A: single projection display with teacher controlling

Scenario B: single OHMD with teacher controlling

Scenario C: single OHMD with student controlling

Scenario E: projection display with teacher controlling \& PC with student controlling

Scenario F: projection display with teacher controlling \& OHMD with student controlling

Table 8: Exercises' Difficulty in Each Experimental Scenario

\begin{tabular}{|c|c|c|c|c|}
\hline Scenarios & Listening & Reading & Speaking & Writing \\
\hline Scenario A & 2.00 & 1.87 & 2.73 & 3.40 \\
\hline Scenario B & 1.87 & 2.07 & 2.87 & 3.20 \\
\hline Scenario C & 2.07 & 1.47 & 2.80 & 3.67 \\
\hline Scenario E & 2.47 & 1.40 & 3.00 & 3.13 \\
\hline Scenario F & 2.33 & 1.60 & 2.87 & 3.27 \\
\hline
\end{tabular}

Table 9: Helpfulness of Experimental Scenario for Each Exercise-Task. Values represent the percentage of participants who chose that task as the one most suited for that scenario.

\begin{tabular}{|c|c|c|c|c|}
\hline Scenarios & Listening & Reading & Speaking & Writing \\
\hline Scenario A & $40 \%$ & $47 \%$ & $13 \%$ & $0 \%$ \\
\hline Scenario B & $20 \%$ & $53 \%$ & $13 \%$ & $13 \%$ \\
\hline Scenario C & $47 \%$ & $47 \%$ & $7 \%$ & $0 \%$ \\
\hline Scenario E & $7 \%$ & $73 \%$ & $7 \%$ & $13 \%$ \\
\hline Scenario F & $33 \%$ & $60 \%$ & $7 \%$ & $0 \%$ \\
\hline
\end{tabular}

Table 10: Most Uncomfortable Task in each Scenario

\begin{tabular}{|c|c|c|c|c|}
\hline Scenarios & Listening & Reading & Speaking & Writing \\
\hline Scenario A & $0 \%$ & $13 \%$ & $27 \%$ & $60 \%$ \\
\hline Scenario B & $13 \%$ & $40 \%$ & $7 \%$ & $40 \%$ \\
\hline Scenario C & $7 \%$ & $7 \%$ & $20 \%$ & $67 \%$ \\
\hline Scenario E & $13 \%$ & $0 \%$ & $40 \%$ & $47 \%$ \\
\hline Scenario F & $27 \%$ & $20 \%$ & $13 \%$ & $40 \%$ \\
\hline
\end{tabular}

Table 11: Things Learned the Most in Each Experimental Scenario

\begin{tabular}{|c|c|c|c|c|}
\hline Scenarios & Pronunciation & Understanding & Recognition & Writing \\
\hline Scenario A & $20 \%$ & $13 \%$ & $67 \%$ & $0 \%$ \\
\hline Scenario B & $27 \%$ & $7 \%$ & $67 \%$ & $0 \%$ \\
\hline Scenario C & $13 \%$ & $27 \%$ & $60 \%$ & $0 \%$ \\
\hline Scenario E & $7 \%$ & $27 \%$ & $47 \%$ & $0 \%$ \\
\hline Scenario F & $20 \%$ & $27 \%$ & $40 \%$ & $7 \%$ \\
\hline
\end{tabular}


The last question of Post-Quiz study was: "what should be improved if you have a chance to use this learning mode in class?" For scenario A (single projection display with teacher controlling), participants' feedback was distributed, since it was the most familiar learning mode for most participants. There were suggestions like improving the interactivity, letting students control the pace of the slides, providing more exercises, and making the font size larger. For scenario B (single OHMD with teacher controlling), the participants focused on touchpad controller issues when doing the writing exercise-task. A few suggested that they preferred to have control of the device rather than teacher's control. For scenario C (single OHMD with student controlling), participants' comments were focused on the physical fatigue (eyes and head) and difficulty of using of the touchpad. For scenario E (projection display with teacher controlling \& PC with student controlling), some participants commented that switching between two screens made them distracted, and that the audio chips from the teacher's and student's devices might affect each other. Some participants suggested having the PC synchronized with the projection display, and that students should have independent audio input sets to avoid affecting other students. For scenario F (projection display with teacher controlling \& OHMD with student controlling), one third of participants complained about difficulty focusing on the virtual screen of the OHMD and the projection display at the same time. On the contrary, 2 participants reported that they liked to have their own virtual screen and the teacher's projection display at the same time. Providing more relevant materials was also suggested, so that when the teacher was teaching with the projection display, the student could explore more related information on their own with teacher's voice in the background.

\subsection{User Feedback in Post-Study Survey}

The post-study survey was considered as an extra source of information while the research mainly relied on the analysis of the evaluation criteria. It consisted of only three open questions:

(1) overall, was there anything that made you feel uncomfortable during the test?

(2) which was your favourite learning scenario?

(3) what would you improve about the see-through head-mounted display interaction method for studying? 
No interview or extended formal qualitative data acquisition and analysis were planned. This resulted in limited information from this part of research. Still, the answers did provide some key insight. Table 12 demonstrates the main comments for question 1 . The physical feeling was mostly considered to be the main source of discomfort; and the eye-fatigue caused by wearing the OHMD for too long was another factor that caused unpleasantness for participants. Participants generally reported that looking at two screens was not an enjoyable experience, and they also reported that the virtual screen size and prescription lenses should be customized. Noticeably, providing a notes-taking option by the device was also identified as a potential need.

Table 12: Participants' Response to overall, was there anything that made you feel uncomfortable during the test?

\begin{tabular}{|l|l|}
\hline Point 1 & Eye-fatigue, physically uncomfortable when wearing the OHMD long time (8/15) \\
\hline Point 2 & Difficult to look at both the virtual and projection screen, hard to focus $(4 / 15)$ \\
\hline Point 3 & Insensitive use of the touchpad (4/15) \\
\hline Point 4 & I wear glasses, so it was little inconvenient to wear the OHMD (3/15) \\
\hline Point 5 & The virtual screen was not customized/adjustable $(3 / 15)$ \\
\hline Point 6 & No taking notes option (1/15) \\
\hline
\end{tabular}

Figure 18 shows the result of the second question. We allowed participants to choose more than one scenario. Eight participants preferred scenario C (single OHMD with student controlling). The scenario F (projection display with teacher controlling \& OHMD with student controlling) was in second place with 4 participants. Scenario A (single projection display with teacher controlling) and E (projection display with teacher controlling \& PC with student controlling) were next with 3 participants. Lastly, 1 participant chose scenario B (single OHMD with teacher controlling). 


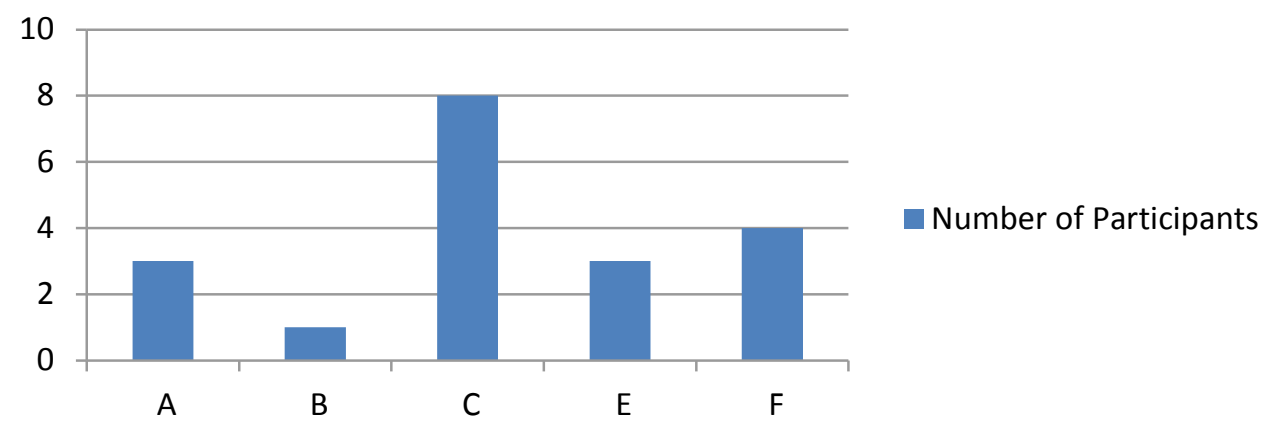

A: single projection display with teacher controlling
B: single OHMD with teacher controlling
C: single OHMD with student controlling
E: projection display with teacher controlling \& PC with student controlling
F: projection display with teacher controlling \& OHMD with student controlling

Figure 18: Participants' Response to overall, which was your favourite learning scenario?

The reasons behind the choices were also collected and shown in Table 13. The scenarios are presented from the most favoured scenario to the least favoured one.

Table 13: Reasons for Participants' Favourite Learning Scenario

\begin{tabular}{|l|l|}
\hline Scenario C & $\begin{array}{l}\text { Participants wanted to have own pace but still hear the teacher's explanation in } \\
\text { the background }\end{array}$ \\
\hline Scenario F & Participants wanted to proceed at own pace, but still follow the teacher's slides \\
\hline Scenario A & Participants felt relaxed \\
\hline Scenario E & Participants believed a laptop was easier to control \\
\hline Scenario B & Participant preferred passive listening in class \\
\hline
\end{tabular}

In response to the third question, the participants provided suggestions related to making the OHMD lighter, providing customized vision for individuals, making the virtual screen adjustable, advancing the control pad, and using electronic stylus for writing practice.

\subsection{Discussion}

While the study did not show a significant difference in participants' evaluation of scenarios based on the given criteria, it did provide valuable insight into the use of OHMD technology in classroom. In particular, the general comments did show that participants overall favoured the OHMD as a single replacement for all screens, and preferred a control system that provides certain level of flexibility and control by students. While this was not enough to 
positively verify our main hypothesis (H2), it suggests that the OHMD technology has the potential to satisfy the requirements and achieve higher ratings on our evaluation criteria provided some conditions are met. The verification of $\mathrm{H} 2$ showed that the only significant difference was in physical comfort, in favour of not using OHMD. This and further inspection of results offer candidates for improving the usability of OHMD, among them the comfort level and more effective control interfaces are the primary items.

\section{Physical Comfort and Technical Difficulties}

It was observed that changing the control mechanism while the display variable was constant, did not change the perception of comfort, but with the same control system, OHMD was rated less comfortable than the projection screen. One can expect that this physical discomfort had negative effect on the overall experience and could have resulted in lower ratings of other criteria due to lowered general usability. Eye fatigue in addition to technological issues such as lack of screen size-adjusting and prescription lenses, weight of the device and inconvenient controls which can be resolved in near future are likely to be the cause of OHMDbased scenarios' inability in significantly improving the experience. Improving these issues is very likely to happen in future version of OHMD devices and this will make the technology still an attractive option for research and development in education field. Participants' rating of OHMD for ability to focus was not higher than the projection display either, which again could be explained by the difficulties of using OHMD. Moreover, familiarity with more traditional mechanisms and the learning curve associated with new technologies can also have a potential effect on the evaluation, and make the scenarios look equal while the OHMD-based ones could potentially be more effective and helpful.

Three participants reported that it was inconvenient to wear the OHMD over their own glasses. This could be one of the reasons that made participants physically uncomfortable. However, it was not possible to evaluate the effects. There were two reasons: 1. 3 complained, but we do not know if others also had this issue; 2. it was possible that not everyone wearing glasses have problems when replacing their own glasses with OHMD. Therefore, as far as we can tell, eye-fatigue caused by wearing the OHMD for too long was the major reason that made participants uncomfortable. 


\section{Motivation and Enjoyment}

The participants' motivation and enjoyment ratings were higher than other criteria in the scenario C (single OHMD with student controlling); we did not find a similar pattern in other scenarios. This suggests that most of the participants had positive attitudes toward using OHMD by themselves for educational activities. The results of the post-study survey also verified this suggestion. Considering participants viewed and interacted with the same interface among five experimental scenarios, the reason behind this variance should be due to the novelty of OHMD and students' desire to play with new technology, rather than the design and implementation of class material software. In other words, if it was the design and implementation of class material software that motivated participants and made them enjoy using OHMD, then the motivation and enjoyment ratings should stay high among all five scenarios. This indicates that the attraction of new technology could be a power to push students to actively explore and learn knowledge; and this power could possibly positively affect other factors such as learning efficiency and understandability. The perceived efficiency and understandability ratings were also the highest in scenario C. Based on the experimental design and statistics, we could conclude that the novelty of new technology affected the participants' overall responses, but there was no evidence indicating how much novelty affected the results. Further research could explore the deep relations between novelty of technology and user motivation.

\section{Educational Features}

Contrary to our assumption, participants' responses to ability to focus questions were not the highest when using OHMD. According to the statistical analysis, people generally preferred scenario A (single projection display with teacher controlling) as the most satisfying scenario for concentration when learning. This suggested that participants' ability to focus might not only be affected by wearing an "eye-close" virtual screen at all times, but also by who controls the content or interpersonal distractions during a learning procedure. Also we found that the ability to focus rating was the lowest in the experimental scenario which involved projection display and OHMD screen. Most of the participants were not comfortable with switching their eye-focus between OHMD screen and teacher's projection display. This indicates that we need further research to figure out a better way for OHMD to improve user's concentration capability.

Among the seven evaluation criteria, understandability had the highest ratings $(\mathrm{M}=5.71)$ overall after the experiment. This could be due to the appropriate class material design. 
Participants' satisfaction with the material might increase their general evaluation feedback in enjoyment, ability to focus, and motivation. This is supported by the fact that the mean of motivation $(\mathrm{M}=5.41)$, enjoyment $(\mathrm{M}=5.11)$, and ability to focus $(\mathrm{M}=5.03)$ were slightly higher than that of perceived efficiency $(\mathrm{M}=4.93)$, relaxation $(\mathrm{M}=4.79)$, and physical comfort $(\mathrm{M}=4.65)$. However, participants' satisfaction did not affect their evaluation feedback of experimental scenario preference. The material design and interface layouts were the same in all the visual screens, so participants' preference was based on the scenario design itself. In other words, we kept the material and interface consistent in the five experimental scenarios to make sure participants' choices were determined by the various combinations of control mechanism and screen variables.

\section{Other Considerations}

Our experimental design was to have participants repeat the same learning material 5 times. Participants may have gotten bored with the tests/materials and stopped caring. So when planning the user study, we made three decisions to minimize the possible negative effects. First, the participants were informed of the experimental procedure and asked to answer the questionnaires according to the related experimental scenarios as objectively as possible. Second, participants completed the five experimental scenarios in randomized order so that potential boredom and fatigue would affect scenarios in an unbiased way. Third, we made the hypothesis H1, and conducted a two-way repeated measure ANOVA to examine participants' responses. The results for $\mathrm{H} 1$ verified that participants' responses varied significantly based on changes to the experimental scenarios and evaluation criteria. Therefore, we had enough reason to believe that boredom only had a slight effect on the result.

We did not include experimental scenario D (single OHMD with machine controlling) in the official user study because its lack of flexibility affected students' learning experience. The learning software allowed students and the teacher to learn and interact with the content. If we had made the system control the interactive content automatically (timer controlling), students would not have had the flexibility to ask the system to re-present the materials in which they were most interested. However, the machine (timer) controlled experimental scenario could have its practical uses. For example, it could help to conduct a quiz. We could set the system to display each exercise-question for an equal period of time, and then turn to the next question. Therefore, the system could help us measure students' exercise performance in a pre-set time. 
Moreover, we could design the system to generate randomized exercises for each student to avoid cheating. These can be investigated in future research.

According to participants' self-evaluation outcomes, we found that participants preferred the experimental scenarios with a single controller rather than those experimental scenarios which involved multiple controllers. In other words, no matter who controlled the OHMD, having a single person controlling it would lead to participants' better learning performance. We also found that participants would like to control the studying tool (either OHMD or personal computer) at their own pace. The overall evaluation outcomes of listening, reading, speaking and writing exercises suggested that the OHMD was not the best tool to help students to do language learning exercises, but it was good for helping students to understand class materials, to remember knowledge and to improve efficiency in a classroom learning scenario.

Last but not least the sample size and design of educational content and software interface had undeniable effects on the study and its results. The research was done using the maximum number of participants available which would provide an acceptable population size for similar experiments, but we admit that larger sample sizes could have more reliable results. Better system and content design could have made the tasks easier. While we used a similar interface for all scenarios, one can argue that the interface and content should be customized to match the technology.

\section{Overall Impression and Result}

Overall, the results are encouraging for the OHMD-based solutions as they show promise that by resolving some issues they can provide a more effective solution in classrooms and replace the need for multiple screens with a single see-through option with multiple control mechanisms. We believe the ergonomic design and hardware will be developed as time goes by, which will make OHMD as comfortable as normal glasses and so improve its overall usability. Although the research findings were not decisive, the lack of support for OHMD can be explained by the technical and setup issues that were discussed above. This suggests that research on usability of OHMD in classroom should continue along with advancing the technology and customized content development. 


\section{Chapter 7: Conclusion}

\subsection{Summary and Recommendations}

The research presented in this thesis developed an OHMD-based prototype and designed a user study in order to investigate the ability of OHMD devices as a single screen in the classroom. The research originated from the observation that students' attention in the classroom is divided between multiple visual sources, including the instructor and screen(s). The recent availability of wearable sensors especially OHMD devices, provides an alternative that we aimed to explore.

We used the Epson Moverio BT-200 and developed programs that allowed the presentation of Chinese language lessons through 3 displays and 2 control options. The user studies were designed to compare various feasible combinations using a series of evaluation criteria. The user studies included students' perceptive responses on OHMD's usability during the experiments and their subjective opinion of the overall experience. We defined a series of hypotheses and evaluation criteria that would help us answer the following questions:

- Can the optical head-mounted display (OHMD) assist students with learning in a typical classroom, based on a series of evaluation criteria?

- How do the control mechanisms for OHMD (student vs. Instructor) compare based on the same criteria?

According to the results, there was no significant difference between participants' perceptive responses towards the enjoyment, ability to focus, motivation, perceived efficiency, understandability, and relaxation among the five feasible scenarios. This did not positively support our main hypothesis that OHMD-based approach is preferred but suggested physical comfort as a main issue. Similarly, there was no statistical significant difference between control mechanisms but over various questions participants showed a general interest toward having control over process.

However, participants' feedback showed that they favoured OHMD as a single screen, while their main complaints about it were related to physical comfort and ease of control. Our studies also showed that participants were more motivated and found it more enjoyable to learn when using OHMD. This suggests that improved technology will have the potential ability to be effective in classroom learning. 
Based on this study, we believe the following guidelines can be recommended:

- Effort has to be made to make OHMD technology more comfortable and convenient.

- The research into design of OHMD-based educational systems should continue as the technology is expected to mature and become more user friendly.

- Educational content should be designed with OHMD as base technology in mind.

- Researchers and educators should allow a certain period of adjustment for the new technology before it can be used effectively.

\subsection{Contributions}

While the research hypotheses relating to the ability of OHMD-based systems were not verified in our results, our research had the following main contributions:

- Design, development and integration of an educational system prototype (hardware, software and content) using the novel OHMD technology

- Initial exploration of using OHMD technology in classroom through identifying control approaches, evaluation criteria and usability studies

- Recommendations for future work in the area of OHMD use in classroom

\subsection{Limitations}

Our study was concentrated on student's perception; however, there are two stakeholders in a learning experience, teacher and student. To improve and evaluate the students' learning effect, the teacher should also be considered in the design. For example, we designed the scenario where the teacher could control the student's OHMD and lead him/her to review the various learning materials; while in the practice session, the teacher could monitor student's exercise performance from their own device.

For the evaluation, we could use more objective and quantitative measures, such as time to complete exercise and number of the correct answers, to assess the performance results more accurately. This could be a better or an additional option in our study. The qualitative responses could also be analyzed in a more rigorous and systematic way such with the Emergent Coding method. It was noticed that in absence of clear statistical significance, we could rely on qualitative and open-ended responses to learn about participants' preferences and the issues they 
had. While we did not plan a more formal data acquisition and analysis of qualitative data, this could result in better understanding of the experience.

Because of the limited number of the OHMD devices, we only designed a one-on-one teaching scenario; however, in a common classroom learning scenario, the teacher is usually facing multiple students. As one participant commented, new challenges would appear when a group of students were using the devices at the same time.

The machine-controlled scenario was removed from our study after the pilot test since the participants found it too restrictive. A more intelligent system could still be implemented that would somehow interact with participants and detect their needs before deciding on progressing through content.

Finally, the number of participants in our study was relatively low. We would need to run the study with a larger sample size to validate and generalize our findings.

\subsection{Future Work}

The limitations described in previous section can be basis for designing further research that does not suffer from such limitations and so will have more reliable results. Future work could also focus on exploring more possibilities of using OHMD in other educational subjects. For example, developing and adding the augmented reality function with OHMD could help students with understanding physics models. Another interesting direction for the future work could be exploring OHMD applications to help students with outside classroom studying. Students' cooperation for projects with OHMD could also be an option. For example, two students could use gestures to co-work on a 3D architecture model design when wearing OHMD and seeing the same interface. It would also be intriguing to see how OHMD could help students with disability, provide them with equal learning conditions as their peers. Last but not least, future OHMD versions and models may resolve some of the technical issues and so should be used in later studies. 


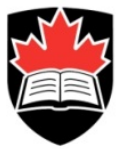

\section{Carleton}

U N I V E R S I T Y

\section{Canada's Capital University}

\section{Carleton University} 1125 Colonel By Drive

Tel: 613-520-2600

www.carleton.ca

The purpose of this informed consent is to ensure that you understand the purpose of the study and the nature of your involvement. This informed consent must provide sufficient information such that you have the opportunity to determine whether you wish to participate in the study.

The research is being conducted by:

\section{Dr. Ali Arya}

School of Information Technology

Carleton University

1125 Colonel By Drive

Ottawa, ON, Canada

arya@carleton.ca

\author{
Xiao Du \\ Human Computer Interaction \\ School of Information Technology \\ Carleton University \\ Ottawa, ON, Canada \\ xiao.du@carleton.ca
}

Purpose: The purpose of this user test study is to examine and evaluate the effectiveness of multiple interaction approaches of which the users use for assisting learning. In particular, we record and analyse the participants' behaviour during the test, and generate a report.

Task Description: The participant's task in this usability test is to use a variety of manipulating approaches to complete three task modules (receiving information, controlling content, managing feedback) in a simulated class environment.

Duration: The interview should take approximately 20-30 minutes.

Potential Risk/Discomfort: There will be no psychological or physical risk.

Dissemination: The result of this research will be used in Mr. Du's thesis and might also be published and/or presented in conferences and/or journals, as well as grant applications.

Anonymity/Confidentiality: All collected data will remain anonymous. Any data collected will be encrypted and saved in a secure system with password protection at Carleton University. Only the research team will have access to this data. It may be used for research projects on a related topic. 
Right to Withdraw: You have the right to withdraw at any time, without any explanation as to the reason for withdrawing from the study. You also have the right to refuse to answer any questions you do not feel comfortable answering, for any reason and without explanation.

Compensation: You will receive a \$10 Tim Card.

This research has been reviewed and cleared by the Carleton University Research Ethics Board (REB) and questions and concerns can be addressed to the REB chair.

\section{Research Ethics Board:}

Professor Andy Adler, Chair

Research Ethics Board

Carleton University Research Office

Carleton University

1125 Colonel By Drive

Ottawa, Ontario K1S 5B6

Tel: 613-520-2517 E-mail: ethics@carleton.ca

Consent: I have read and understand the above terms of user testing and I understand the conditions of my participation. My signature below indicates that I agree to participate in this experiment.

Participant Name:

Participant Signature:

Researcher Name:

Researcher Signature:

Date: 


\section{Appendix B: Pre-Study Survey}

1. What is your gender?
Female
Male
Other

2. Which age group are you a part of?
20 or younger
$21-25$
26-30
31-35
36 or older

3. Is English your mother tongue?

$\square$ Yes $\quad \square$ No If no, please indicate your native language

4. For how many days have you been studying Chinese (Mandarin)?
$\square 0$
$\square 30$
$\square 90$
$\square 180$
$\square 360$
$>2$ years

5. Have you ever used a head-mounted display, such as Google Glass or GlassUp?

$\square$ Yes $\quad \square$ No If yes, which device

6. Have you ever used padding-touch controlled devices?

$\square$ Yes $\quad \square$ No

On a scale of 1 (very low) to 7 (very high), please rate your level with each of the following statements. 1 = very low, 2 = low, $3=$ somewhat low, $4=$ neutral, $5=$ somewhat high, $6=$ high, $7=$ very high.

7. My level of interest in studying Chinese (Mandarin) is

$\begin{array}{llllllll}\text { [Very Low] } & 1 & 2 & 3 & 4 & 5 & 6 & 7 \text { [Very High] }\end{array}$

8. My current Chinese (Mandarin) skill is

$\begin{array}{llllllll}\text { [Very Low] } & 1 & 2 & 3 & 4 & 5 & 6 & 7 \text { [Very High] }\end{array}$

9. The frequency that I use mobile applications to assist my daily life (such as surfing the internet, checking email, playing games, watching movies, listening to music, reading e-books, etc.) is
[Very Low] 1
23
$4 \quad 5 \quad 6$
7 [Very High]

10. My ability to concentrate in a typical language classroom is

$\begin{array}{llllllll}\text { [Very Low] } & 1 & 2 & 3 & 4 & 5 & 6 & 7 \text { [Very High] }\end{array}$

11. What makes you distracted when learning in a typical language class? Why? 


\section{Appendix C: In-Study Survey}

Based on this learning experience (A.B.C.E.F.), on a scale of 1 (strongly disagree) to 7 (strongly agree), please rate your level of agreement with each of the following statements. $1=$ strongly disagree, $2=$ disagree, $3=$ somewhat disagree, $4=$ undecided, $5=$ somewhat agree, $6=$ agree, $7=$ strongly agree.

1. I found the experience stressful.

$\begin{array}{llllllll}\text { [Strongly Disagree] } & 1 & 2 & 3 & 4 & 5 & 6 & 7 \text { [Strongly Agree] }\end{array}$

2. I enjoyed the experience.

$\begin{array}{llllllll}\text { [Strongly Disagree] } & 1 & 2 & 3 & 4 & 5 & 6 & 7 \text { [Strongly Agree] }\end{array}$

3. I found it easy to focus on the text.

$\begin{array}{llllllll}\text { [Strongly Disagree] } & 1 & 2 & 3 & 4 & 5 & 6 & 7 \text { [Strongly Agree] }\end{array}$

4. I was motivated to learn.

$\begin{array}{llllllll}\text { [Strongly Disagree] } & 1 & 2 & 3 & 4 & 5 & 6 & 7 \text { [Strongly Agree] }\end{array}$

5. I found it an efficient way of learning.

$\begin{array}{llllllll}\text { [Strongly Disagree] } & 1 & 2 & 3 & 4 & 5 & 6 & 7 \text { [Strongly Agree] }\end{array}$

6. I felt physically comfortable.

$\begin{array}{llllllll}\text { [Strongly Disagree] } & 1 & 2 & 3 & 4 & 5 & 6 & 7 \text { [Strongly Agree] }\end{array}$

7. I found it easy to understand the content.

$\begin{array}{llllllll}\text { [Strongly Disagree] } & 1 & 2 & 3 & 4 & 5 & 6 & 7 \text { [Strongly Agree] }\end{array}$

8. I found it relaxing.

$\begin{array}{llllllll}\text { [Strongly Disagree] } & 1 & 2 & 3 & 4 & 5 & 6 & 7 \text { [Strongly Agree] }\end{array}$ 


\section{Appendix D: Post-Quiz Survey}

Based on this learning experience (A. B. C. E. F), answer the questions below.

1. From 1 (the easiest) to 4 (the hardest), please rate the difficulty of the following quizzes according to how you feel

Listening

Reading

Speaking

Writing

2. This learning scenario (A. B. C. E. F) could help me the most in studying of

$\square$ Listening $\square$ Reading $\square$ Speaking $\square$ Writing

3. This learning scenario makes me the most uncomfortable in studying of

$\square$ Listening $\square$ Reading $\square$ Speaking $\square$ Writing

4. I feel I learned the most in

$\square$ Pronunciation $\quad \square$ Understanding $\quad \square$ Recognition $\quad \square$ Writing

5. What should be improved if you have a chance to use this learning mode in class? Why? 


\section{Appendix E: Post-Study Questionnaire}

1. Overall, was there anything that made you feel uncomfortable during the test? Explain.

2. Which was your favourite learning scenario? Why?

3. What would you improve about the see-through head-mounted display interaction method for studying? 


\section{Appendix F: Poster Call for Participants}

\section{Participants Needed FOR STUDY ON HEAD-MOUNTED DISPLAY IN EDUCATION}

Do you want to play with wearable transparent Head-Mounted display? Join study! My name is Xiao Du and I am a $\mathrm{HCl}$ graduate student from Carleton University working under the supervision of Dr. Ali Arya. I am conducting a research on usability of wearable heads-up augmented-reality displays (similar to Google Glass) in classroom learning. Participants will have a chance to play with the device below to experience a new way of learning.

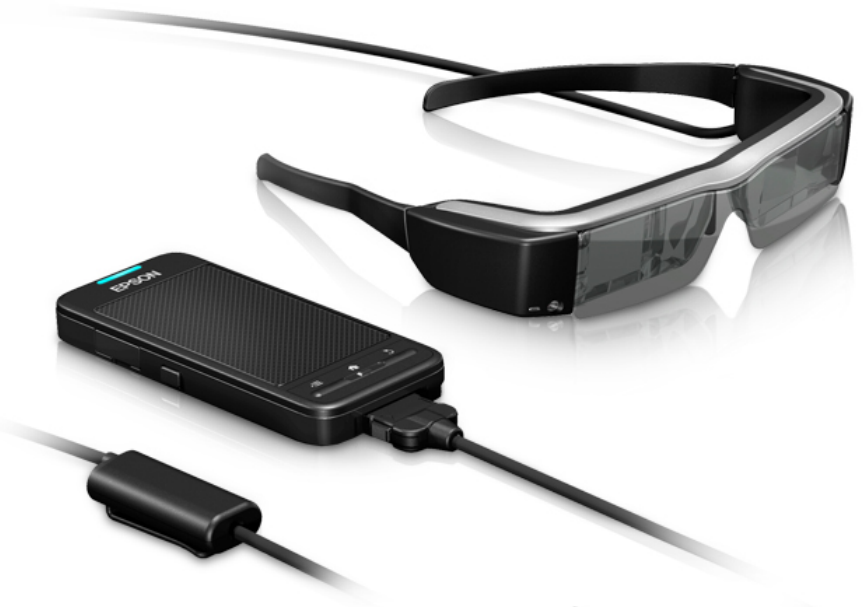

Location: Room 4109, Interactive Media lab, Canal Building.

Eligibility: Participants should be over 18 years old, fluent in English.

Compensation: You will receive a \$10 Tim Card or small gift.

Ethical Review: This research has been reviewed and approved by the Carleton University Research Ethics Board

Contact Info: Anyone who is interested in participating in this study, please contact: xiaodu@cmail.carleton.ca to schedule a meeting time.

Thanks! 


\section{Appendix G: Email Call for Participants}

My name is Xiao Du and I am a student researcher from Carleton University working under the supervision of Dr. Ali Arya. I am conducting a research on usability of wearable see-through displays (similar to Google Glass) in classrooms. I have developed a simple prototype that demonstrates the use of such devices in language teaching.

Participants will be asked to fill out paper questionnaires relating to their experience of using the device. It should take approximately 60 minutes to complete.

To be eligible, participants should be over 18 years old, fluent in English and have basic understanding of Mandarin.

Ethical Review: This research has been reviewed and approved by the Carleton University Research Ethics Board

Anyone who is interested in participating in this study or needs any extra information, please contact me at xiaodu@cmail.carleton.ca or call me at: 613-890-0829.

Thank you!

Regards,

Xiao 


\section{Appendix H: Results of Two-way Repeated Measures ANOVA of Scenarios and Evaluation Criteria}

\section{Descriptive Statistics for the Scenarios}

Dependent Variable: Rating

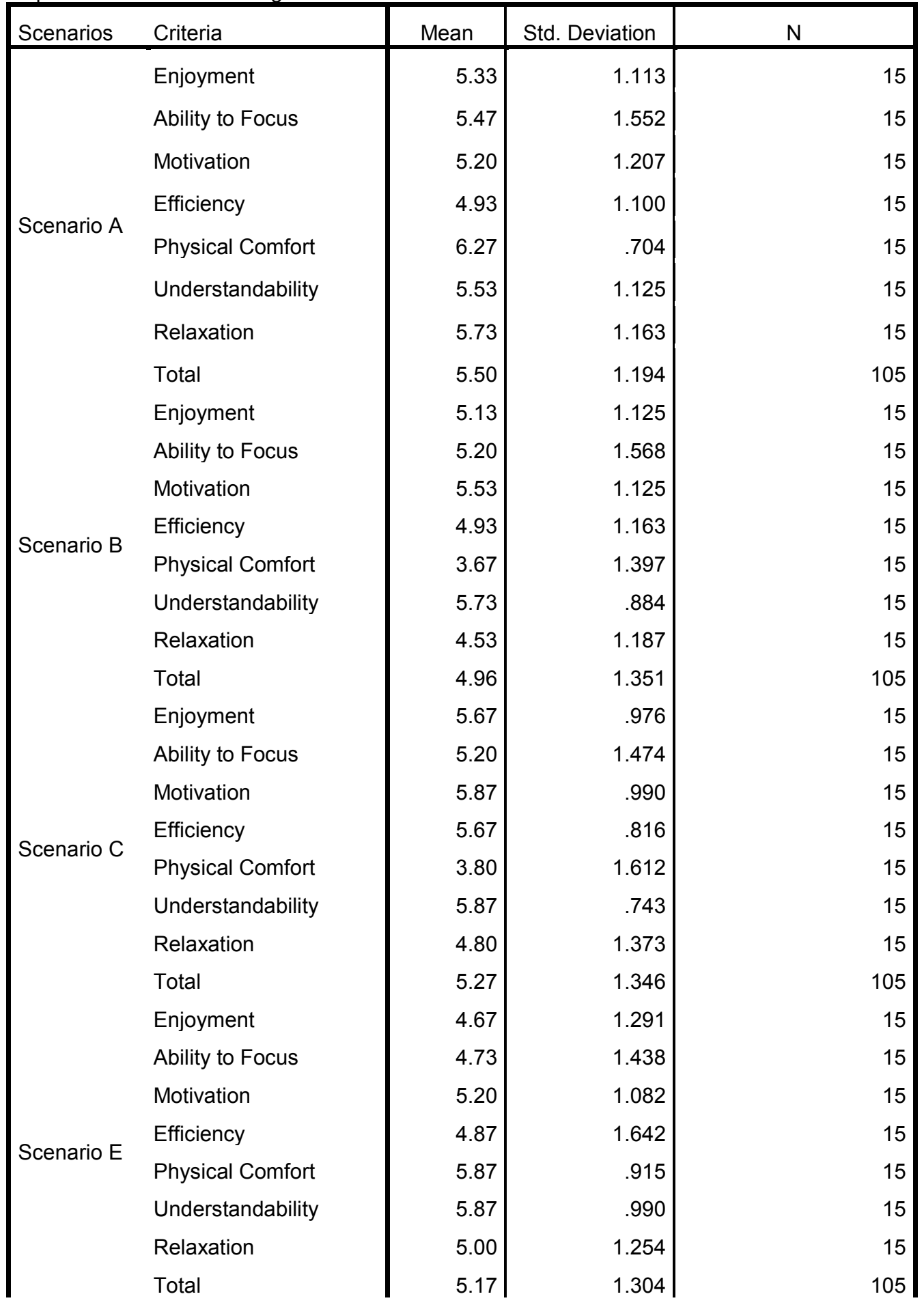




\begin{tabular}{|l|r|r|r|} 
& Enjoyment & 4.73 & 1.033 \\
4.53 & 1.302 & 15 \\
Ability to Focus & 5.27 & 1.163 & 15 \\
Motivation & 4.27 & 1.751 & 15 \\
Scenario F Efficiency & 3.67 & 1.496 & 15 \\
& Physical Comfort & .915 & 15 \\
Understandability & 5.53 & 1.506 & 15 \\
Relaxation & 3.87 & 1.448 & 15 \\
Total & 4.55 & 1.146 & 105 \\
Enjoyment & 5.11 & 1.470 & 75 \\
Ability to Focus & 5.03 & 1.116 & 75 \\
Motivation & 5.41 & 1.379 & 75 \\
Efficiency & 4.93 & 1.704 & 75 \\
Physical Comfort & 4.65 & .927 & 75 \\
Total & 5.71 & 1.407 & 75 \\
Understandability & 4.79 & 1.364 & 75 \\
Relaxation & 5.09 & & 525 \\
Total & &
\end{tabular}

Descriptive Statistics for the Usability Criteria

Dependent Variable: Rating

\begin{tabular}{|ll|r|r|r|}
\hline Criteria & Scenarios & Mean & Std. Deviation & $\mathrm{N}$ \\
\hline \multirow{5}{*}{ Enjoyment } & 5.33 & 1.113 & 15 \\
& Scenario A & 5.13 & 1.125 & 15 \\
& Scenario B & 5.67 & .976 & 15 \\
& Scenario C & 4.67 & 1.291 & 15 \\
& Scenario E & 4.73 & 1.033 & 15 \\
& Scenario F & 5.11 & 1.146 & 75 \\
& Total & 5.47 & 1.552 & 15 \\
Ability to & Scenario A & 5.20 & 1.568 & 15 \\
Focus & Scenario B & 5.20 & 1.474 & 15 \\
& Scenario C & 4.73 & 1.438 & 15 \\
& Scenario E & 4.53 & 1.302 & 15 \\
& Scenario F & 5.03 & 1.470 & 75 \\
& Total & 5.20 & 1.207 & 15 \\
& Scenario A & 5.53 & 1.125 & 15 \\
& Scenario B & 5.87 & .990 & 15 \\
Motivation & Scenario C & 5.20 & 1.082 & 15 \\
& Scenario E & 5.27 & 1.163 & 15
\end{tabular}




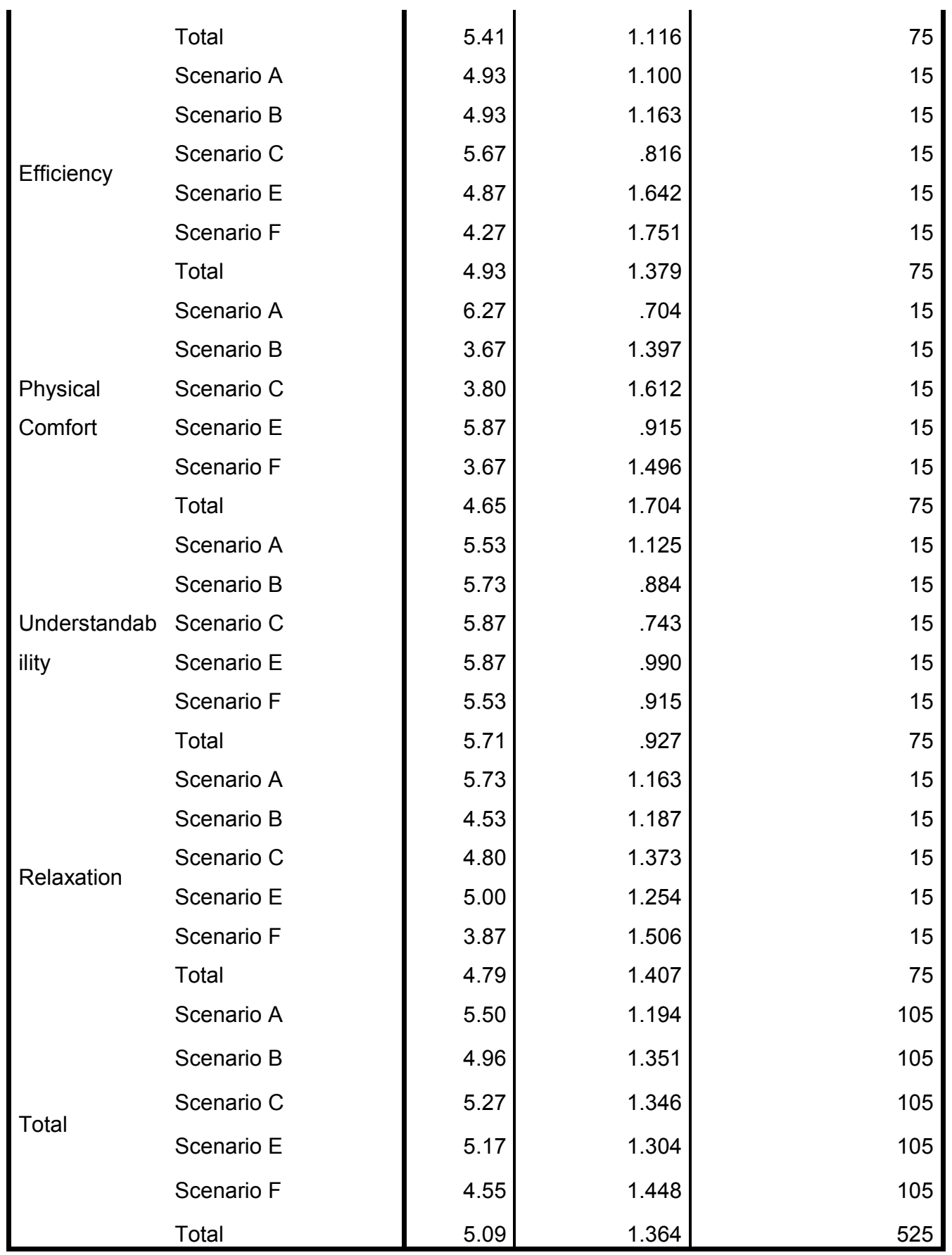




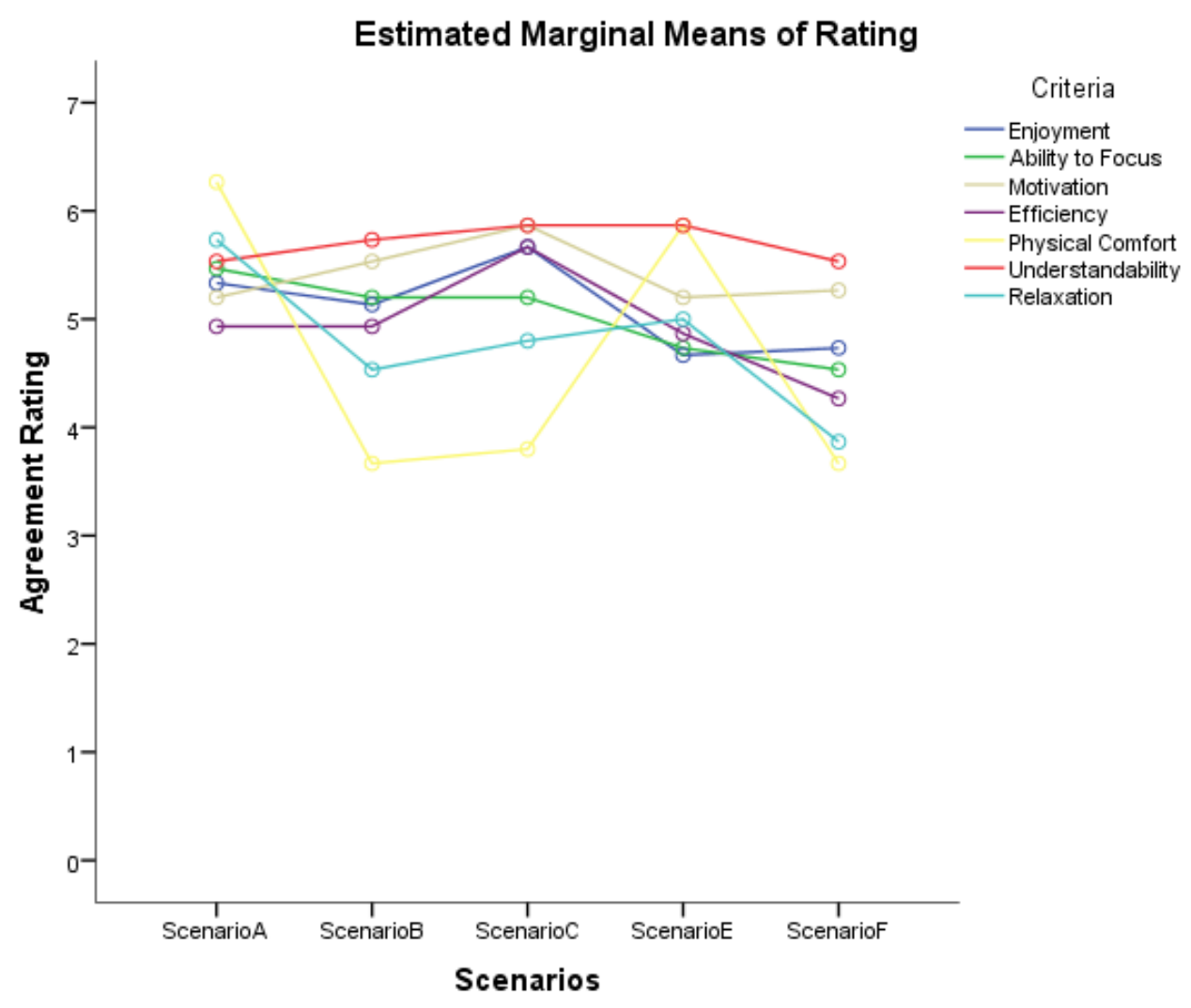

Profile Plots of Participants' Responses for each Scenario 


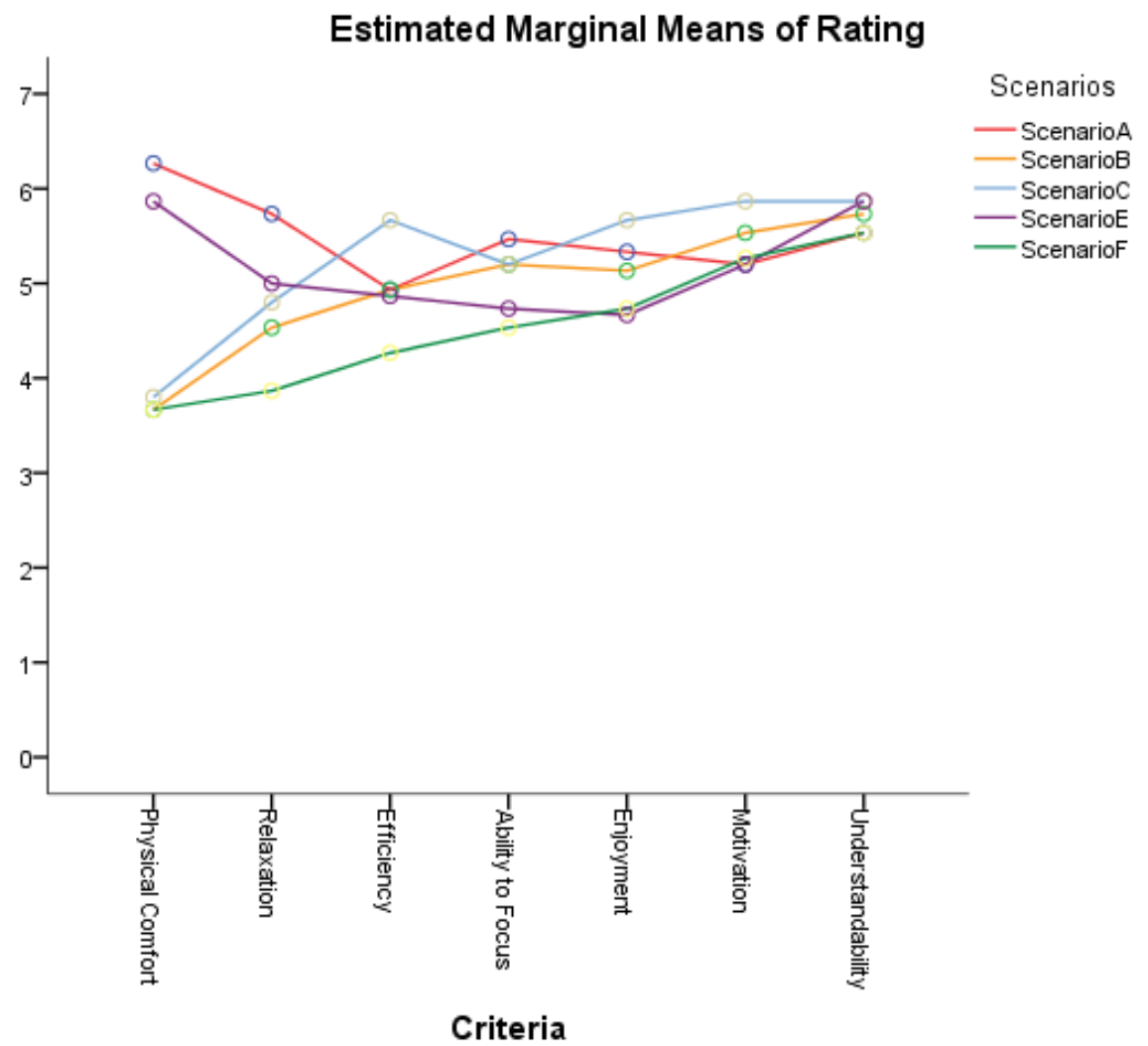

Profile Plots of Participants' Responses for each Evaluation Criteria 


\section{Appendix I: Participants' Responses for each Evaluation Criteria}

\section{Enjoyment}
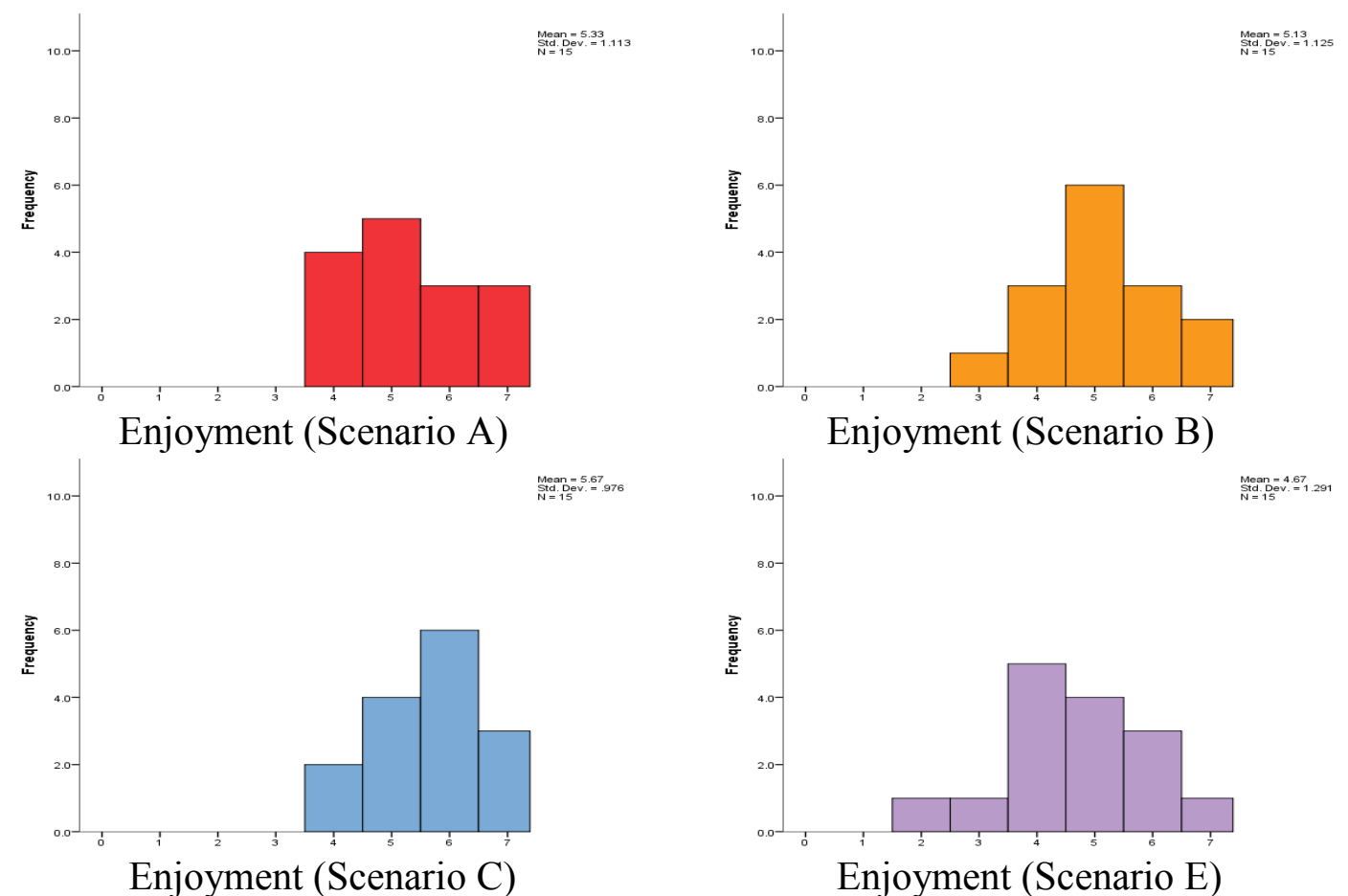

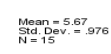

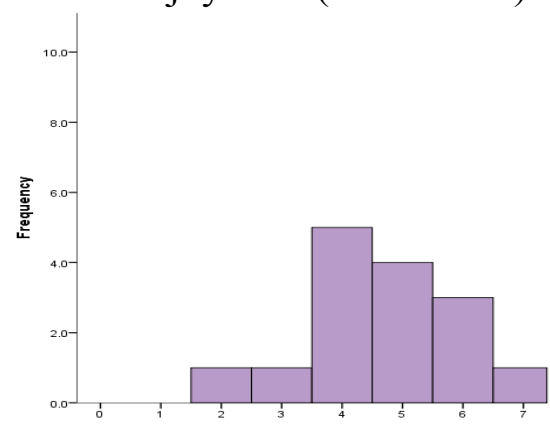

Enjoyment (Scenario C)

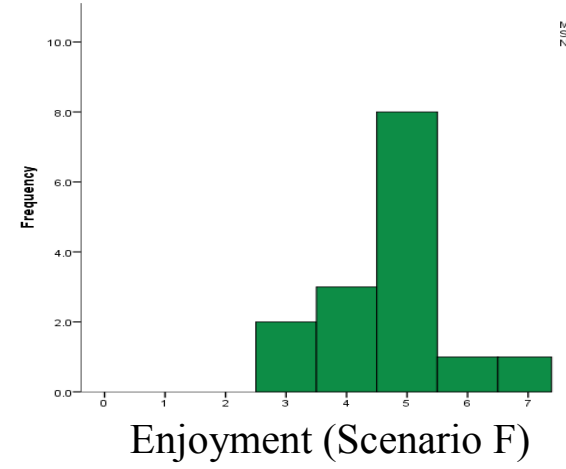

Enjoyment (Scenario E)

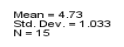




\begin{tabular}{|l|r|r|r|r|r|r|r|r|}
\hline ScenarioA_Q2 & 15 & 4 & 7 & 5.33 & 1.113 & .306 & .580 & -1.157 \\
ScenarioB_Q2 & 15 & 3 & 7 & 5.13 & 1.125 & .050 & .580 & -.232 \\
1.121 \\
ScenarioC_Q2 & 15 & 4 & 7 & 5.67 & .976 & -.276 & .580 & -.646 \\
ScenarioE_Q2 & 15 & 2 & 7 & 4.67 & 1.291 & -.196 & .580 & .125 \\
ScenarioF_Q2 & 15 & 3 & 7 & 4.73 & 1.033 & .167 & .580 & .860 \\
Valid N (listwise) & 15 & & & & & & \\
\hline
\end{tabular}

Tests of Within-Subjects Effects for Enjoyment

\begin{tabular}{|c|c|c|c|c|c|c|c|}
\hline \multicolumn{2}{|l|}{ Source } & $\begin{array}{l}\text { Type III } \\
\text { Sum of } \\
\text { Squares }\end{array}$ & $d f$ & $\begin{array}{l}\text { Mean } \\
\text { Square }\end{array}$ & $\mathrm{F}$ & Sig. & $\begin{array}{c}\text { Partial Eta } \\
\text { Squared }\end{array}$ \\
\hline \multirow{5}{*}{ scenario } & Sphericity Assumed & 10.480 & 4 & 2.620 & 2.370 & .063 & .145 \\
\hline & Greenhouse-Geisser & 10.480 & 3.236 & 3.239 & 2.370 & .079 & .145 \\
\hline & Huynh-Feldt & 10.480 & 4.000 & 2.620 & 2.370 & .063 & .145 \\
\hline & Lower-bound & 10.480 & 1.000 & 10.480 & 2.370 & .146 & .145 \\
\hline & Sphericity Assumed & 61.920 & 56 & 1.106 & & & \\
\hline \multirow{3}{*}{ Error(scenario) } & Greenhouse-Geisser & 61.920 & 45.301 & 1.367 & & & \\
\hline & Huynh-Feldt & 61.920 & 56.000 & 1.106 & & & \\
\hline & Lower-bound & 61.920 & 14.000 & 4.423 & & & \\
\hline
\end{tabular}

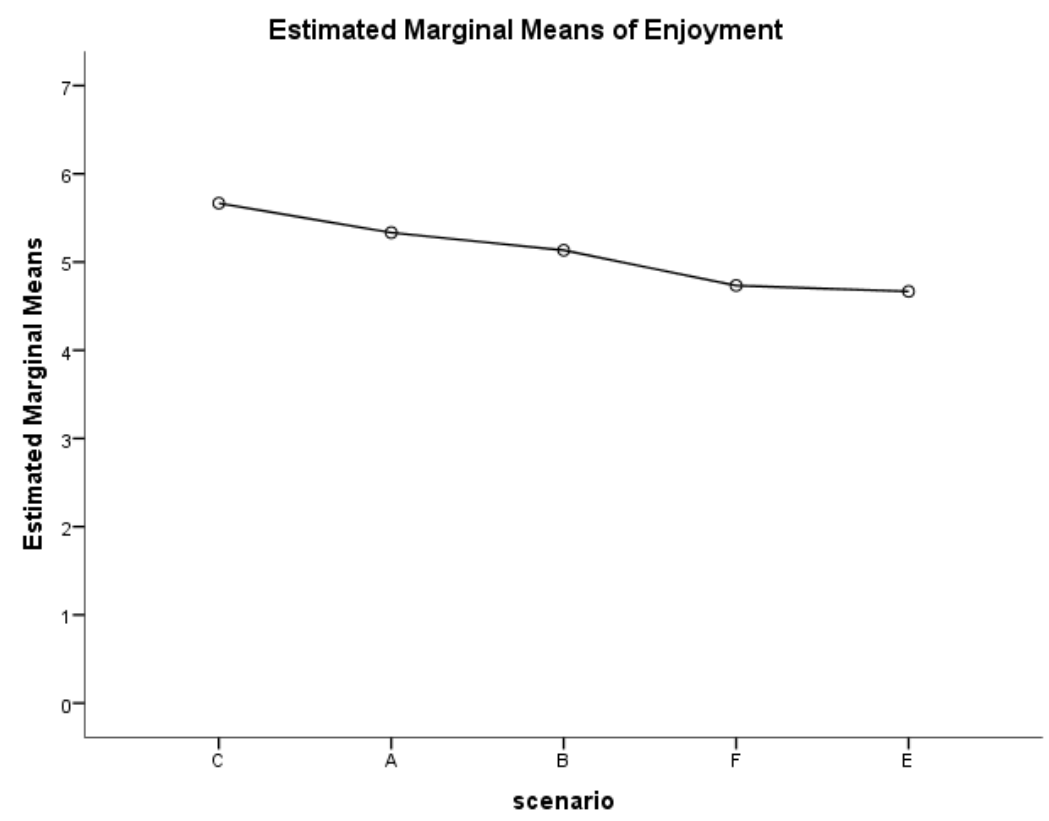

Profile Plots of Participants' Responses towards Enjoyment among Scenarios 
Friedman's Test Statistics for Enjoyment

\begin{tabular}{|l|r|}
\hline N & 15 \\
Chi-Square & 8.912 \\
Df & 4 \\
Asymp. Sig. & .063 \\
\hline
\end{tabular}

The Median Statistics for Enjoyment

\begin{tabular}{|c|c|c|c|c|c|c|}
\hline & & $\begin{array}{c}\text { Scenario } \\
\text { A_Enjoyment }\end{array}$ & $\begin{array}{c}\text { Scenario } \\
\text { B_Enjoyment }\end{array}$ & $\begin{array}{c}\text { Scenario } \\
\text { C_Enjoyment }\end{array}$ & $\begin{array}{c}\text { Scenario } \\
\text { E_Enjoyment }\end{array}$ & $\begin{array}{c}\text { Scenario } \\
\text { F_Enjoyment }\end{array}$ \\
\hline \multirow{2}{*}{$N$} & Valid & 15 & 15 & 15 & 15 & 15 \\
\hline & Missing & 510 & 510 & 510 & 510 & 510 \\
\hline Median & & 5.00 & 5.00 & 6.00 & 5.00 & 5.00 \\
\hline
\end{tabular}

\section{Ability to Focus}

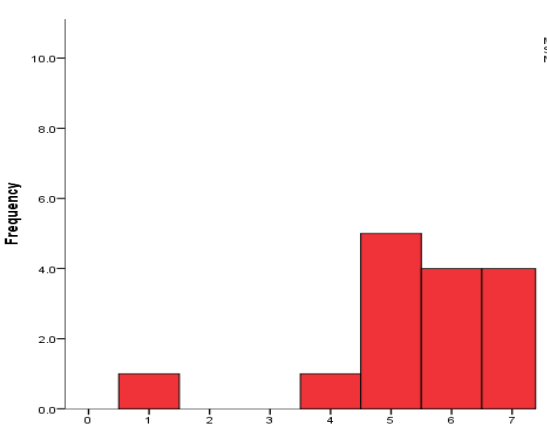

Ability to Focus (Scenario A)

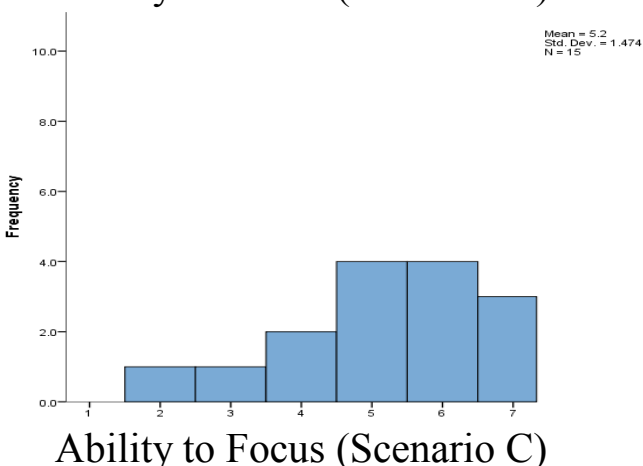

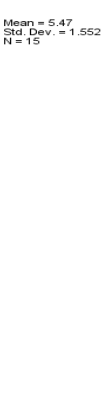

tats

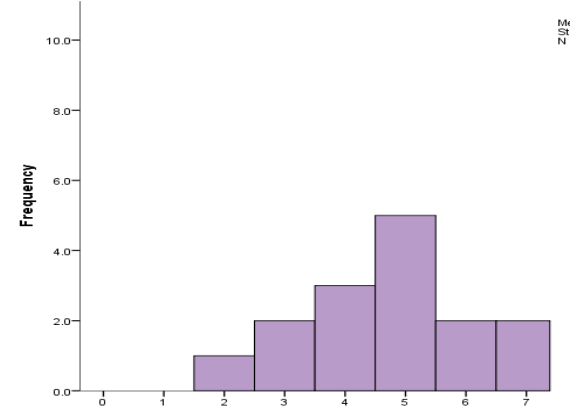

Ability to Focus (Scenario E)

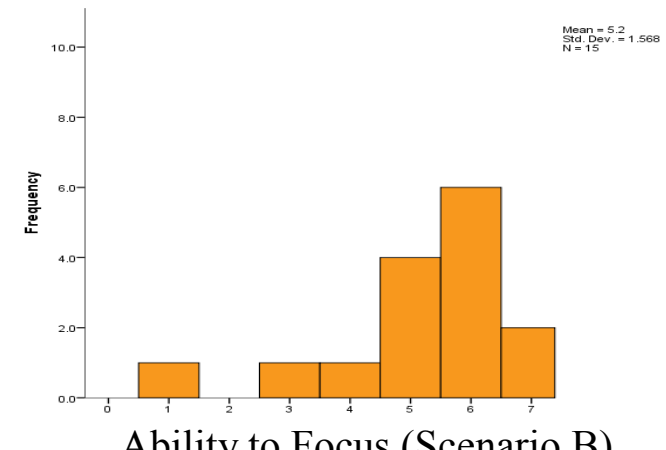

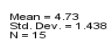




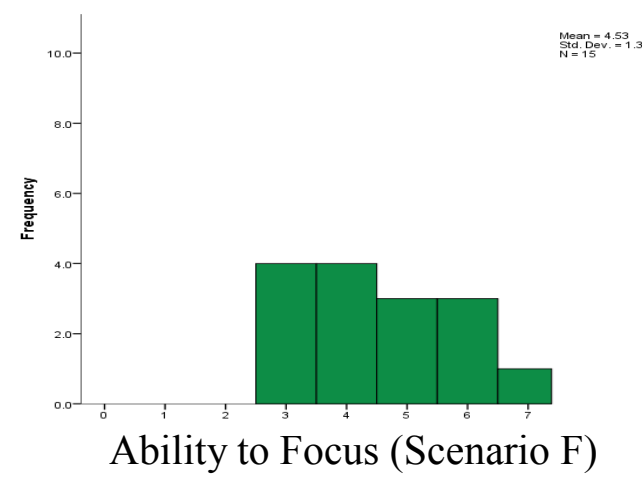

Histogram for Participants' Responses of Ability to Focus $(1=$ strongly disagree, $2=$ disagree, $3=$ somewhat disagree, 4 = undecided, $5=$ somewhat agree, $6=$ agree, $7=$ strongly agree)

Descriptive Statistics for Participants' Responses of Ability to Focus

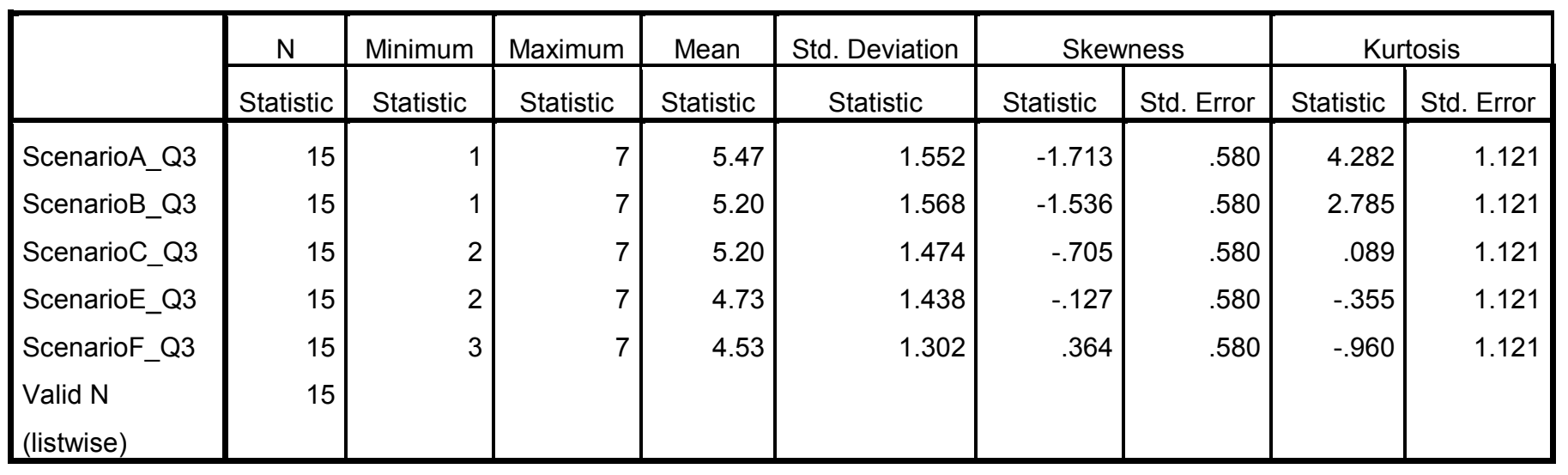

Tests of Within-Subjects Effects for Ability to Focus

\begin{tabular}{|c|c|c|c|c|c|c|c|}
\hline \multicolumn{2}{|l|}{ Source } & $\begin{array}{l}\text { Type III } \\
\text { Sum of } \\
\text { Squares }\end{array}$ & df & $\begin{array}{l}\text { Mean } \\
\text { Square }\end{array}$ & $\mathrm{F}$ & Sig. & $\begin{array}{c}\text { Partial Eta } \\
\text { Squared }\end{array}$ \\
\hline \multirow{5}{*}{ scenario } & Sphericity Assumed & 8.747 & 4 & 2.187 & 1.423 & .238 & .092 \\
\hline & Greenhouse-Geisser & 8.747 & 2.621 & 3.337 & 1.423 & .253 & .092 \\
\hline & Huynh-Feldt & 8.747 & 3.280 & 2.667 & 1.423 & .246 & .092 \\
\hline & Lower-bound & 8.747 & 1.000 & 8.747 & 1.423 & .253 & .092 \\
\hline & Sphericity Assumed & 86.053 & 56 & 1.537 & & & \\
\hline \multirow{3}{*}{ Error(scenario) } & Greenhouse-Geisser & 86.053 & 36.698 & 2.345 & & & \\
\hline & Huynh-Feldt & 86.053 & 45.916 & 1.874 & & & \\
\hline & Lower-bound & 86.053 & 14.000 & 6.147 & & & \\
\hline
\end{tabular}




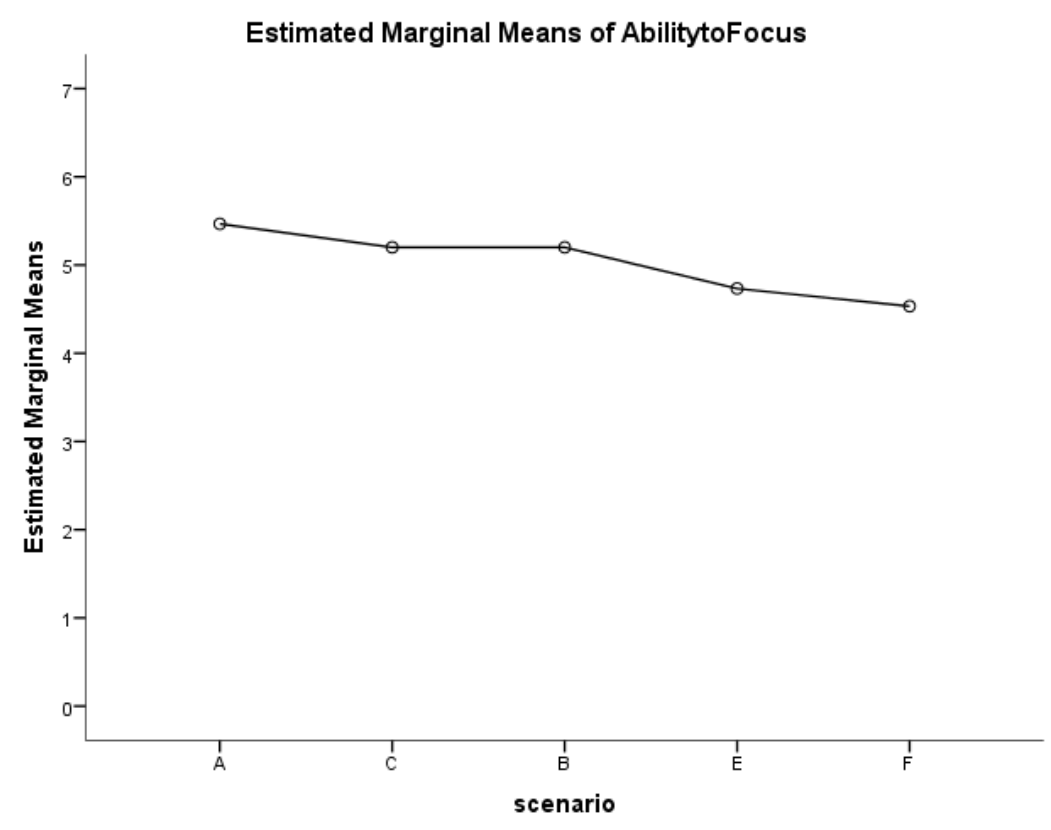

Profile Plots of Participants' Responses towards Ability to Focus among Scenarios

Friedman's Test Statistics

for Ability to Focus

\begin{tabular}{|l|r|}
\hline N & 15 \\
Chi-Square & 5.145 \\
Df & 4 \\
Asymp. Sig. & .273 \\
\hline
\end{tabular}

The Median Statistics for Ability to Focus Ratings

\begin{tabular}{|c|c|c|c|c|c|c|}
\hline & & ScenarioA_Q3 & ScenarioB_Q3 & ScenarioC_Q3 & ScenarioE_Q3 & ScenarioF_Q3 \\
\hline \multirow{2}{*}{$\mathrm{N}$} & Valid & 15 & 15 & 15 & 15 & 15 \\
\hline & Missing & 510 & 510 & 510 & 510 & 510 \\
\hline \multicolumn{2}{|c|}{ Median } & 6.00 & 6.00 & 5.00 & 5.00 & 4.00 \\
\hline
\end{tabular}


Motivation
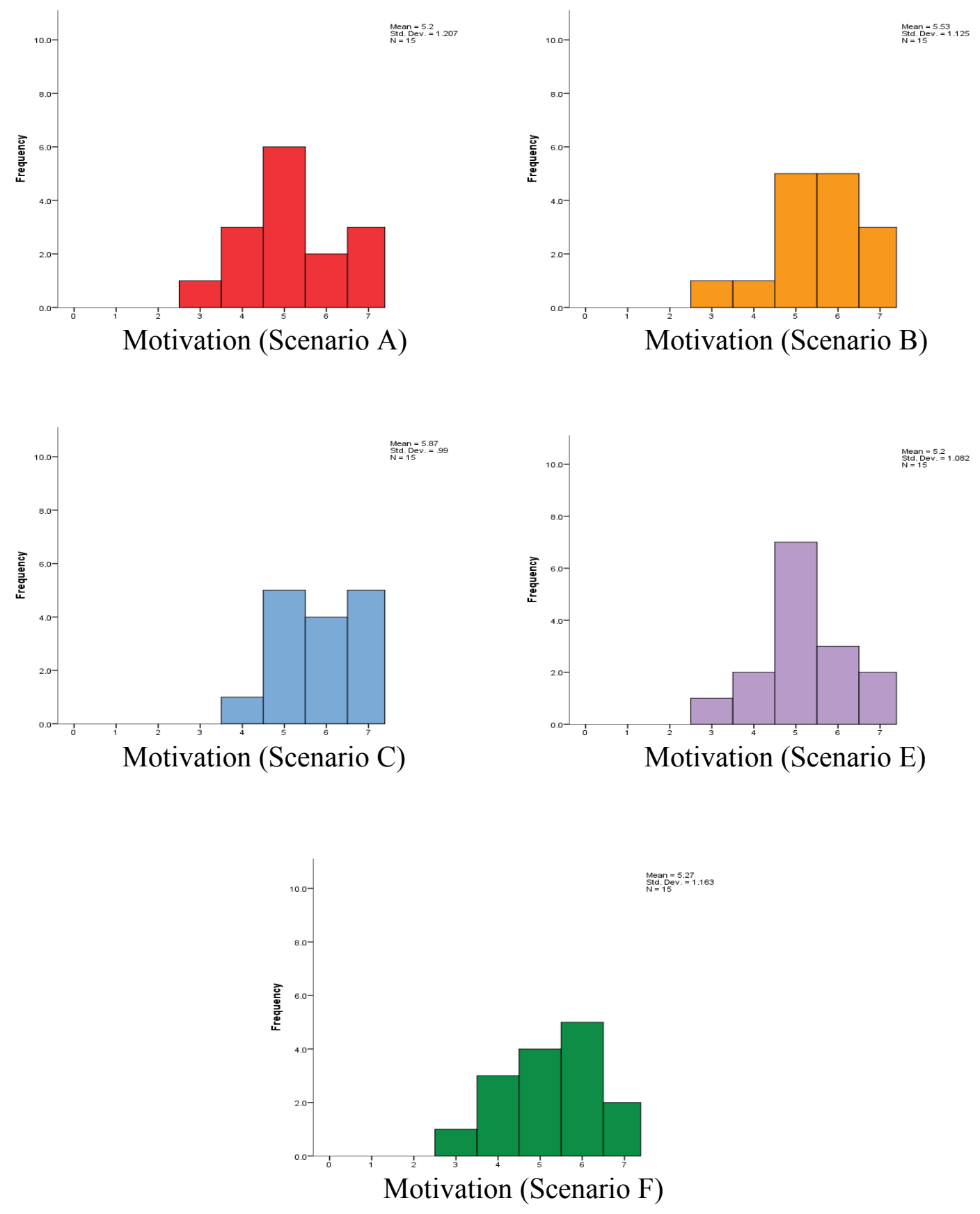

Histogram for Participants' Responses of Motivation $(1=$ strongly disagree, $2=$ disagree, $3=$ somewhat disagree, $4=$ undecided, $5=$ somewhat agree, $6=$ agree, $7=$ strongly agree) 
Descriptive Statistics for Participants' Responses of Motivation

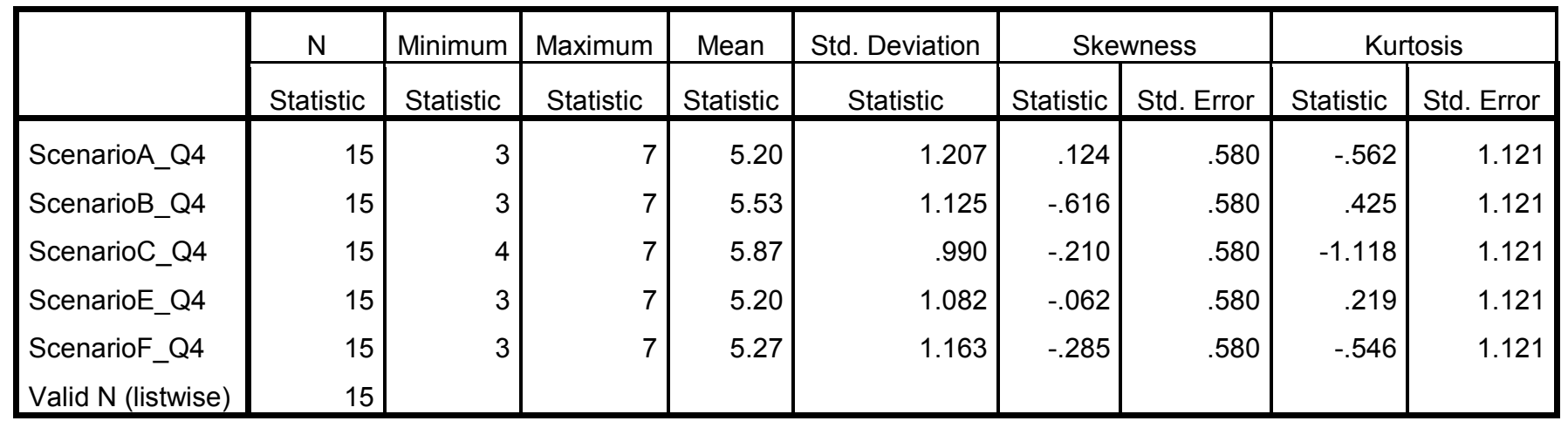

Tests of Within-Subjects Effects for Motivation

\begin{tabular}{|c|c|c|c|c|c|c|c|}
\hline \multicolumn{2}{|l|}{ Source } & $\begin{array}{l}\text { Type III } \\
\text { Sum of } \\
\text { Squares }\end{array}$ & $d f$ & $\begin{array}{l}\text { Mean } \\
\text { Square }\end{array}$ & $\mathrm{F}$ & Sig. & $\begin{array}{c}\text { Partial Eta } \\
\text { Squared }\end{array}$ \\
\hline \multirow{4}{*}{ scenario } & Sphericity Assumed & 4.987 & 4 & 1.247 & 1.424 & .238 & .092 \\
\hline & Greenhouse-Geisser & 4.987 & 2.532 & 1.970 & 1.424 & .254 & .092 \\
\hline & Huynh-Feldt & 4.987 & 3.137 & 1.590 & 1.424 & .248 & .092 \\
\hline & Lower-bound & 4.987 & 1.000 & 4.987 & 1.424 & .253 & .092 \\
\hline \multirow{4}{*}{ Error(scenario) } & Sphericity Assumed & 49.013 & 56 & .875 & & & \\
\hline & Greenhouse-Geisser & 49.013 & 35.445 & 1.383 & & & \\
\hline & Huynh-Feldt & 49.013 & 43.919 & 1.116 & & & \\
\hline & Lower-bound & 49.013 & 14.000 & 3.501 & & & \\
\hline
\end{tabular}




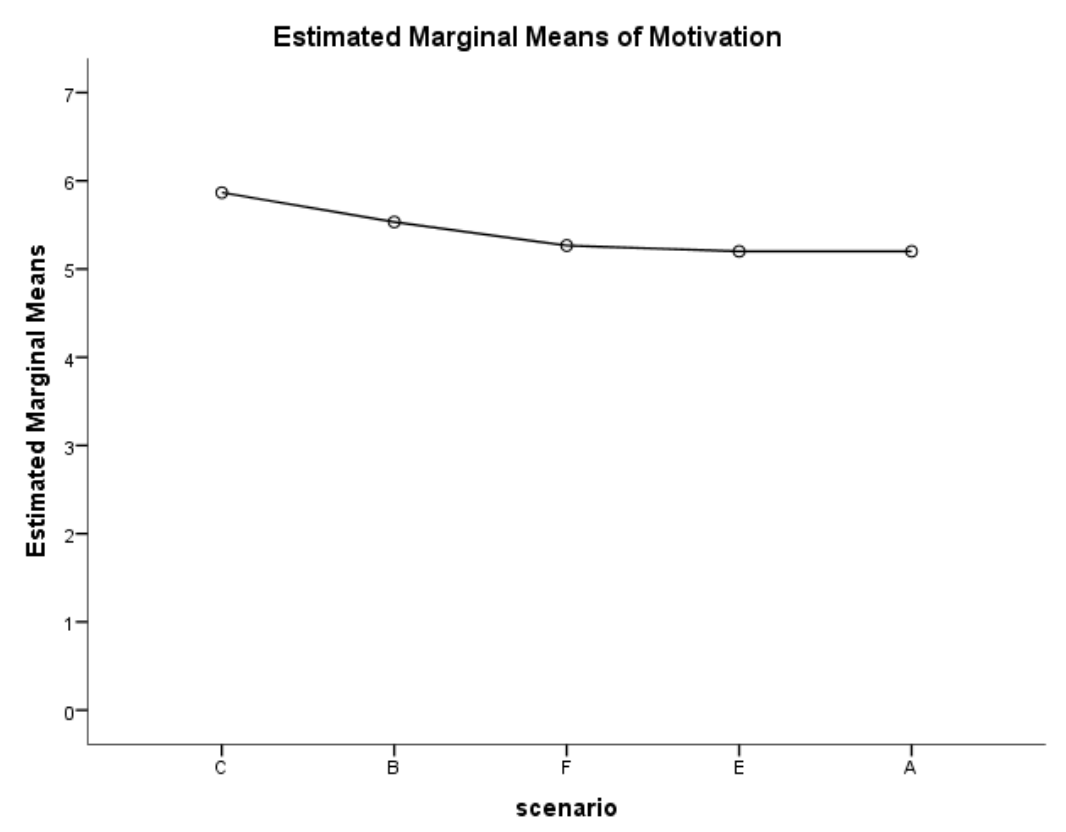

Profile Plots of Participants' Responses towards Motivation among Scenarios

Friedman's Test Statistics

for Motivation

\begin{tabular}{|l|r|}
\hline N & 15 \\
Chi-Square & 6.070 \\
Df & 4 \\
Asymp. Sig. & .194 \\
\hline
\end{tabular}

The Median Statistics for Motivation Ratings

\begin{tabular}{|c|c|c|c|c|c|c|}
\hline & & ScenarioA_Q4 & ScenarioB_Q4 & ScenarioC_Q4 & ScenarioE_Q4 & ScenarioF_Q4 \\
\hline \multirow{2}{*}{$\mathrm{N}$} & Valid & 15 & 15 & 15 & 15 & 15 \\
\hline & Missing & 510 & 510 & 510 & 510 & 510 \\
\hline Median & & 5.00 & 6.00 & 6.00 & 5.00 & 5.00 \\
\hline
\end{tabular}


Perceived Efficiency
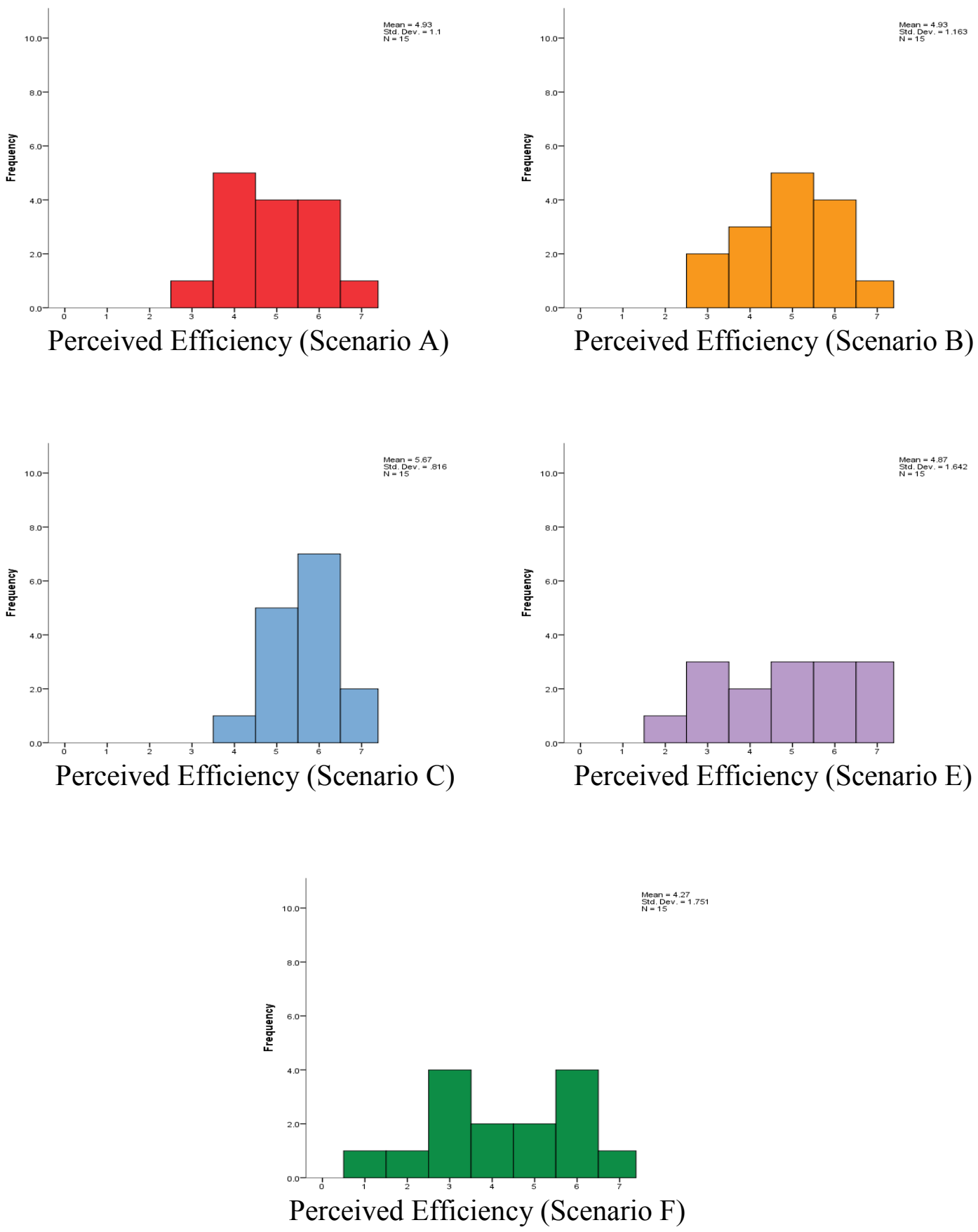

Histogram for Participants' Responses of Perceived Efficiency $(1=$ strongly disagree, $2=$ disagree, $3=$ somewhat disagree, $4=$ undecided, $5=$ somewhat agree, $6=$ agree, $7=$ strongly agree) 
Descriptive Statistics for Participants' Responses of Efficiency

\begin{tabular}{|c|c|c|c|c|c|c|c|c|c|}
\hline & $\mathrm{N}$ & Minimum & Maximum & Mean & Std. Deviation & \multicolumn{2}{|c|}{ Skewness } & \multicolumn{2}{|c|}{ Kurtosis } \\
\hline & Statistic & Statistic & Statistic & Statistic & Statistic & Statistic & Std. Error & Statistic & Std. Error \\
\hline ScenarioA_Q5 & 15 & 3 & 7 & 4.93 & 1.100 & .148 & .580 & -.676 & 1.121 \\
\hline ScenarioB_Q5 & 15 & 3 & 7 & 4.93 & 1.163 & -.168 & .580 & -.546 & 1.121 \\
\hline ScenarioC_Q5 & 15 & 4 & 7 & 5.67 & .816 & -.168 & .580 & -.033 & 1.121 \\
\hline ScenarioE_Q5 & 15 & 2 & 7 & 4.87 & 1.642 & -.202 & .580 & -1.165 & 1.121 \\
\hline ScenarioF_Q5 & 15 & 1 & 7 & 4.27 & 1.751 & -.194 & .580 & -.929 & 1.121 \\
\hline Valid N & 15 & & & & & & & & \\
\hline & & & & & & & & & \\
\hline
\end{tabular}

Tests of Within-Subjects Effects for Perceived Efficiency

Measure: Efficiency

\begin{tabular}{|c|c|c|c|c|c|c|c|}
\hline Source & & $\begin{array}{l}\text { Type III } \\
\text { Sum of } \\
\text { Squares }\end{array}$ & $d f$ & $\begin{array}{l}\text { Mean } \\
\text { Square }\end{array}$ & $\mathrm{F}$ & Sig. & $\begin{array}{c}\text { Partial Eta } \\
\text { Squared }\end{array}$ \\
\hline \multirow{4}{*}{ scenario } & Sphericity Assumed & 14.800 & 4 & 3.700 & 2.123 & .090 & .132 \\
\hline & Greenhouse-Geisser & 14.800 & 2.777 & 5.330 & 2.123 & .117 & .132 \\
\hline & Huynh-Feldt & 14.800 & 3.533 & 4.189 & 2.123 & .099 & .132 \\
\hline & Lower-bound & 14.800 & 1.000 & 14.800 & 2.123 & .167 & .132 \\
\hline \multirow{4}{*}{ Error(scenario) } & Sphericity Assumed & 97.600 & 56 & 1.743 & & & \\
\hline & Greenhouse-Geisser & 97.600 & 38.876 & 2.511 & & & \\
\hline & Huynh-Feldt & 97.600 & 49.464 & 1.973 & & & \\
\hline & Lower-bound & 97.600 & 14.000 & 6.971 & & & \\
\hline
\end{tabular}




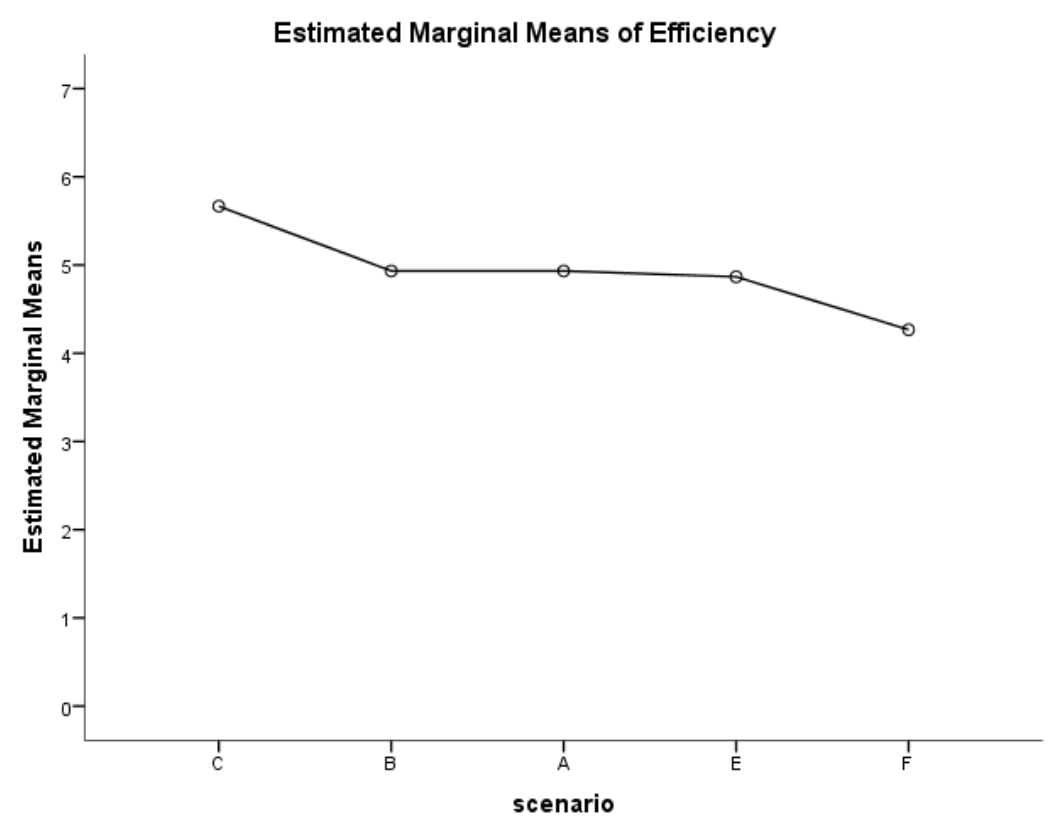

Profile Plots of Participants' Responses towards Efficiency among Scenarios

Friedman's Test Statistics for Efficiency

\begin{tabular}{|l|r|}
\hline N & 15 \\
Chi-Square & 7.915 \\
Df & 4 \\
Asymp. Sig. & .095 \\
\hline
\end{tabular}

The Median Statistics for Perceived Efficiency Ratings

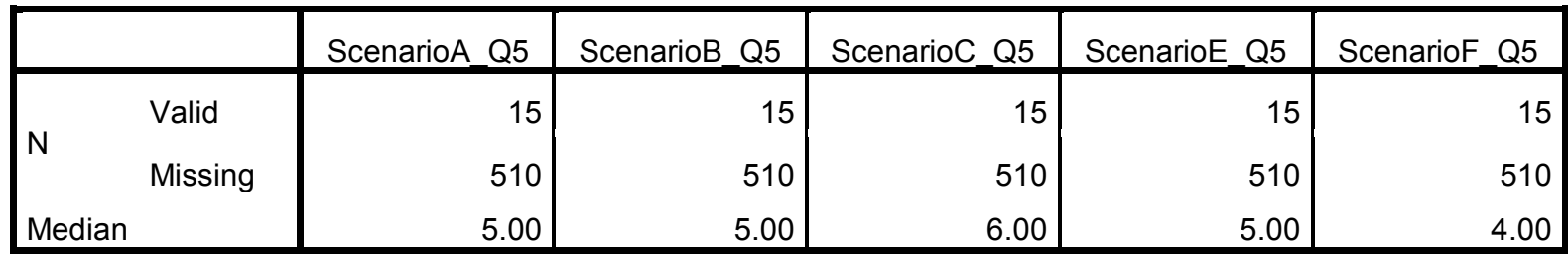


Physical Comfort

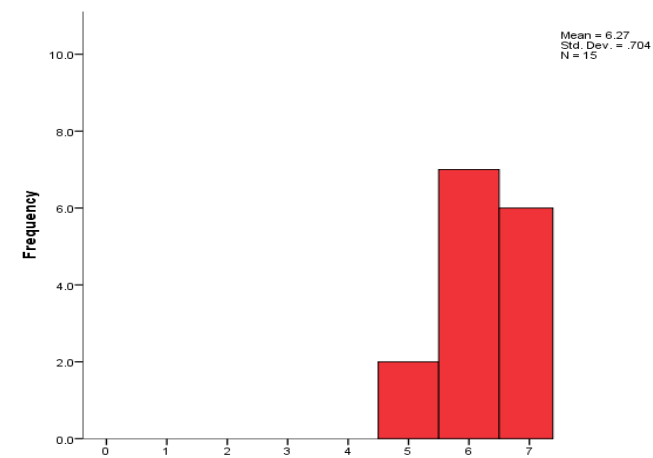

Physical Comfort (Scenario A)

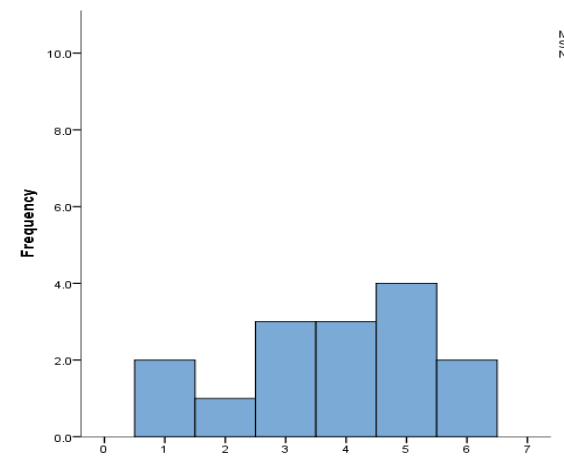

Physical Comfort (Scenario C)

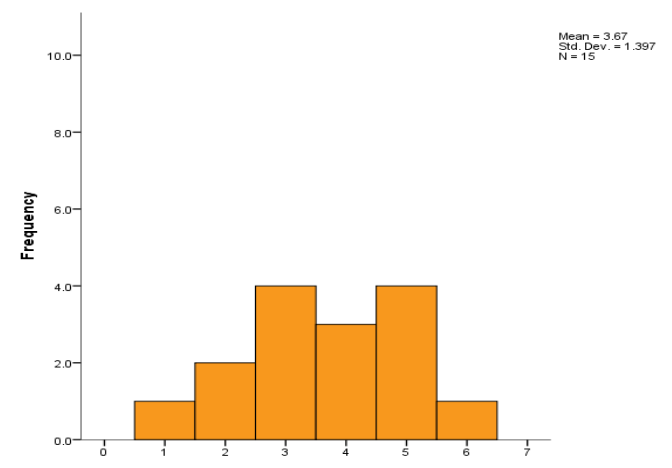

Physical Comfort (Scenario B)
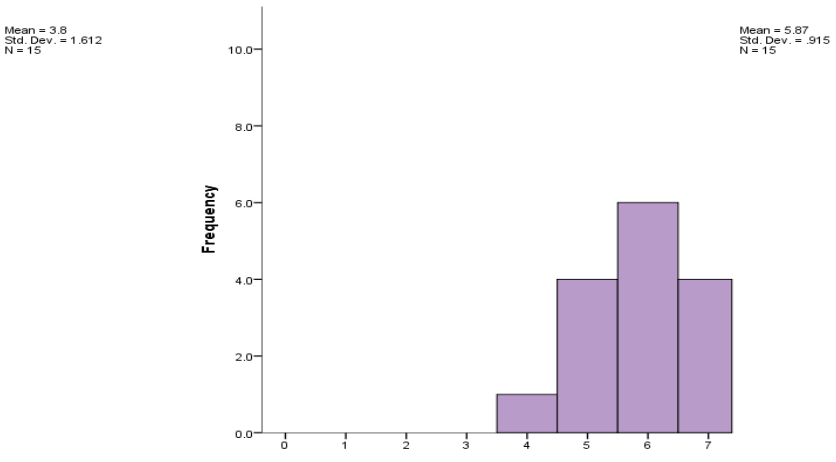

Physical Comfort (Scenario E)

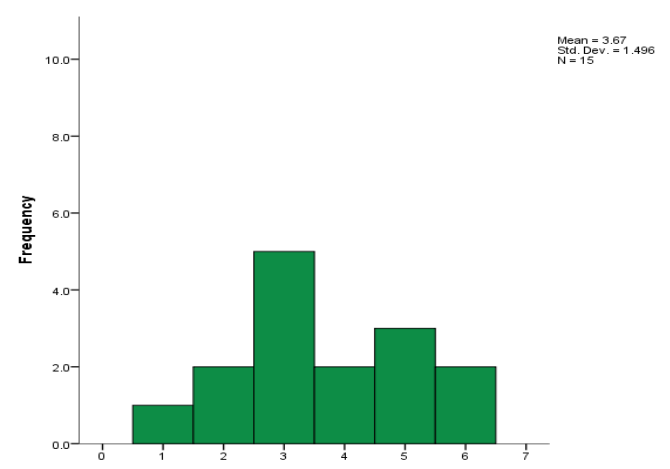

Physical Comfort (Scenario F)

Histogram for Participants' Responses of Physical Comfort $(1=$ strongly disagree, $2=$ disagree, $3=$ somewhat disagree, $4=$ undecided, $5=$ somewhat agree, $6=$ agree, $7=$ strongly agree) 
Descriptive Statistics for Participants' Responses of Physical Comfort

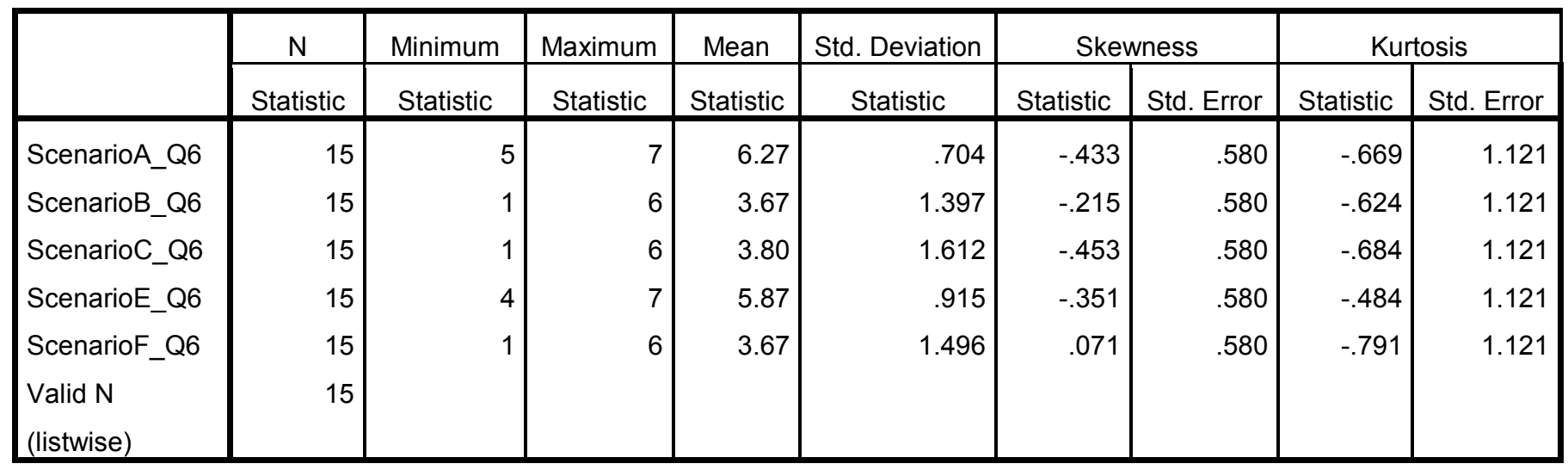

Tests of Within-Subjects Effects for Physical Comfort

Measure: PhysicalComfort

\begin{tabular}{|c|c|c|c|c|c|c|c|}
\hline Source & & $\begin{array}{l}\text { Type III } \\
\text { Sum of } \\
\text { Squares }\end{array}$ & $d f$ & $\begin{array}{l}\text { Mean } \\
\text { Square }\end{array}$ & $\mathrm{F}$ & Sig. & $\begin{array}{c}\text { Partial Eta } \\
\text { Squared }\end{array}$ \\
\hline \multirow{4}{*}{ scenario } & Sphericity Assumed & 101.253 & 4 & 25.313 & 17.555 & .000000 & .556 \\
\hline & Greenhouse-Geisser & 101.253 & 2.613 & 38.744 & 17.555 & .000001 & .556 \\
\hline & Huynh-Feldt & 101.253 & 3.267 & 30.992 & 17.555 & .000000 & .556 \\
\hline & Lower-bound & 101.253 & 1.000 & 101.253 & 17.555 & .000908 & .556 \\
\hline \multirow{4}{*}{ Error(scenario) } & Sphericity Assumed & 80.747 & 56 & 1.442 & & & \\
\hline & Greenhouse-Geisser & 80.747 & 36.587 & 2.207 & & & \\
\hline & Huynh-Feldt & 80.747 & 45.739 & 1.765 & & & \\
\hline & Lower-bound & 80.747 & 14.000 & 5.768 & & & \\
\hline
\end{tabular}




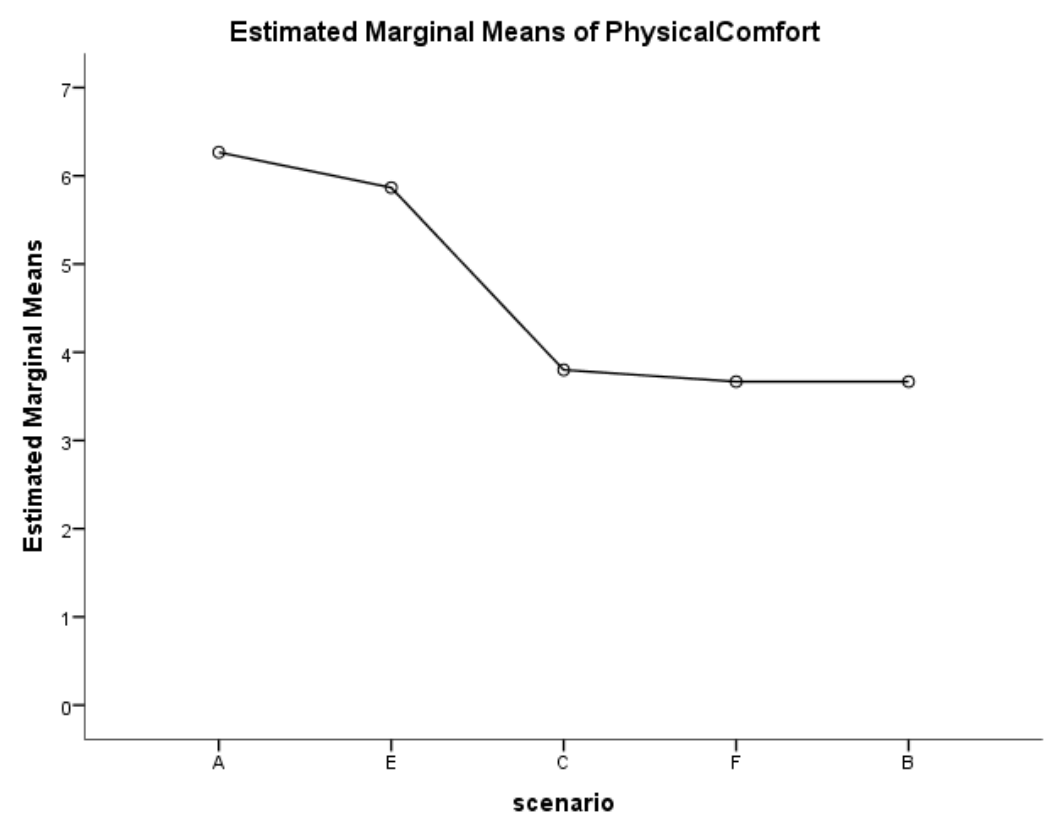

Profile Plots of Participants' Responses towards Physical Comfort among Scenarios

Friedman's Test Statistics

for Physical Comfort

\begin{tabular}{|l|r|}
\hline N & 15 \\
Chi-Square & 37.790 \\
Df & 4 \\
Asymp. Sig. & .00000012 \\
\hline
\end{tabular}

The Median Statistics for Physical Comfort Ratings

\begin{tabular}{|c|c|c|c|c|c|c|}
\hline & & ScenarioA_Q6 & ScenarioB_Q6 & ScenarioC_Q6 & ScenarioE_Q6 & ScenarioF_Q6 \\
\hline \multirow{2}{*}{$N$} & Valid & 15 & 15 & 15 & 15 & 15 \\
\hline & Missing & 510 & 510 & 510 & 510 & 510 \\
\hline Median & & 6.00 & 4.00 & 4.00 & 6.00 & 3.00 \\
\hline
\end{tabular}




\section{Understandability}
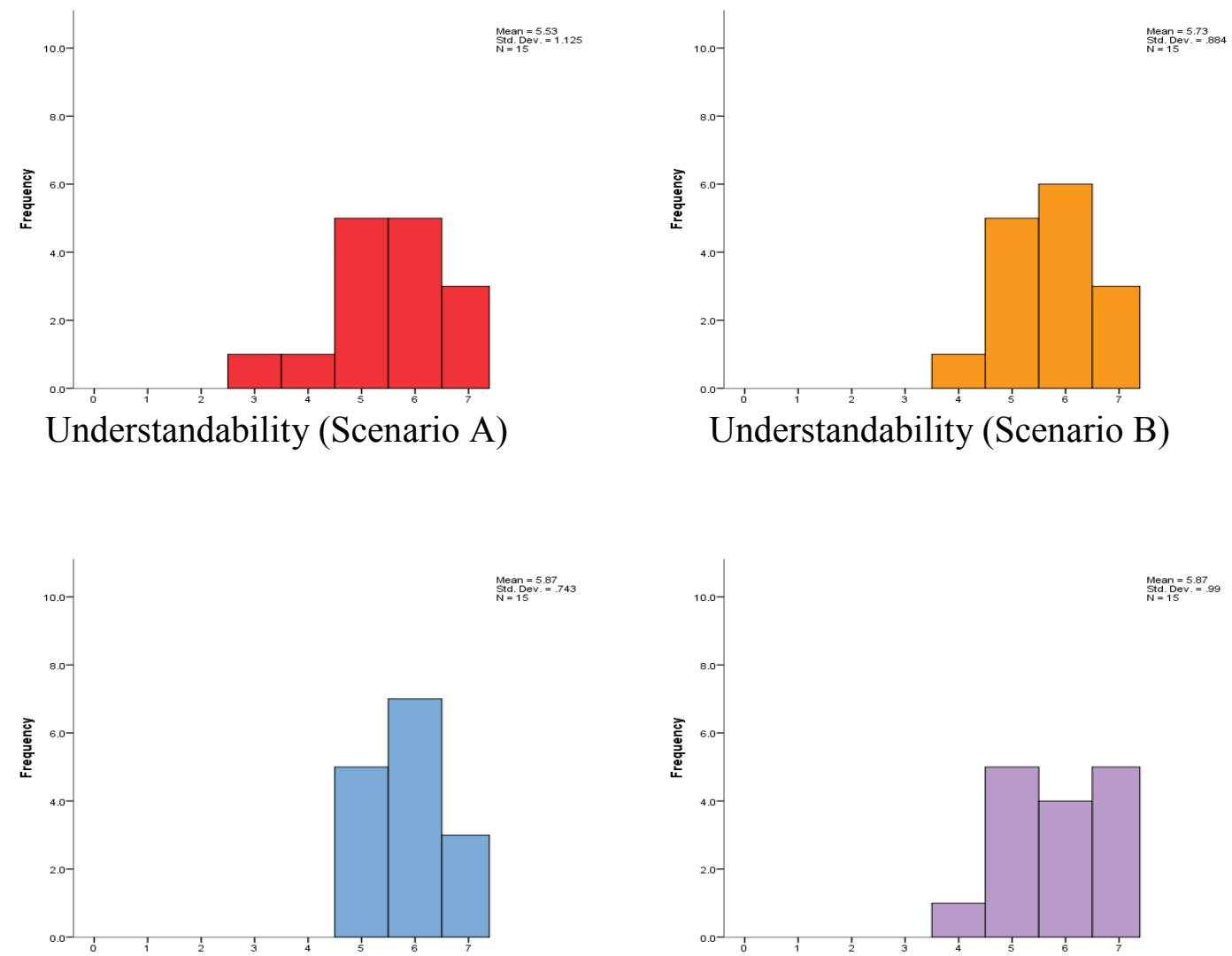

Understandability (Scenario C)
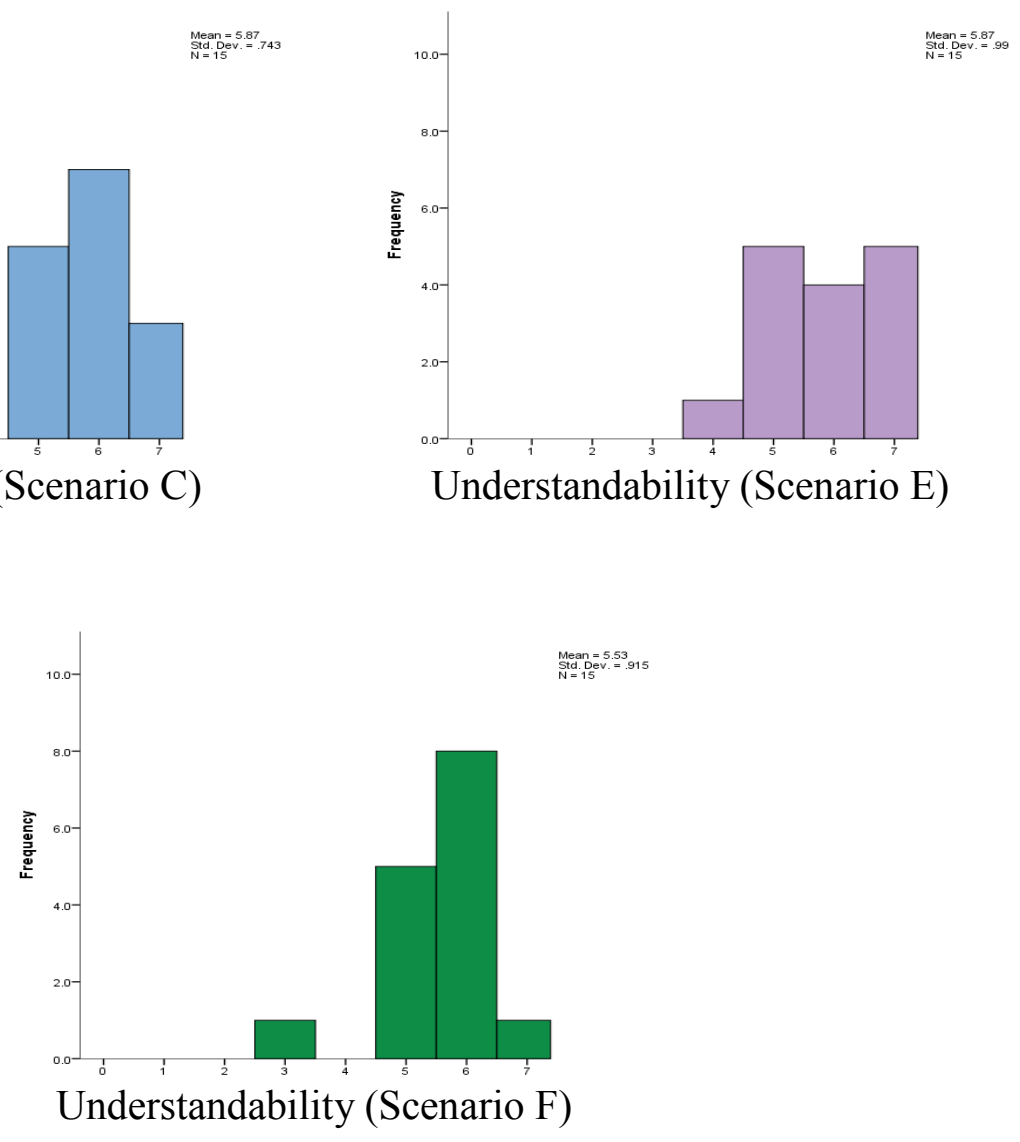

Histogram for Participants' Responses of Understandability $(1=$ strongly disagree, 2 = disagree, $3=$ somewhat disagree, $4=$ undecided, $5=$ somewhat agree, $6=$ agree, $7=$ strongly agree) 
Descriptive Statistics for Participants' Responses of Understandability

\begin{tabular}{|c|c|c|c|c|c|c|c|c|c|}
\hline & $\mathrm{N}$ & Minimum & Maximum & Mean & Std. Deviation & \multicolumn{2}{|c|}{ Skewness } & \multicolumn{2}{|c|}{ Kurtosis } \\
\hline & Statistic & Statistic & Statistic & Statistic & Statistic & Statistic & Std. Error & Statistic & Std. Error \\
\hline ScenarioA_Q7 & 15 & 3 & 7 & 5.53 & 1.125 & -.616 & .580 & .425 & 1.121 \\
\hline ScenarioB_Q7 & 15 & 4 & 7 & 5.73 & .884 & -.116 & .580 & -.485 & 1.121 \\
\hline ScenarioC_Q7 & 15 & 5 & 7 & 5.87 & .743 & .227 & .580 & -.970 & 1.121 \\
\hline ScenarioE_Q7 & 15 & 4 & 7 & 5.87 & .990 & -.210 & .580 & -1.118 & 1.121 \\
\hline ScenarioF_Q7 & 15 & 3 & 7 & 5.53 & .915 & -1.402 & .580 & 3.521 & 1.121 \\
\hline Valid N & 15 & & & & & & & & \\
\hline (listwise) & & & & & & & & & \\
\hline
\end{tabular}

Tests of Within-Subjects Effects for Understandability

Measure: Understandability

\begin{tabular}{|c|c|c|c|c|c|c|c|}
\hline Source & & $\begin{array}{l}\text { Type III } \\
\text { Sum of } \\
\text { Squares }\end{array}$ & $d f$ & $\begin{array}{l}\text { Mean } \\
\text { Square }\end{array}$ & $\mathrm{F}$ & Sig. & $\begin{array}{c}\text { Partial Eta } \\
\text { Squared }\end{array}$ \\
\hline \multirow{5}{*}{ scenario } & Sphericity Assumed & 1.680 & 4 & .420 & .607 & .659 & .042 \\
\hline & Greenhouse-Geisser & 1.680 & 2.650 & .634 & .607 & .595 & .042 \\
\hline & Huynh-Feldt & 1.680 & 3.326 & .505 & .607 & .630 & .042 \\
\hline & Lower-bound & 1.680 & 1.000 & 1.680 & .607 & .449 & .042 \\
\hline & Sphericity Assumed & 38.720 & 56 & .691 & & & \\
\hline \multirow{3}{*}{ Error(scenario) } & Greenhouse-Geisser & 38.720 & 37.097 & 1.044 & & & \\
\hline & Huynh-Feldt & 38.720 & 46.559 & .832 & & & \\
\hline & Lower-bound & 38.720 & 14.000 & 2.766 & & & \\
\hline
\end{tabular}




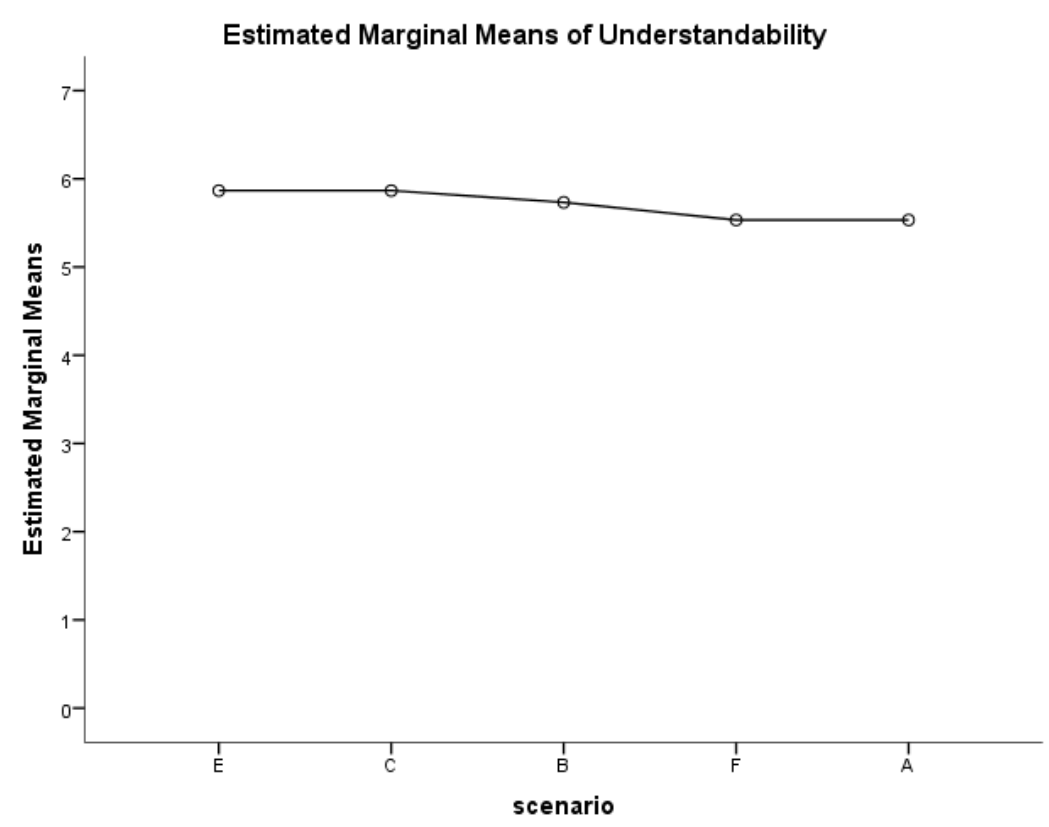

Profile Plots of Participants' Responses towards Understandability among Scenarios

Friedman's Test Statistics

for Understandability

\begin{tabular}{|l|r|}
\hline N & 15 \\
Chi-Square & 1.219 \\
Df & 4 \\
Asymp. Sig. & .875 \\
\hline
\end{tabular}

The Median Statistics for Understandability Ratings

\begin{tabular}{|c|c|c|c|c|c|c|}
\hline & & ScenarioA_Q7 & ScenarioB_Q7 & ScenarioC_Q7 & ScenarioE_Q7 & ScenarioF_Q7 \\
\hline \multirow{2}{*}{$N$} & Valid & 15 & 15 & 15 & 15 & 15 \\
\hline & Missing & 510 & 510 & 510 & 510 & 510 \\
\hline Median & & 6.00 & 6.00 & 6.00 & 6.00 & 6.00 \\
\hline
\end{tabular}


Relaxation

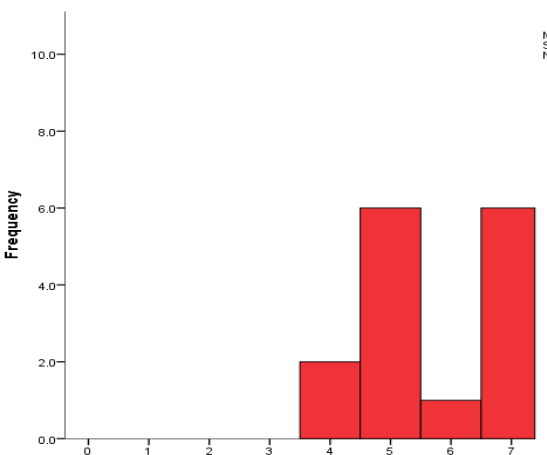

Relaxation (Scenario A)

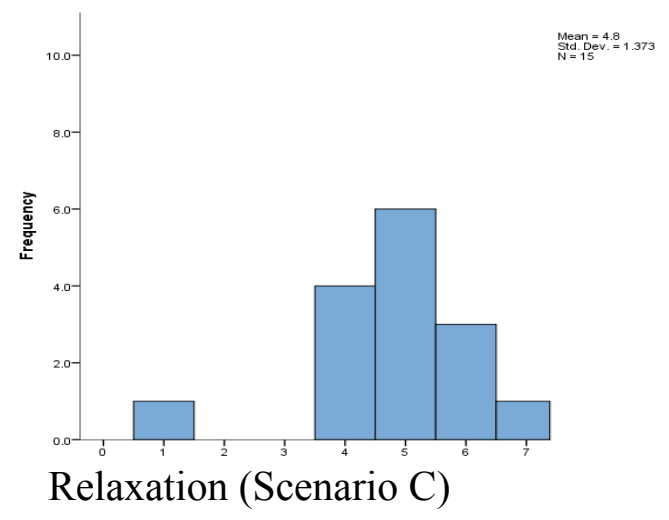

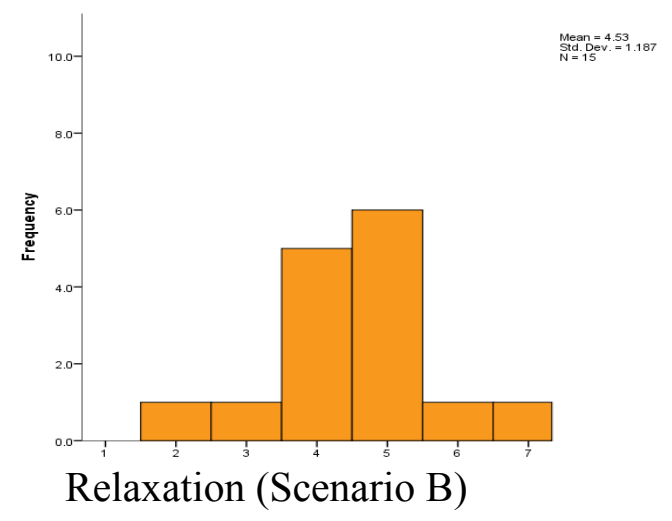

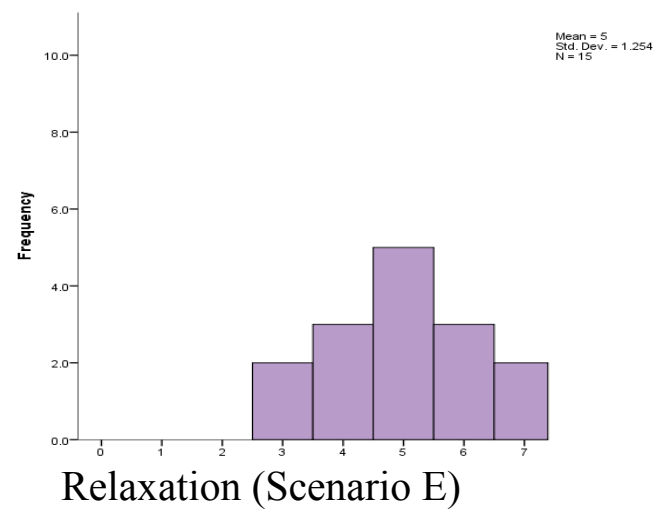

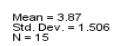

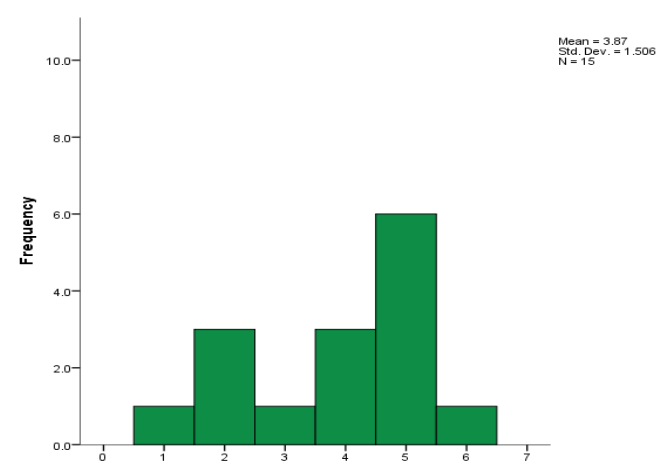

Relaxation (Scenario F)

Histogram for Participants' Responses of Relaxation $(1=$ strongly disagree, $2=$ disagree, $3=$ somewhat disagree, 4 = undecided, $5=$ somewhat agree, $6=$ agree, $7=$ strongly agree) 
Descriptive Statistics for Participants' Responses of Relaxation

\begin{tabular}{|c|c|c|c|c|c|c|c|c|c|}
\hline & $\mathrm{N}$ & Minimum & Maximum & Mean & Std. Deviation & \multicolumn{2}{|c|}{ Skewness } & \multicolumn{2}{|c|}{ Kurtosis } \\
\hline & Statistic & Statistic & Statistic & Statistic & Statistic & Statistic & Std. Error & Statistic & Std. Error \\
\hline ScenarioA_Q8 & 15 & 4 & 7 & 5.73 & 1.163 & -.030 & .580 & -1.652 & 1.121 \\
\hline ScenarioB_Q8 & 15 & 2 & 7 & 4.53 & 1.187 & -.091 & .580 & 1.156 & 1.121 \\
\hline ScenarioC_Q8 & 15 & 1 & 7 & 4.80 & 1.373 & -1.306 & .580 & 3.642 & 1.121 \\
\hline ScenarioE_Q8 & 15 & 3 & 7 & 5.00 & 1.254 & .000 & .580 & -.654 & 1.121 \\
\hline ScenarioF_Q8 & 15 & 1 & 6 & 3.87 & 1.506 & -.610 & .580 & -.879 & 1.121 \\
\hline Valid N & 15 & & & & & & & & \\
\hline (listwise) & & & & & & & & & \\
\hline
\end{tabular}

Tests of Within-Subjects Effects for Relaxation

\begin{tabular}{|c|c|c|c|c|c|c|c|}
\hline \multicolumn{2}{|l|}{ Source } & $\begin{array}{l}\text { Type III } \\
\text { Sum of } \\
\text { Squares }\end{array}$ & df & $\begin{array}{l}\text { Mean } \\
\text { Square }\end{array}$ & $\mathrm{F}$ & Sig. & $\begin{array}{c}\text { Partial Eta } \\
\text { Squared }\end{array}$ \\
\hline \multirow{4}{*}{ scenario } & Sphericity Assumed & 27.787 & 4 & 6.947 & 4.512 & .003 & .244 \\
\hline & Greenhouse-Geisser & 27.787 & 2.649 & 10.491 & 4.512 & .011 & .244 \\
\hline & Huynh-Feldt & 27.787 & 3.324 & 8.360 & 4.512 & .006 & .244 \\
\hline & Lower-bound & 27.787 & 1.000 & 27.787 & 4.512 & .052 & .244 \\
\hline \multirow{4}{*}{ Error(scenario) } & Sphericity Assumed & 86.213 & 56 & 1.540 & & & \\
\hline & Greenhouse-Geisser & 86.213 & 37.081 & 2.325 & & & \\
\hline & Huynh-Feldt & 86.213 & 46.533 & 1.853 & & & \\
\hline & Lower-bound & 86.213 & 14.000 & 6.158 & & & \\
\hline
\end{tabular}




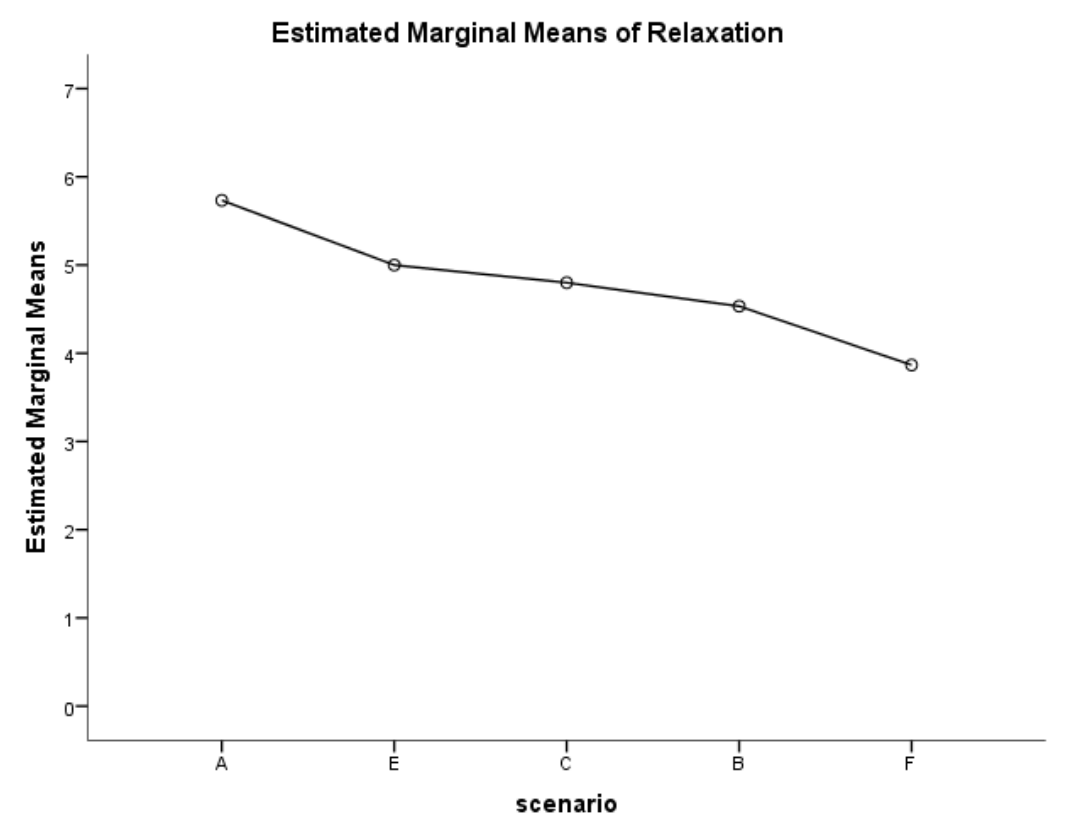

Profile Plots of Participants' Responses towards Relaxation among Scenarios

Friedman's Test Statistics for Relaxation

\begin{tabular}{|l|r|}
\hline $\mathrm{N}$ & 15 \\
Chi-Square & 11.631 \\
$\mathrm{df}$ & 4 \\
Asymp. Sig. & .020 \\
\hline
\end{tabular}

The Median Statistics for Relaxation Ratings

\begin{tabular}{|c|c|c|c|c|c|c|}
\hline & & ScenarioA_Q8 & ScenarioB_Q8 & ScenarioC_Q8 & ScenarioE_Q8 & ScenarioF_Q8 \\
\hline \multirow{2}{*}{$N$} & Valid & 15 & 15 & 15 & 15 & 15 \\
\hline & Missing & 510 & 510 & 510 & 510 & 510 \\
\hline \multicolumn{2}{|c|}{ Median } & 5.00 & 5.00 & 5.00 & 5.00 & 4.00 \\
\hline
\end{tabular}




\section{Appendix J: Detailed Sub-Hypotheses for $\mathbf{H 2}$}

Sub-Hypotheses Related to Enjoyment Effect among Scenarios

\begin{tabular}{|c|c|c|}
\hline \multicolumn{2}{|r|}{ Hypotheses } & \multirow{6}{*}{$\begin{array}{l}\text { (T = teacher; } \\
\mathrm{S}=\text { student; } \\
\text { Pro = projection display; } \\
\text { PC = personal computer; } \\
\text { OHMD = optical head-mounted } \\
\text { display) } \\
\text { (a) Keep T-control unchanged, } \\
\text { but changing S's device, examine } \\
\text { enjoyment effect. } \\
\text { (b) Keep S's device unchanged, } \\
\text { but changing controller, examine } \\
\text { enjoyment effect. }\end{array}$} \\
\hline $\mathrm{H} 2.1(\mathrm{a})_{0}$ & $\begin{array}{l}\text { There will be no significant effect on enjoyment } \\
\text { rating between scenarios "T + Pro" and "T + } \\
\text { OHMD". }\end{array}$ & \\
\hline $\mathrm{H} 2.1(\mathrm{a})_{1}$ & $\begin{array}{l}\text { The enjoyment rating will be significantly } \\
\text { higher in scenario " } \mathrm{T}+\mathrm{OHMD"} \text { than " } \mathrm{T}+ \\
\text { Pro". }\end{array}$ & \\
\hline $\mathrm{H} 2.1(\mathrm{~b})_{0}$ & o.11 h & \\
\hline $\mathrm{H} 2.1(\mathrm{~b})_{1}$ & ly & \\
\hline $\mathrm{H} 2.1(\mathrm{c})_{0}$ & 1 he poimifint on & \\
\hline $\mathrm{H} 2.1(\mathrm{c})_{1}$ & y & $\begin{array}{l}\text { (c) Keep S's device unchanged, } \\
\text { but changing T's tool, examine } \\
\text { enjoyment effect. }\end{array}$ \\
\hline $\mathrm{H} 2$ & $\begin{array}{l}\text { There will be no significant effect on enjoyment } \\
\text { rating among scenario "T + Pro", "(T + Pro })+ \\
(\mathrm{S}+\mathrm{PC}) \text { ", and "(T + Pro })+(\mathrm{S}+\mathrm{OHMD}) \text { ". }\end{array}$ & T's tool unchan \\
\hline $\mathrm{H} 2.1(\mathrm{~d})_{1}$ & $\begin{array}{l}\text { The enjoyment rating will be significantly } \\
\text { higher in scenario "(T + Pro })+(\mathrm{S}+\mathrm{OHMD}) \text { " } \\
\text { than "T + Pro" and "( } \mathrm{T}+\mathrm{Pro})+(\mathrm{S}+\mathrm{PC}) \text { ". }\end{array}$ & \\
\hline
\end{tabular}

Sub-Hypotheses Related to Ability to Focus Effect among Scenarios

\begin{tabular}{|c|c|c|}
\hline \multicolumn{2}{|r|}{ Hypotheses } & \multirow{3}{*}{\begin{tabular}{l}
\multicolumn{1}{c}{ Description } \\
$(\mathrm{T}=$ teacher; \\
$\mathrm{S}=$ student; \\
Pro = projection display; \\
$\mathrm{PC}=$ personal computer; \\
$\mathrm{OHMD}=$ optical head-mounted \\
display)
\end{tabular}} \\
\hline $\mathrm{H} 2.2(\mathrm{a})_{0}$ & $\begin{array}{l}\text { There will be no significant effect on ability to } \\
\text { focus rating between scenarios " } \mathrm{T}+\text { Pro" and "T } \\
\text { + OHMD". }\end{array}$ & \\
\hline $\mathrm{H} 2.2(\mathrm{a})_{1}$ & $\begin{array}{l}\text { The ability to focus rating will be significantly } \\
\text { higher in scenario "T + OHMD" than "T + Pro". }\end{array}$ & \\
\hline $\mathrm{H} 2.2(\mathrm{~b})_{0}$ & $\begin{array}{l}\text { There will be no significant effect on ability to } \\
\text { focus rating between scenarios " } \mathrm{T}+\mathrm{OHMD} \text { " } \\
\text { and "S + OHMD". }\end{array}$ & \multirow{3}{*}{$\begin{array}{l}\text { (a) Keep T-control unchanged, } \\
\text { but changing S's device, } \\
\text { examine ability to focus effect. } \\
\text { (b) Keep S's device unchanged, } \\
\text { but changing controller, examine }\end{array}$} \\
\hline $\mathrm{H} 2.2(\mathrm{~b})_{1}$ & $\begin{array}{l}\text { The ability to focus rating will be significantly } \\
\text { higher in scenario "S + OHMD" than "T + } \\
\text { OHMD". }\end{array}$ & \\
\hline $\mathrm{H} 2.2(\mathrm{c})_{0}$ & $\begin{array}{l}\text { There will be no significant effect on ability to } \\
\text { focus rating between scenario "S }+ \text { OHMD" and }\end{array}$ & \\
\hline
\end{tabular}




\begin{tabular}{|c|c|c|}
\hline & "(S + OHMD $)+(\mathrm{T}+$ Pro $) "$. & \multirow{4}{*}{$\begin{array}{l}\text { ability to focus effect. } \\
\text { (c) Keep S's device unchanged, } \\
\text { but changing T's tool, examine } \\
\text { ability to focus effect. } \\
\text { (d) Keep T's tool unchanged, but } \\
\text { changing S's device, examine } \\
\text { ability to focus effect. }\end{array}$} \\
\hline $\mathrm{H} 2.2(\mathrm{c})_{1}$ & $\begin{array}{l}\text { The ability to focus rating will be significantly } \\
\text { higher in scenario "S + OHMD" than "(S + } \\
\text { OHMD) + (T + Pro)". }\end{array}$ & \\
\hline $\mathrm{H} 2.2(\mathrm{~d})_{0}$ & $\begin{array}{l}\text { There will be no significant effect on ability to } \\
\text { focus rating among scenario "T + Pro", "(T + } \\
\text { Pro })+(\mathrm{S}+\mathrm{PC}) \text { ", and "( }+ \text { Pro })+(\mathrm{S}+ \\
\text { OHMD)". }\end{array}$ & \\
\hline $\mathrm{H} 2.2(\mathrm{~d})_{1}$ & $\begin{array}{l}\text { The ability to focus rating will be significantly } \\
\text { higher in scenario "T + Pro" than "(T + Pro ) + (S } \\
\text { + OHMD)" and "(T + Pro }+(\mathrm{S}+\mathrm{PC}) \text { ". }\end{array}$ & \\
\hline
\end{tabular}

Sub-Hypotheses Related to Motivation Effect among Scenarios

\begin{tabular}{|c|c|c|}
\hline \multicolumn{2}{|r|}{ Hypotheses } & \multirow{3}{*}{\begin{tabular}{l}
\multicolumn{1}{c}{ Description } \\
$(\mathrm{T}=$ teacher; \\
$\mathrm{S}=$ student; \\
Pro = projection display; \\
$\mathrm{PC}=$ personal computer; \\
$\mathrm{OHMD}=$ optical head-mounted \\
display)
\end{tabular}} \\
\hline $\mathrm{H} 2.3(\mathrm{a})_{0}$ & $\begin{array}{l}\text { There will be no significant effect on motivation } \\
\text { rating between scenarios " } \mathrm{T}+\text { Pro" and "T }+ \\
\text { OHMD". }\end{array}$ & \\
\hline $\mathrm{H} 2.3(\mathrm{a})_{1}$ & $\begin{array}{l}\text { The motivation rating will be significantly higher } \\
\text { in scenario "T + OHMD" than "T + Pro". }\end{array}$ & \\
\hline $\mathrm{H} 2.3(\mathrm{~b})_{0}$ & $\begin{array}{l}\text { There will be no significant effect on motivation } \\
\text { rating between scenarios " } \mathrm{T}+\mathrm{OHMD} \text { " and " } \mathrm{S}+ \\
\text { OHMD". }\end{array}$ & $\begin{array}{l}\text { display) } \\
\text { (a) Keep T-control unchanged, }\end{array}$ \\
\hline $\mathrm{H} 2.3(\mathrm{~b})_{1}$ & $\begin{array}{l}\text { The motivation rating will be significantly higher } \\
\text { in scenario "S + OHMD" than "T + OHMD". }\end{array}$ & $\begin{array}{l}\text { but changing S's device, } \\
\text { examine motivation effect. }\end{array}$ \\
\hline $\mathrm{H} 2.3(\mathrm{c})_{0}$ & $\begin{array}{l}\text { There will be no significant effect on motivation } \\
\text { rating between scenario "S + OHMD" and "(S + } \\
\text { OHMD) + (T + Pro)". }\end{array}$ & $\begin{array}{l}\text { (b) Keep S's device unchanged, } \\
\text { but changing controller, examine }\end{array}$ \\
\hline $\mathrm{H} 2.3(\mathrm{c})_{1}$ & $\begin{array}{l}\text { The motivation rating will be significantly higher } \\
\text { in scenario "S + OHMD" than "(S + OHMD })+ \\
\text { ( } \mathrm{T}+\text { Pro)". }\end{array}$ & $\begin{array}{l}\text { motivation effect. } \\
\text { (c) Keep S's device unchanged, }\end{array}$ \\
\hline $\mathrm{H} 2.3(\mathrm{~d})_{0}$ & $\begin{array}{l}\text { There will be no significant effect on motivation } \\
\text { rating among scenario " } \mathrm{T}+\mathrm{Pro} \text { ", "(T + Pro }+(\mathrm{S} \\
+\mathrm{PC}) \text { ", and "( } \mathrm{T}+\mathrm{Pro})+(\mathrm{S}+\mathrm{OHMD}) \text { ". }\end{array}$ & $\begin{array}{l}\text { but changing T's tool, examine } \\
\text { motivation effect. }\end{array}$ \\
\hline $\mathrm{H} 2.3(\mathrm{~d})_{1}$ & $\begin{array}{l}\text { The motivation rating will be significantly higher } \\
\text { in scenario "( } \mathrm{T}+\mathrm{Pro})+(\mathrm{S}+\mathrm{OHMD}) \text { " than " } \mathrm{T}+ \\
\text { Pro" and "( }+ \text { Pro }+(\mathrm{S}+\mathrm{PC}) \text { ". }\end{array}$ & $\begin{array}{l}\text { (d) Keep T's tool unchanged, but } \\
\text { changing S's device, examine } \\
\text { motivation effect. }\end{array}$ \\
\hline
\end{tabular}

Sub-Hypotheses Related to Perceived Efficiency Effect among Scenarios

\begin{tabular}{|l|l|l|}
\hline \multicolumn{2}{|c|}{ Hypotheses } & \multicolumn{1}{|c|}{ Description } \\
\hline H2.4(a) $)_{0}$ & $\begin{array}{l}\text { There will be no significant effect on perceived } \\
\text { efficiency rating between scenarios "T + Pro" }\end{array}$ & $\begin{array}{l}\text { (T = teacher; } \\
\text { S = student; } \\
\text { and "T + OHMD". }\end{array}$ \\
\hline P2.4(a) = projection display; & $\begin{array}{l}\text { The perceived efficiency rating will be } \\
\text { significantly higher in scenario "T + OHMD" }\end{array}$ & $\begin{array}{l}\text { PC = personal computer; } \\
\text { OHMD = optical head-mounted }\end{array}$ \\
\hline
\end{tabular}




\begin{tabular}{|c|c|c|}
\hline & than "T + Pro". & \multirow{7}{*}{$\begin{array}{l}\text { display) } \\
\text { (a) Keep T-control unchanged, } \\
\text { but changing S's device, } \\
\text { examine perceived efficiency } \\
\text { effect. } \\
\text { (b) Keep S's device unchanged, } \\
\text { but changing controller, examine } \\
\text { perceived efficiency effect. }\end{array}$} \\
\hline $\mathrm{H} 2.4(\mathrm{~b})_{0}$ & $\begin{array}{l}\text { There will be no significant effect on perceived } \\
\text { efficiency rating between scenarios "T + OHMD" } \\
\text { and "S + OHMD". }\end{array}$ & \\
\hline $\mathrm{H} 2.4(\mathrm{~b})_{1}$ & $\begin{array}{l}\text { The perceived efficiency rating will be } \\
\text { significantly higher in scenario "S + OHMD" } \\
\text { than "T + OHMD". }\end{array}$ & \\
\hline $\mathrm{H} 2.4(\mathrm{c})_{0}$ & $\begin{array}{l}\text { There will be no significant effect on perceived } \\
\text { efficiency rating between scenario "S + OHMD" } \\
\text { and "(S + OHMD }+(\mathrm{T}+\text { Pro)". }\end{array}$ & \\
\hline $\mathrm{H} 2.4(\mathrm{c})_{1}$ & $\begin{array}{l}\text { The perceived efficiency ra } \\
\text { significantly higher in scen } \\
\text { than "( }+ \text { OHMD })+(T+\end{array}$ & \\
\hline $\mathrm{H} 2.4(\mathrm{~d})_{0}$ & $\begin{array}{l}\text { There will be no significant effect on perceived } \\
\text { efficiency rating among scenario "T + Pro", "( } \\
+ \text { Pro }+(\mathrm{S}+\mathrm{PC}) \text { ", and "( } \mathrm{T}+\mathrm{Pro})+(\mathrm{S}+ \\
\text { OHMD)". }\end{array}$ & \\
\hline $\mathrm{H} 2.4(\mathrm{~d})_{1}$ & $\begin{array}{l}\text { The perceived efficiency rating will be } \\
\text { significantly higher in scenario "(T + Pro })+(\mathrm{S}+ \\
\text { OHMD)" than "T + Pro" and "(T + Pro })+(\mathrm{S}+ \\
\mathrm{PC}) \text { ". }\end{array}$ & \\
\hline
\end{tabular}

Sub-Hypotheses Related to Physical Comfort Effect among Scenarios

\begin{tabular}{|c|c|c|}
\hline & Hypotheses & \multirow{8}{*}{\begin{tabular}{l}
\multicolumn{1}{c}{ Description } \\
(T = teacher; \\
$\mathrm{S}=$ student; \\
Pro = projection display; \\
PC = personal computer; \\
OHMD = optical head-mounted \\
display) \\
(a) Keep T-control unchanged, \\
but changing S's device, \\
examine physical comfort effect. \\
(b) Keep S's device unchanged, \\
but changing controller, examine \\
physical comfort effect. \\
(c) Keep S's device unchanged, \\
but changing T's tool, examine \\
physical comfort effect. \\
(d) Keep T's tool unchanged, but \\
changing S's device, examine
\end{tabular}} \\
\hline $\mathrm{H} 2.5(\mathrm{a})_{0}$ & $\begin{array}{l}\text { There will be no significant effect on physical } \\
\text { comfort rating between scenarios " } \mathrm{T}+\text { Pro" and } \\
\text { "T + OHMD". }\end{array}$ & \\
\hline $\mathrm{H} 2.5(\mathrm{a})_{1}$ & $\begin{array}{l}\text { The physical comfort rating will be significantly } \\
\text { higher in scenario " } \mathrm{T}+\text { Pro" than "T + OHMD". }\end{array}$ & \\
\hline $\mathrm{H} 2.5(\mathrm{~b})_{0}$ & $\begin{array}{l}\text { There will be no significant effect on physical } \\
\text { comfort rating between scenarios " } \mathrm{T}+\mathrm{OHMD} \text { " } \\
\text { and "S + OHMD". }\end{array}$ & \\
\hline $\mathrm{H} 2.5(\mathrm{~b})_{1}$ & $\begin{array}{l}\text { The physical comfort rating will be significantly } \\
\text { higher in scenario "S + OHMD" than "T + } \\
\text { OHMD". }\end{array}$ & \\
\hline $\mathrm{H} 2.5(\mathrm{c})_{0}$ & $\begin{array}{l}\text { There will be no significant effect on physical } \\
\text { comfort rating between scenario "S + OHMD" } \\
\text { and "(S + OHMD }+(\mathrm{T}+\text { Pro)". }\end{array}$ & \\
\hline $\mathrm{H} 2.5(\mathrm{c})_{1}$ & $\begin{array}{l}\text { The physical comfort rating will be significantly } \\
\text { higher in scenario "S + OHMD" than "( }+ \\
\text { OHMD }+(\mathrm{T}+\text { Pro)". }\end{array}$ & \\
\hline $\mathrm{H} 2.5(\mathrm{~d})_{0}$ & $\begin{array}{l}\text { There will be no significant effect on physical } \\
\text { comfort rating among scenario "T }+ \text { Pro", "(T + } \\
\text { Pro }+(\mathrm{S}+\mathrm{PC}) \text { ", and "(T + Pro })+(\mathrm{S}+ \\
\text { OHMD)". }\end{array}$ & \\
\hline
\end{tabular}




\begin{tabular}{|l|l|l|}
\hline $\mathrm{H} 2.5(\mathrm{~d})_{1}$ & $\begin{array}{l}\text { The physical comfort rating will be significantly } \\
\text { higher in scenario "T + Pro" than "(T + Pro })+(\mathrm{S} \\
\text { + OHMD)" and "(T + Pro })+(\mathrm{S}+\mathrm{PC}) \text { ". }\end{array}$ & physical comfort effect. \\
\hline
\end{tabular}

Sub-Hypotheses Related to Understandability Effect among Scenarios

\begin{tabular}{|c|c|c|}
\hline \multicolumn{2}{|r|}{ Hypotheses } & \multirow{3}{*}{\begin{tabular}{l}
\multicolumn{1}{c}{ Description } \\
$(\mathrm{T}=$ teacher; \\
$\mathrm{S}=$ student; \\
Pro = projection display; \\
$\mathrm{PC}=$ personal computer; \\
OHMD = optical head-mounted \\
display)
\end{tabular}} \\
\hline $\mathrm{H} 2.6(\mathrm{a})_{0}$ & $\begin{array}{l}\text { There will be no significant effect on } \\
\text { understandability rating between scenarios " } \mathrm{T}+ \\
\text { Pro" and "T + OHMD". }\end{array}$ & \\
\hline $\mathrm{H} 2.6(\mathrm{a})_{1}$ & $\begin{array}{l}\text { The understandability rating will be significantly } \\
\text { higher in scenario "T + OHMD" than "T + Pro". }\end{array}$ & \\
\hline $\mathrm{H} 2.6(\mathrm{~b})_{0}$ & $\begin{array}{l}\text { There will be no significant effect on } \\
\text { understandability rating between scenarios "T + } \\
\text { OHMD" and "S + OHMD". }\end{array}$ & $\begin{array}{l}\text { display) } \\
\text { (a) Keep T-control unchanged, }\end{array}$ \\
\hline $\mathrm{H} 2.6(\mathrm{~b})_{1}$ & $\begin{array}{l}\text { The understandability rating will be significantly } \\
\text { higher in scenario "T + OHMD" than " } \mathrm{S}+ \\
\text { OHMD". }\end{array}$ & $\begin{array}{l}\text { but changing S's device, } \\
\text { examine understandability } \\
\text { effect. }\end{array}$ \\
\hline $\mathrm{H} 2.6(\mathrm{c})_{0}$ & $\begin{array}{l}\text { There will be no significant effect on } \\
\text { understandability rating between scenario "S + } \\
\text { OHMD" and "(S + OHMD) + (T + Pro)". }\end{array}$ & $\begin{array}{l}\text { (b) Keep S's device unchanged, } \\
\text { but changing controller, examine }\end{array}$ \\
\hline $\mathrm{H} 2.6(\mathrm{c})_{1}$ & $\begin{array}{l}\text { The understandability rating will be significantly } \\
\text { higher in scenario "S + OHMD" than "(S + } \\
\text { OHMD) + (T + Pro)". }\end{array}$ & $\begin{array}{l}\text { understandability effect. } \\
\text { (c) Keep S's device unchanged, }\end{array}$ \\
\hline $\mathrm{H} 2.6(\mathrm{~d})_{0}$ & $\begin{array}{l}\text { There will be no significant effect on } \\
\text { understandability rating among scenario "T + } \\
\text { Pro", "(T + Pro })+(\mathrm{S}+\mathrm{PC}) \text { ", and " }(\mathrm{T}+\mathrm{Pro})+(\mathrm{S} \\
+ \text { OHMD)". }\end{array}$ & $\begin{array}{l}\text { but changing T's tool, examine } \\
\text { understandability effect. } \\
\text { (d) Keep T's tool unchanged, but }\end{array}$ \\
\hline $\mathrm{H} 2.6(\mathrm{~d})_{1}$ & $\begin{array}{l}\text { The understandability rating will be significantly } \\
\text { higher in scenario "(T + Pro }+(\mathrm{S}+\text { OHMD }) \text { " } \\
\text { than "T + Pro" and "( }+ \text { + Pro }+(\mathrm{S}+\mathrm{PC}) \text { ". }\end{array}$ & $\begin{array}{l}\text { changing S's device, examine } \\
\text { understandability effect. }\end{array}$ \\
\hline
\end{tabular}

Sub-Hypotheses Related to Relaxation Effect among Scenarios

\begin{tabular}{|c|c|c|}
\hline \multicolumn{2}{|r|}{ Hypotheses } & \multirow{3}{*}{\begin{tabular}{l}
\multicolumn{1}{c}{ Description } \\
$(\mathrm{T}=$ teacher; \\
$\mathrm{S}=$ student; \\
Pro = projection display; \\
$\mathrm{PC}=$ personal computer; \\
$\mathrm{OHMD}=$ optical head-mounted \\
display)
\end{tabular}} \\
\hline $\mathrm{H} 2.7(\mathrm{a})_{0}$ & $\begin{array}{l}\text { There will be no significant effect on Relaxation } \\
\text { rating between scenarios "T }+ \text { Pro" and " } \mathrm{T}+ \\
\text { OHMD". }\end{array}$ & \\
\hline $\mathrm{H} 2.7(\mathrm{a})_{1}$ & $\begin{array}{l}\text { The relaxation rating will be significantly higher } \\
\text { in scenario " } \mathrm{T}+\text { Pro" than " } \mathrm{T}+\mathrm{OHMD} \text { ". }\end{array}$ & \\
\hline $\mathrm{H} 2.7(\mathrm{~b})_{0}$ & $\begin{array}{l}\text { There will be no significant effect on relaxation } \\
\text { rating between scenarios "T + OHMD" and "S }+ \\
\text { OHMD". }\end{array}$ & \multirow{2}{*}{$\begin{array}{l}\text { (a) Keep T-control unchanged, } \\
\text { but changing S's device, } \\
\text { examine relaxation effect. }\end{array}$} \\
\hline $\mathrm{H} 2.7(\mathrm{~b})_{1}$ & $\begin{array}{l}\text { The relaxation rating will be significantly higher } \\
\text { in scenario "S + OHMD" than " } \mathrm{T}+\mathrm{OHMD"}\end{array}$ & \\
\hline
\end{tabular}




\begin{tabular}{|c|c|c|}
\hline 2.7 & io "S + OHMD" and "( $\mathrm{S}+$ & \multirow{4}{*}{$\begin{array}{l}\text { (b) Keep S's device unchanged, } \\
\text { but changing controller, examine } \\
\text { relaxation effect. } \\
\text { (c) Keep S's device unchanged, } \\
\text { but changing T's tool, examine } \\
\text { relaxation effect. } \\
\text { (d) Keep T's tool unchanged, but } \\
\text { changing S's device, examine } \\
\text { relaxation effect. }\end{array}$} \\
\hline $\mathrm{H} 2.7$ & & \\
\hline $\mathrm{H} 2.7($ & & \\
\hline $\mathrm{H} 2.7(\mathrm{c}$ & & \\
\hline
\end{tabular}




\section{References}

[1] A surgeons review of google glass in the operating room: 2013. http://www.fastcompany.com/3022534/internet-of-things/a- surgeons-review-of-googleglass-in-the-operating-room/.

[2] Ahmed, S. and Parsons, D. 2013. Abductive science inquiry using mobile devices in the classroom. Computers \& Education. 63, 4, 62-72.

[3] Amft, O. and Lukowicz, P. 2009. From Backpacks to Smartphones : Past, Present, and Future of Wearable Computers. IEEE Pervasive Computing. 8, 3 , 8-13.

[4] Aragon, C.R. 2005. Improving Aviation Safety with Information Visualization : A Flight Simulation Study. , 441-450.

[5] Axholt, M. and Ellis, S.R. 2008. User Boresight Calibration Precision for Large-Format Head-Up Displays. VRST '08: Proceedings of the 2008 ACM symposium on Virtual reality software and technology, 141-148.

[6] Bachman, K.M. and Gannod, G.C. 2012. Work in Progress: The Effects of Mobile Learning on Inquiry-Based Instruction. Frontiers in Education Conference (FIE), 2012, $1-2$.

[7] Bergig, O., Hagbi, N., EI-Sana, J. and Billinghurst, M. 2009. In-Place 3D Sketching for Authoring and Augmenting Mechanical Systems. 8th IEEE International Symposium on Mixed and Augmented Reality, 87 - 94.

[8] Bitner, N. and Bitner, J. 2002. Integrating technology into the classroom: Eight keys to success. Journal of Technology and Teacher Education. 10, 1, 95 - 100.

[9] Bodén, M., Dekker, A., Viller, S. and Matthews, B. 2013. Augmenting play and learning in the primary classroom. Proceedings of the 12th International Conference on Interaction Design and Children - IDC '13 (New York, New York, USA), 228-236.

[10] Boulos, M.N.K., Hetherington, L. and Wheeler, S. 2007. Second Life: an overview of the potential of 3-D virtual worlds in medical and health education. Health information and libraries journal. 24, 4, 233-45.

[11] Bronack, S.C. 2009. The Role of Immersive Media in Online Education. 2nd IEEE International Conference on Computer Science and Information Technology, , 73-78.

[12] Broun, C.C. and Campbell, W.M. 2001. Force XXI Land Warrior: A Systems Approach to Speech Recognition. 2001 IEEE International Conference on Acoustics, Speech, and Signal Processing, , 973-976. 
[13] Buergy, C. and Seitz, J. 2013. The Bumpy Road of Bringing Wearable Augmented Reality Systems to Market. UbiComp '13 Adjunct: Proceedings of the 2013 ACM conference on Pervasive and ubiquitous computing adjunct publication (New York, New York, USA), 1483-1486.

[14] Chan, M., Estève, D., Fourniols, J.-Y., Escriba, C. and Campo, E. 2012. Smart wearable systems: Current status and future challenges. Artificial intelligence in medicine. 56, 3 , $137-156$.

[15] Chen, C.-C. and Huang, T.-C. 2012. Learning in a u-Museum: Developing a contextaware ubiquitous learning environment. Computers \& Education. November, 59(3) , 873883.

[16] Chen, C.-M., Yi-Yun, C. and Liu, C.-Y. 2007. Learning Performance Assessment Approach using Web-Based Learning Portfolios for E-Learning Systems. IEEE Journals \& Magazines. 37, 6, 1349-1359.

[17] Chi, H.-L., Kang, S.-C. and Wang, X. 2013. Research trends and opportunities of augmented reality applications in architecture, engineering, and construction. Automation in Construction. 33, , 116-122.

[18] Christian, W., Smarkola, C. and Gaffney, M.A. 2008. Ubiquitous laptop usage in higher education: Effects on student achievement, student satisfaction, and constructivist measures in honors and traditional classrooms. Computers \& Education. 51, 4, $1766-$ 1783.

[19] Cleveland, G. and Mcninch, L. 1999. Force XXI Land Warrior: Implementing Spoken Commands for Soldier Wearable Systems. The Third International Symposium on Wearable Computers, 183-184.

[20] Crawford, K. 2004. E'Learning and Activity: Supporting Communication, Cooperation and Coinvention. The 2nd IEEE International Workshop on Wireless and Mobile Technologies in Education, 2004. Proceedings.134-138.

[21] Curran, C.R., Elfrink, V. and Mays, B. 2009. Building a virtual community for nursing education: the town of Mirror Lake. The Journal of nursing education. 48, 1, 30-5.

[22] Doctor wearing Google Glass Live Streams Surgery: 2013. http://mashable.com/2013/08/30/google-glass-surgery-live-stream/.

[23] Doshi, A., Cheng, S.Y. and Trivedi, M.M. 2009. A novel active heads-up display for driver assistance. IEEE transactions on systems, man, and cybernetics Society. 39, 1, 8593. 
[24] Dunleavy, M., Dede, C. and Mitchell, R. 2009. Affordances and Limitations of Immersive Participatory Augmented Reality Simulations for Teaching and Learning. Journal of Science Education and Technology. 18, 1, 7-22.

[25] Fabry, D.L. and Higgs, J.R. 1997. Barriers to the effective use of technology in education: Current status. Educational Computing Researc. 17, 4 , 385 - 395.

[26] Facer, K., Joiner, R., Stanton, D., Reid, J., Hull, R. and Kirk, D. 2004. Savannah: mobile gaming and learning? Journal of Computer Assisted Learning. 20, 6 , 399-409.

[27] Faria, S., Weston, T. and Cepeda, N.J. 2013. Laptop multitasking hinders classroom learning for both users and nearby peers. Computers \& Education. 62, 2 , $24-31$.

[28] Feiner, S., Macintyre, B., Höllerer, T. and Webster, A. 1997. A Touring Machine: Prototyping 3D Mobile Augmented Reality Systems for Exploring the Urban Environment. First International Symposium on Wearable Computers, 74-81.

[29] Finger, S., Terk, M., Subrahmanian, E., Kasabach, C., Prinz, F., Siewiorek, D.P., Smailagic, A., Stivoric, J. and Weiss, L. 1996. Rapid Design and Manufacture of Wearable Computers. 39, 2 , 63-70.

[30] Furlan, R. 2013. This Wearable Computer Augments the Self, not Reality. IEEE Spectrum.

[31] H1 Headset Computer: 2013. http://www.motorolasolutions.com/USEN/Business + Product + and + Services/Mobile + Computers/Wearable + Computers/HC1? W T.mc_id=HCl.

[32] Ha, K., Chen, Z., Hu, W., Richter, W., Pillai, P. and Satyanarayanan, M. 2014. Towards wearable cognitive assistance. Proceedings of the 12th annual international conference on Mobile systems, applications, and services - MobiSys '14 (New York, New York, USA), 68-81.

[33] Head-up display: 2013. http://en.wikipedia.org/wiki/Head-up_display.

[34] Horizon Report Wiki - Wearable Technology: 2014. http://horizon.wiki.nmc.org/Wearable+Technology. Accessed: 2014-07-25.

[35] Hornecker, E. and Dünser, A. 2009. Of pages and paddles: Children's expectations and mistaken interactions with physical- digital tools. Interacting with Computers. 21, 1-2, 95-107.

[36] Imagining the Classroom of 2016, Empowered by Wearable Technology: 2014. http://www.emergingedtech.com/2014/04/imaging-the-classroom-of-2016-empowered-bywearable-technology/. Accessed: 2014-07-24. 
[37] Introduce the next generation: Moverio BT-200: 2014. http://www.epson.com/cgibin/Store/jsp/Landing/moverio-bt-200-smart-glasses.do?ref=van_moverio.

[38] Is Google Glass suitable for schools? 2013. http://www.zdnet.com/is-google-glasssuitable-for-schools-7000019634/. Accessed: 2014-07-25.

[39] Is google Glass Useful in the Operating Room? 2013. http://blog.al.com/spotnews/2013/10/uab_surgeon_performs_surgery_u.html.

[40] Ishizaki, A., Ikegami, S., Yamabe, T., Kitagami, S. and Kiyohara, R. 2014. Accelerometer-based HUD Input for Car Navigation. 2014 IEEE International Conference on Consumer Electronics (ICCE) , 278-279.

[41] Khalifa, M. and Lam, R. 2002. Web-Based Learning: Effects on Learning Process and Outcome. IEEE Transactions on Education. 45, 4 (2002), 350-356.

[42] Klopfer, E. and Squire, K. 2008. Environmental Detectives: The Development of an Augmented reality Platform for Environmental Simulations. Educational Technology Research and Development. 56, 2, 203-228.

[43] Lewis, S.A., Havey, G.D. and Hanzal, B. 1998. Handheld and Bodyworn Graphical Displays. Second International Symposium on Wearable Computers, 1998. Digest of Papers., 102-107.

[44] Lin, M.-F., Fulford, C.P., Ho, C.P., Iyoda, R. and Ackerman, L.K. 2012. Possibilities and Challenges in Mobile Learning for K-12 Teachers: A Pilot Retrospetive Survey Study. 2012 IEEE Seventh International Conference on Wireless, Mobile and Ubiquitous Technology in Education (WMUTE)., 132-136.

[45] Liverani, a., Amati, G. and Caligiana, G. 2004. A CAD-augmented Reality Integrated Environment for Assembly Sequence Check and Interactive Validation. Concurrent Engineering. 12, 1, 67-77.

[46] Lopez, J., Martin, S., Castro, M. and Meier, R. 2012. Web-based platform for the Information and Communications Technology (ICT) research in engineering education. 2012 IEEE Global Engineering Education Conference (EDUCON)., 1-6.

[47] M100 Smart Glass: 2013. http://www.vuzix.com/consumer/products_m100/.

[48] Marth, R.B., Durboraw, I.N., Levi, R. and Beam, K. 1998. The Integrated Navigation Capability for the Force XXI Land Warrior Author. IEEE 1998 Position Location and Navigation Symposium, 193-200.

[49] Marzano, R., Pickering, D. and Heflebower, T. 2010. The Highly Engaged Classroom. Marzano Research Laboratory. 
[50] Maurer, U., Rowe, A., Smailagic, A. and Siewiorek, D.P. 2006. eWatch: A Wearable Sensor and Notification Platform. International Workshop on Wearable and Implantable Body Sensor Networks (BSN'06), 142-145.

[51] McCoy, B.R. 2013. Digital Distractions in the Classroom: Student Classroom Use of Digital Devices for Non-Class Related Purposes. Media Education. 10.

[52] McNaney, R., Vines, J., Roggen, D., Balaam, M., Zhang, P., Poliakov, I. and Olivier, P. 2014. Exploring the Acceptability of Google Glass as an Everyday Assistive Device for People with Parkinson's. CHI '14: Proceedings of the SIGCHI Conference on Human Factors in Computing Systems (New York, New York, USA), 2551-2554.

[53] McPherson, S. 2009. A Dance with the Butterflies: A Metamorphosis of Teaching and Learning Through Technology. Early Childhood Education Journal. 37, 3, 229-236.

[54] Mills, N. 2011. Situated Learning through Social Networking Communities: The Development of Joint Enterprise, Mutual Engagement, and a Shared Repertoire. CALICO Journal. 28, 2, 345.

[55] Muensterer, O.J., Lacher, M., Zoeller, C., Bronstein, M. and Kübler, J. 2014. Google Glass in pediatric surgery: An exploratory study. International journal of surgery (London, England). 12, 4, 281-289.

[56] Nakasugi, H. and Yamauchi, Y. 2002. Past Viewer: Development of Wearable Learning System for History Education. International Conference on Computers in Education, 2002. Proceedings., 1311-1312.

[57] Narayanaswami, C. and Raghunath, M.T. 2000. Application design for a smart watch with a high resolution display. Digest of Papers. Fourth International Symposium on Wearable Computers., 7-14.

[58] Ngai, G., Chan, S.C.F., Cheung, J.C.Y. and Lau, W.W.Y. 2010. Deploying a Wearable Compuyting Platform for Computing Education. IEEE Transactions on Learning Technologies Learning Technologies. 3, 1, 45-55.

[59] Nguyen, E., Modak, T., Dias, E., Yu, Y. and Huang, L. 2014. Fitnamo: Using BodyData to Encourage Exercise through Google Glass ${ }^{\text {TM }}$. Proceeding CHI EA '14 CHI '14 Extended Abstracts on Human Factors in Computing Systems, 239-244.

[60] Okojie, M.C.P.O. and Olinzock, A. 2006. Developing a Positive Mind-Set toward the Use of Technology for Classroom Instruction. International Journal of Instructional Media. 33, 1,33 .

[61] Ong, S.K. and Wang, Z.B. 2011. Augmented assembly technologies based on 3D barehand interaction. CIRP Annals - Manufacturing Technology. 60, 1, 1-4. 
[62] Optical head-mounted display: 2013. http://en.wikipedia.org/wiki/Optical_headmounted_display.

[63] Osawa, N. and Asai, K. 2006. A wearable learning support system with a head-mounted display and a foot-mounted RFID reader. ITHET '06. 7th International Conference on Information Technology Based Higher Education and Training, 523-530.

[64] Owen, C.B., Zhou, J., Tang, A. and Xiao, F. 2004. Display-Relative Calibration for Optical See-Through Head-Mounted Displays. ISMAR '04: Proceedings of the 3rd IEEE/ACM International Symposium on Mixed and Augmented Reality.

[65] Park, S.W. 2013. The Potential of Web 2.0 Tools to Promote Reading Engagement in a General Education Course. TechTrends. 57, 2, 46-53.

[66] Pedersen, I. 2014. Are Wearables Really Ready to Wear? IEEE Technology and Society Magazine. 33, 2, 16-18.

[67] Pedersen, I. and Trueman, D. 2013. "Sergey Brin is Batman ": Google 's Project Glass \& the Instigation of Computer Adoption in Popular Culture. CHI EA '13: CHI '13 Extended Abstracts on Human Factors in Computing Systems, 2089-2097.

[68] Post, E.R. and Orth, M. 1997. Smart fabric, or "wearable clothing." Digest of Papers. First International Symposium on Wearable Computers, 167-168.

[69] Roggen, D., Perez, D.G., Fukumoto, M. and van Laerhoven, K. 2014. ISWC 2013-Wearables Are Here to Stay. IEEE Pervasive Computing. 13, 1, 14-18.

[70] Rosenberg, M.J. 2000. E-Learning: Strategies for Delivering Knowledge in the Digital Age. McGraw-Hill.

[71] Rossett, A. 2001. The ASTD e-Learning Handbook: Best Practices, Strategies, and Case Studies for an Emerging Field. McGraw-Hill.

[72] Sayed, N.A.M. El, Zayed, H.H. and Sharawy, M.I. 2011. ARSC: Augmented Reality Student Card - An Augmented Reality Solution for the Education Field. Computers \& Education. 56, 4, 1045-1061.

[73] Schiele, B., Jebara, T. and Oliver, N. 2001. Sensory-augmented computing: wearing the museum's guide. IEEE Journals \& Magazines. 21, 3, 44-52.

[74] Shelton, B.E. and Hedley, N.R. 2002. Using Augmented Reality for Teaching Earth-Sun Relationships to Undergraduate Geography Students. Toolkit, The First IEEE International Workshop, 1-14.

[75] Shen, Y., Ong, S.K. and Nee, a. Y.C. 2010. Augmented reality for collaborative product design and development. Design Studies. 31, 2, 118-145. 
[76] Shin, K. and Downing, K. 2011. User Centred e-Learning Platform Design. DPPI '11 Proceedings of the 2011 Conference on Designing Pleasurable Products and Interfaces.

[77] Sony Develops See-through Eyeglass Display for High-luminance Full-color Video Images: 2008. http://techon.nikkeibp.co.jp/english/NEWS_EN/20080523/152287/.

[78] Soros, G., Daiber, F. and Weller, T. 2013. Cyclo - A Personal Bike Coach Through the Glass. Proceeding SA'13 SIGGRAPH Asia 2013 Symposium on Mobile Graphics and Interactive Applications, 3-6.

[79] Spitzer, M.B., Rensing, N.M., McClelland, R. and Aquilino, P. 1997. Eyeglass-based systems for wearable computing. Digest of Papers. First International Symposium on Wearable Computers, $48-51$.

[80] Squire, K. and Dikkers, S. 2012. Amplifications of learning: Use of mobile media devices among youth. Research into New Media Technologies. 18, 4, 445-464.

[81] Starner, T. 2013. Project Glass: An Extension of the Self. IEEE Pervasive Computing. 12, $2,14-16$.

[82] T, A.P. and Boukallel, M. 2013. Belt Mounted IMU With Enhanced Distance Estimation For Pedestrian Indoor Positioning, 28-31.

[83] Tao, L. and Zhang, M. 2013. Understanding an Online Classroom System Design and Implementation Based on a Model Blending Pedagogy and HCI. IEEE Transactions on Human-Machine Systems. 43, 5, 465-478.

[84] The Future of Education as Seen Through Google Glass: 2014. http://www.edutopia.org/blog/future-education-through-google-glass-andrew-marcinek. Accessed: 2014-07-25.

[85] The Paradox of Wearable Technologies: 2013. http://m.technologyreview.com/news/517346/the-paradox-of-wearable-technologies/.

[86] Thomas, B.H. 2012. Have We Achieved the Ultimate Wearable Computer? 2012 16th International Symposium on Wearable Computers, 104-107.

[87] Toyoura, M., Kashiwagi, K., Sugiura, A. and Mao, X. 2012. Mono-glass for Providing Distance Information for People Losing Sight in One Eye. VRCAI'12: Proceedings of the 11th ACM SIGGRAPH International Conference on Virtual-Reality Continuum and its Applications in Industry, 39-42.

[88] TRAVIS Callisto: 2010. http://www.brueckner.com/en/brueckner-servtec/services/remoteservices/remote-service-tools/. 
[89] Vallurupalli, S., Paydak, H., Agarwal, S.K., Agrawal, M. and Assad-Kottner, C. 2013. Wearable technology to improve education and patient outcomes in a cardiology fellowship program - a feasibility study. Health and Technology. 3, 4, 267-270.

[90] Vavoula, G. and Sharples, M. 2009. Meeting the Challenges in Evaluating Mobile Learning: A 3-level Evaluation Framework. International Journal of Mobile and Blended Learning. 1, 2, 54-75.

[91] Wei, B.J. and Moverio, E. 2014. How Wearables Intersect with the Cloud and the Internet of Things. IEEE Consumer Electronics Magazine. 3, 3, 53-56.

[92] Williams, M., Jones, O., Fleuriot, C. and Wood, L. 2005. Children and Emerging Wireless Technologies: Investigating the Potential for Spatial Practice. CHI '05 Proceedings of the SIGCHI Conference on Human Factors in Computing Systems, 819-828.

[93] Within-subjects vs. Between-subjects Designs: Which to Use?: 2013. http://www.yorku.ca/mack/RN-Counterbalancing.html.

[94] Wu, H.-K., Lee, S.W.-Y., Chang, H.-Y. and Liang, J.-C. 2013. Current status, opportunities and challenges of augmented reality in education. Computers \& Education. $62,41-49$.

[95] Wu, T., Dameff, C. and Tully, J. 2014. Integrating Google Glass into simulation-based training: experiences and future directions. Journal of Biomedical Graphics and Computing. 4, 2, 49-54.

[96] Wu, W., Blaicher, F., Yang, J., Ave, F., Seder, T. and Cui, D. 2009. A Prototype of Landmark-Based Car Navigation Using a Full-Windshield Head-Up Display System. Proceeding in AMC'09 Proceedings of the 2009 workshop on Ambient media computing, 21-28.

[97] Yang, F.-Y., Chang, C.-Y., Chien, W.-R., Chien, Y.-T. and Tseng, Y.-H. 2013. Tracking learners' visual attention during a multimedia presentation in a real classroom. Computers \& Education. 62, $208-220$.

[98] Yang, J., Yang, W., Denecke, M. and Waibel, A. 1999. Smart Sight: A Tourist Assistant System. The Third International Symposium on Wearable Computers, 73-78.

[99] Yao, J., Limberis, L. and Warren, S. 2010. Work in Progress - A Ubiquitous Laboratory Model to Enhance Learning in Electronics Courses Offered by Two Universities with Dissimilar Curricula. Frontiers in Education Conference (FIE), F3C-1 - T1A-2. 